\title{
A Review of Recent Studies on the Antioxidant and Anti- Infectious Properties of Senna Plants
}

\author{
Mohammed M. Alshehri $\left(\mathbb{D},{ }^{1}\right.$ Cristina Quispe, ${ }^{2}$ Jesús Herrera-Bravo ${ }^{D},{ }^{3,4}$ \\ Javad Sharifi-Rad $\mathbb{D}^{5}{ }^{5}$ Sena Tutuncu, ${ }^{6}$ Elif Feyza Aydar, ${ }^{6}$ Cansu Topkaya, ${ }^{7}$ \\ Zehra Mertdinc $\mathbb{D}^{6}{ }^{6}$ Beraat Ozcelik $\mathbb{D}^{6},{ }^{6,8}$ Mahima Aital, ${ }^{9}$ N. V. Anil Kumar ${ }^{\mathbb{D}},{ }^{9}$ \\ Natallia Lapava ${ }^{(D)}{ }^{10}$ Jovana Rajkovic, ${ }^{11}$ Andrea Ertani, ${ }^{12}$ Silvana Nicola, ${ }^{12}$ \\ Prabhakar Semwal ${ }^{10},{ }^{13,14}$ Sakshi Painuli, ${ }^{13,15}$ Carlos González-Contreras, ${ }^{16}$ \\ Miquel Martorell ${ }^{D},{ }^{16,17}$ Monica Butnariu ${ }^{1 D},{ }^{18}$ Iulia Cristina Bagiu $(\mathbb{D}),{ }^{19,20}$ \\ Radu Vasile Bagiu (D), ${ }^{19,21}$ Mrunal D. Barbhai ${ }^{20},{ }^{22}$ Manoj Kumar ${ }^{1 D}$, ${ }^{22}$ \\ Sevgi Durna Daștan, ${ }^{23,24}$ Daniela Calina $\mathbb{D}^{25}$ and William C. Cho $\mathbb{D}^{26}$
}

${ }^{1}$ Pharmaceutical Care Department, Ministry of National Guard-Health Affairs, Riyadh, Saudi Arabia

${ }^{2}$ Facultad de Ciencias de la Salud, Universidad Arturo Prat, Avda. Arturo Prat 2120, Iquique 1110939, Chile

${ }^{3}$ Departamento de Ciencias Básicas, Facultad de Ciencias, Universidad Santo Tomas, Chile

${ }^{4}$ Center of Molecular Biology and Pharmacogenetics, Scientific and Technological Bioresource Nucleus, Universidad de La Frontera, Temuco 4811230, Chile

${ }^{5}$ Facultad de Medicina, Universidad del Azuay, Cuenca, Ecuador

${ }^{6}$ Department Food Engineering, Faculty of Chemical and Metallurgical Engineering, Istanbul Technical University, Maslak, 34469 Istanbul, Turkey

${ }^{7}$ Bahçeşehir University-School of Applied Disciplines-Gastronomy and Culinary Arts, Beşiktaş, İstanbul 34022, Turkey ${ }^{8}$ BIOACTIVE Research \& Innovation Food Manufacturing Industry Trade Ltd. Co., Maslak, Istanbul 34469, Turkey ${ }^{9}$ Department of Chemistry, Manipal Institute of Technology, Manipal Academy of Higher Education, Manipal 576104, India

${ }^{10}$ Medicine Standardization Department of Vitebsk State Medical University, Belarus

${ }^{11}$ Institute of Pharmacology, Clinical Pharmacology and Toxicology, Medical Faculty, University of Belgrade, 11129 Belgrade, Serbia

${ }^{12}$ Department of Agricultural, Forest and Food Sciences, University of Turin, Italy

${ }^{13}$ Department of Biotechnology, Graphic Era University, Dehradun, 248001 Uttarakhand, India

${ }^{14}$ Uttarakhand State Council for Science and Technology, 248 007, Dehradun, Uttarakhand, India

${ }^{15}$ Himalayan Environmental Studies and Conservation Organization, 248 001, Dehradun, Uttarakhand, India

${ }^{16}$ Department of Nutrition and Dietetics, Faculty of Pharmacy, University of Concepción, 4070386 Concepción, Chile

${ }^{17}$ Centre for Healthy Living, University of Concepción, Concepción 4070386, Chile

${ }^{18}$ Banat's University of Agricultural Sciences and Veterinary Medicine "King Michael I of Romania" from Timisoara, Timisoara, Romania

${ }^{19}$ Victor Babes University of Medicine and Pharmacy of Timisoara Department of Microbiology, Timisoara, Romania

${ }^{20}$ Multidisciplinary Research Center on Antimicrobial Resistance, Timisoara, Romania

${ }^{21}$ Preventive Medicine Study Center, Timisoara, Romania

${ }^{22}$ Chemical and Biochemical Processing Division, Central Institute for Research (ICAR) on Cotton Technology, 400019, Mumbai, India

${ }^{23}$ Department of Biology, Faculty of Science, Sivas Cumhuriyet University, 58140 Sivas, Turkey

${ }^{24}$ Beekeeping Development Application and Research Center, Sivas Cumhuriyet University, 58140 Sivas, Turkey

${ }^{25}$ Department of Clinical Pharmacy, University of Medicine and Pharmacy of Craiova, 200349 Craiova, Romania

${ }^{26}$ Department of Clinical Oncology, Queen Elizabeth Hospital, Kowloon, Hong Kong

Correspondence should be addressed to Javad Sharifi-Rad; javad.sharifirad@gmail.com,

Monica Butnariu; monicabutnariu@yahoo.com, Manoj Kumar; manojkumarpuniya114@gmail.com,

Daniela Calina; calinadaniela@gmail.com, and William C. Cho; chocs@ha.org.hk 
Received 15 August 2021; Revised 4 December 2021; Accepted 7 January 2022; Published 4 February 2022

Academic Editor: Alin Ciobica

Copyright (C) 2022 Mohammed M. Alshehri et al. This is an open access article distributed under the Creative Commons Attribution License, which permits unrestricted use, distribution, and reproduction in any medium, provided the original work is properly cited.

\begin{abstract}
The use of phytochemicals is gaining interest for the treatment of metabolic syndromes over the synthetic formulation of drugs. Senna is evolving as one of the important plants which have been vastly studied for its beneficial effects. Various parts of Senna species including the root, stem, leaves, and flower are found rich in numerous phytochemicals. In vitro, in vivo, and clinical experiments established that extracts from Senna plants have diverse beneficial effects by acting as a strong antioxidant and antimicrobial agent. In this review, Senna genus is comprehensively discussed in terms of its botanical characteristics, traditional use, geographic presence, and phytochemical profile. The bioactive compound richness contributes to the biological activity of Senna plant extracts. The review emphasizes on the in vivo and in vitro antioxidant and anti-infectious properties of the Senna plant. Preclinical studies confirmed the beneficial effects of the Senna plant extracts and its bioactive components in regard to the health-promoting activities. The safety, side effects, and therapeutic limitations of the Senna plant are also discussed in this review. Additional research is necessary to utilize the phenolic compounds towards its use as an alternative to pharmacological treatments and even as an ingredient in functional foods.
\end{abstract}

\section{Introduction}

Senna-a genus belonging to family Fabaceae, subfamily Caesalpinioideae, tribe Cassieae ser. Aphyllae-has roughly 350 species of tree shrubs and subshrubs [1,2]. It was set apart from Cassia s. 1. with the identification of three definite genera, viz., Senna, Cassia L. (s.s), and Chamaecrista Moench [3, 4]. This genus can be found in wide-ranging habitats, in distinct climatic conditions, latitudes, and continents such as America, Africa, and Oceania and to a minor extent in Asia and Pacific islands [5]. Senna plants colonized forests (both humid and dry), deserts (both cold and dry), and rock outcrops [6]. Some ornamental species are widely used for landscape gardening due to the attractive yellow inflorescences and the high adaptability in terms of soil and environmental conditions [7]. Recently, some species from desert climates were proposed to prevent or block desertification in arid zones. The use of Cassia species is reported in the ancient Ayurvedic literature as a laxative, antimalarial, relaxant, and anti-inflammatory [8]. To date, the genus is also commonly recognized for its biologically active compounds and medicinal properties [9, 10].

The cosmopolitan presence of the Senna genus and its medicinal properties lead to its various traditional medicinal uses and health-promoting effects. These beneficial effects of the Senna genus are contributed by the diverse group of phytoconstituents present in its leaves, stem, and seeds. By phytochemical research, more than 350 compounds were extracted from Senna, together with forty secondary metabolites extracted from Senna spectabilis (DC.) H.S.Irwin \& Barneby. These phytochemicals majorly included classes of pentacyclic triterpenes and piperidine alkaloids displaying health-promoting properties [11]. Many of the parts such as leaves, pods, roots, and fruits of the natural plants have beneficial pharmacological properties against diseases. The studied pharmacological activities of Senna plants include anti-infectious, antioxidant, anticryptococcus, antitumor, antimutagenic, antiplasmodial, anti-inflammatory, anticancer, antidiabetic, wound healing, and antihelmintic activities
$[12,13]$. Some studies have shown the antidiabetic activity of Senna plants due to the content of phenols and flavonoids [14]. The antidiabetic effects have as mechanisms the decrease of the expression levels of different adipokines and the reduction of glucose absorption [15].

Its anti-infectious and antioxidant properties are established using various experiments, i.e., in vitro or in vivo.

The current review is focused on the traditional medicinal uses, phytoconstituents, antioxidant and anti-infectious properties, clinical trials, and toxicological data of Senna species.

\section{Review Methodology}

Information on the antioxidant and anti-infective pharmacological studies of Senna species has been collected from various scientific databases such as PubMed, ScienceDirect, and Google Scholar. The selected studies were analyzed for the phytochemical, antioxidant and anti-infective, toxicological aspects of Senna plants. The next MeSH keywords have been used for searching: "Senna Plant/growth \& development," "Senna Plant/metabolism," "Senna Plant/chemistry," "Senna Extract," "Cassia/chemistry," "Plant Extracts," "Plant Extracts/chemistry," "Oxidative Stress," "Reactive Oxygen Species," "Antioxidants," "Antioxidants/chemistry," "Malondialdehyde," "Anti-Infective Agents/pharmacology "Antioxidants/pharmacology," "Anti-Bacterial Agents," "AntiHIV Agents," "Reverse Transcriptase Inhibitors," "Antifungal "Agents/pharmacology," "Antiprotozoal Agents/pharmacology," "Senna Plant/toxicity," "Animals," and "Humans." The scientific names of the Senna species were validated using the Plant List database and the chemical formulas with ChemSpider $[16,17]$.

\section{Botanical Description and Distribution}

Among the plants of the genus Senna, there is a semishrubby or shrubby habit, reaching 4-9 meters in height. Senna plants will tolerate moistly and very poorly draining soils 
in which it grows naturally. Giving a unique description of general botanical characteristics is tedious given the numerous species included in this genus. Senna has paripinnate compound leaves, with leaflets facing opposite, and globose, cylindrical, or clavate glands on rachis, petiole, or stalk [18]. The flowers are generally yellow and appear in dense racemes. It has large, lateral, terminal inflorescences with branched leafy panicles and can be up to $15-30 \mathrm{~cm}$ long. The flowers have fragrance and are made of 5 bristly bracts that usually are oval, $4-5 \mathrm{~mm}$ long, and caduceus and pedicles $(2-3 \mathrm{~mm})$. The sepals/calyx are unequal, oval to circular, coloured yellow-orange, and $5-7 \mathrm{~mm}$ long in size. The flower has 5 (uneven) golden-yellow-coloured petals and an ellipsoidal or spoon-like structure and is $2-3.5 \mathrm{~cm}$ in length. Anthers are opening by apical pores and a slit. It has sterile stamens that are 7 large and 3 small, while the pistil is curvy, slender, and hairless. The ovary is smooth and recurved with an inconspicuous style and stigma. The fruits of Senna are green in colour that turns black or dark with ripening, and their shape is cylindrical or column-like long pods. These pods are hard, end in a short, none splitting [7]. The size of the seeds is nearly $5 \mathrm{~mm}$ in diameter as they are brown coloured with flattened shapes.

The flowers of genus Senna present an interesting structural specialization that includes outstanding androecial diversity and several floral asymmetry patterns [7]. Classification of Senna flower traits becomes even more complicated due to its extraordinary level of specialization of the buzz-pollination. Ten stamens are present in heterantherous flowers of Senna, out of which 3 adaxial stamens are staminodial and the rest are fertile. These are further divided into two sets, viz., one set of four middle stamens from which the bees buzz and extract pollen, while another set includes 2-3 abaxial stamens, and the pollen from here is deposited on bees through the buzzing and is carried to the stigma of another flower [19]. Senna genus has 3-colporate pollen grains, ranging from size small to medium, and is euripalynic, radiosymmetric, and isopolar; however, the shape is oblates-spheroidic to prolate, nearly circular, and copli is long, subtriangular to triangular. Floral asymmetry is also due to the corolla and androecium. Extrafloral nectaries represent an "archaic feature" of numerous Senna species [5]. This appears in ca. $76 \%$ of the American species, several Australian species, scarcely in African, and none in Southeast Asian species. These glands secreting nectar can draw insects like ants that eat the nectar thus protecting the plant from the herbivores [20]. The fruits of Senna are long, enlarged, and tubular/cylindric, with the pods having 25$32 \mathrm{~cm}$ size, and the colour is black that has brown seeds equipped with pleurogram [11].

Senna can be propagated by seeds that remain viable for several years [21]. Most of the species of Senna require the scarification of the seeds to favour germination. The plant has numerous lateral roots and a robust primary root that contribute to the colonization of different substrates. Among the several species of Senna the series Aphyllae (Benth.) H.S.Irwin \& Barneby is a taxonomically complex group of xeromorphic shrubs and subshrubs of the caesalpinioid legume Senna Mill., from arid, semiarid, and xerophilous areas of southern South America. Among all the Senna species, these seven are morphologically distinct. Fully grown mature plants are without leaves, and stems are junciform, green, and photosynthetic, while roots are woody and deep. These xerophytic attributes assist their survival in harsh conditions [22].

The monophyletic nature of Senna was revealed by phylogenetic investigations making it occupy the place next to Cassia sensu stricto and Chamaecrista [6], and all of these together form the subtribe Cassiinae are morphologically identified based on traits of their androecium, floral architecture, corolla, bracteoles, and fruits [23]. To date, taxonomy is not simply based on floral and vegetative characters, but on several other information, such as anatomy, cytology, serological, and molecular biology, that is useful for determining relationships and affinities among the Senna genus. DNA sequencing of various chloroplast gene sections of Senna plants (matK, rpL16, rpS16) depicted that majority of them are polyphyletic [5]. The chromosome counts exist only for about $20 \%$ of Senna species, with a prevalence of $2 n=28$. There are also records of $2 n=22$, 24 , and $26[24,25]$ and records of polyploidy, such as $2 \mathrm{n}$ $=42,56$, and 112 in Senna rugosa (G.Don) H.S.Irwin \& Barneby [26]; $2 \mathrm{n}=56$ in Senna aversiflora (Herbert) H.S.Irwin \& Barneby; and 2n = 52 and 104 in Senna gardneri (Benth.) H.S.Irwin \& Barneby [27]. Recently, Cordeiro and Felix [23] demonstrated that the karyotypic differences noted in Senna, either interspecific or intraspecific, are making this genus among the most representative taxa of the Fabaceae in several world territories [22].

Plants of Senna genus are present in all the tropical regions and grow well on wasteland, river banks, damp/ moist uncultivated fields, or similar areas in the low-lying coastal region; they also grow at places with altitudes up to 1000-1400 meters [28] (Figure 1).

Senna's evolutionary history is also linked to the arid lands that this genus currently populates, such as deserts and xerophilous regions of South America in southern Bolivia, southeastern Paraguay, and central and northwestern Argentina [22]. Several types of research conducted in plants of genus Senna, growing in diverse climatic conditions, revealed a variation in phenotype between individuals within species that could arise from phenotypic plasticity.

Geographical separation and/or morphological variation among individuals of Senna causes the formation of species and subspecies in a different habitat, thanks to the adaptive strategies. America has the majority of Senna species (74\%), followed by Australia with 13 percent of species and Africa and/or Madagascar having 10 percent, while only a few species are obtained from Near East, South-East Asia, and on the Pacific Islands [29]. Soladoye et al. [30] reported about 19 species in the West African floristic region with the whole 19 species in Nigeria and at least 8 species in SouthWestern Nigeria, with a high variety in habits, ranging from trees (approaching $34 \mathrm{~m}$ in height) to prostrate annual herbs. There are about 18 species of Senna in southern Africa, of which the majority is naturalized, but only Senna italica subsp. arachoides (Burch.) Lock and Senna petersiana (Bolle) Lock are native [31]. 


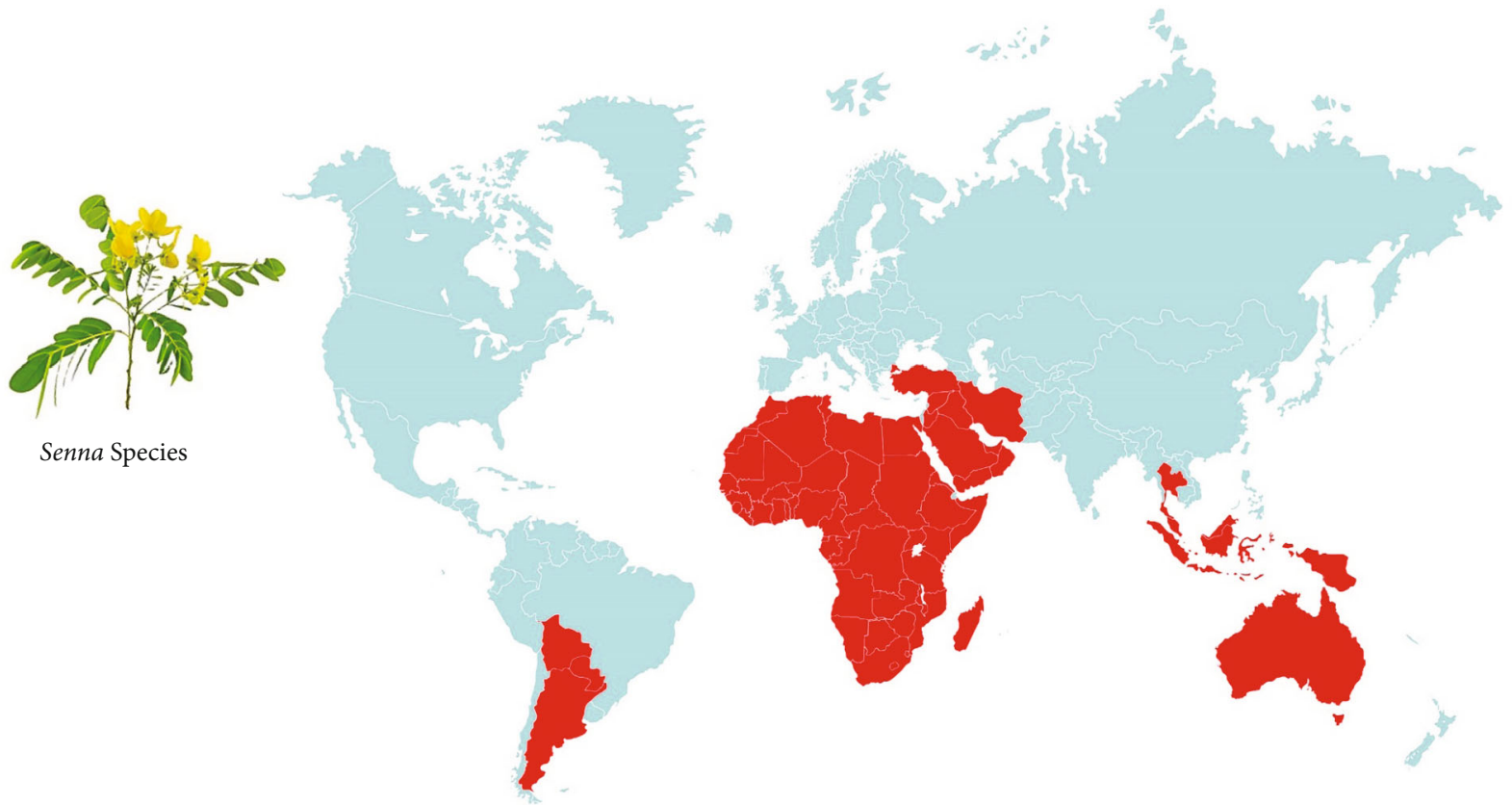

FIGURE 1: Geographical distribution of Senna species. All the regions where Senna plants are most common are highlighted in red

In Thailand, Larsen [32] studied Senna and stated that there are three native species, namely, Senna timoriensis (DC.) H.S.Irwin \& Barneby, Senna siamea (Lam.) H.S.Irwin \& Barneby, and Senna garrettiana (Craib) H.S.Irwin \& Barneby, and fourteen exotic species, namely, Senna alata (L.) Roxb. (syn. Cassia alata L.), Senna singueana (Delile) Lock (syn. Cassia singueana Delile), Senna alexandrina Mill. (syn. Cassia angustifolia M.Vahl), Senna bicapsularis (L.) Roxb., Senna hirsuta (L.) H.S.Irwin \& Barneby, Senna fruticosa (Mill.) H.S.Irwin \& Barneby, Senna occidentalis (L.) Link, Senna pallida (Vahl) H.S.Irwin \& Barneby, Senna surattensis (Burm.f.) H.S.Irwin \& Barneby, Senna septemtrionalis (Viv.) H.S.Irwin \& Barneby, Senna sophera (L.) Roxb., S. spectabilis, Senna sulfurea (Collad.) H.S.Irwin \& Barneby, and Senna tora (L.) Roxb (syn. Cassia tora L.) [33].

\section{Ethnobotanical Uses}

Senna genus is widely used in southern countries in different spheres of life such as building, decoration, rituals, nutrition, poisons, and medicine. Some plants of Senna genus are used as building wood and as a shade plant and landscape ornamental $[33,34]$. S. alata bark decoction has been applied by the west and east Africans while tribal mark incision and tattoo was making on to the cuts [12].

In Uganda Senna obtusifolia (L.) H.S.Irwin \& Barneby is used as a good luck charm before travelling [35]. Shoots and leaves of S. garrettiana and S. siamea are cooked in a dish called kaeng khi lek (a kind of curry) which is found in two forms-with and without coconut milk [33].

Other species consumed as boiled vegetables along with chili sauce include $S$. timoriensis for its tender leaves and flowers and S. sophera for its tender fruits and shoots [33]. The crude pounded bark of $S$. alata is used as fish poison
[36]. And the most popular usage of Senna genus is as a traditional medicine used as a remedy for a vast range of diseases in various countries and cultures (Table 1).

\section{Phytoconstituents}

Ahmed and Shohael [68] reported the presence of anthraquinones named aloe-emodin, chrysophanol, emodin, and rhein from the S. alata leaves. Bradley Morris et al. [3] studied the variation in the concentration of sennosides A and B from pods and leaves of S. alata, S. alexandrina, Senna covesii (A.Gray) H.S.Irwin \& Barneby, Senna angulata (Vogel) H.S.Irwin \& Barneby, S. hirsuta, S. occidentalis, and Senna uniflora (Mill.) H.S.Irwin \& Barneby [3]. Essien et al. [69] isolated oils from hydrodistillation of S. alata, S. hirsuta, and S. occidentalis. The following compounds are reported after analyzing samples using GC-MS (gas chromatography-mass spectrometry) analysis, viz., ar-turmerone, $\beta$-caryophyllene, (E)-phytol, and 6,10,14-trimethyl-2-pentadecanone. (E)-Phytol and pentadecanal were the main components of $S$. hirsuta while $S$. occidentalis had (E)-phytol, hexadecanoic acid, and 6,10,14-trimethyl-2pentadecanone. Epifano et al. [70] isolated madagascin (3isopentenyloxyemodin) and 3-geranyloxyemodine from dried fruits and leave samples of S. alexandrina.

Ahmed et al. [71] isolated the flavonoids quercimeritrin, scutellarein, and rutin from the leaves. Arrieta-Baez et al. [72] reported the isolation of alizarin and purpurin from $S$. alexandrina.

New compounds of pyridine alkaloids $\left(12^{\prime}\right.$-hydroxy- $8^{\prime}$ -multijuguinol, $12^{\prime}$-hydroxy- $7^{\prime}$-multijuguinol, methyl multijuguinate, $7^{\prime}$-multijuguinol, and $8^{\prime}$-multijuguinol) were isolated using leaves of Senna multijuga (Rich.) H.S.Irwin \& Barneby by Francisco et al. [73]. Similarly, Serrano et al. 
TABle 1: Traditional and folk medical usage of Senna species.

\begin{tabular}{|c|c|c|c|c|c|}
\hline Senna species & $\begin{array}{l}\text { Country/ } \\
\text { culture }\end{array}$ & Part of plant & Internal usage & External usage & Ref \\
\hline \multirow{17}{*}{$\begin{array}{l}\text { Senna alata (L.) } \\
\text { Roxb. }\end{array}$} & Bangladesh & Leaves & Helminthiasis & Ringworm, eczema & $\begin{array}{l}{[37,} \\
38]\end{array}$ \\
\hline & $\begin{array}{c}\text { Benin } \\
\text { Republic }\end{array}$ & Whole plant & Diabetes & - & [12] \\
\hline & Bolivia & Root, leaves & Malaria, salmonella, fever, cold & Bath & [39] \\
\hline & Brazil & $\begin{array}{l}\text { Root, whole plant, } \\
\text { flower, leaves }\end{array}$ & Flu, cough, malaria & $\begin{array}{l}\text { Ringworms, scabies, } \\
\text { blotch, eczema, } \\
\text { tinea infections }\end{array}$ & $\begin{array}{l}{[12,} \\
40]\end{array}$ \\
\hline & Cameroon & Stem, bark, leaves & Gastroenteritis, hepatitis & $\begin{array}{l}\text { Ringworm, dermal } \\
\text { infections }\end{array}$ & [12] \\
\hline & China & $\begin{array}{l}\text { Stem, bark, leaves seed, } \\
\text { root, leaves, flower, } \\
\text { whole plant }\end{array}$ & $\begin{array}{l}\text { Intestinal parasitosis, helminthiasis, diabetes, } \\
\text { uterus disorder, asthma, constipation, fungal } \\
\text { infections, poor eyesight diabetes }\end{array}$ & - & [12] \\
\hline & Cuba & Whole plant & Diabetes & - & [41] \\
\hline & Egypt & Leaves & Constipation & - & {$[12]$} \\
\hline & Ghana & Whole plant & Diabetes & - & [12] \\
\hline & Guatemala & $\begin{array}{c}\text { Whole plant flower, } \\
\text { leaves }\end{array}$ & Flu, malaria & $\begin{array}{l}\text { Ringworms, tinea } \\
\text { infections scabies, } \\
\text { eczema, blotch }\end{array}$ & [12] \\
\hline & Guinea & $\begin{array}{c}\text { Whole plant flower, } \\
\text { leaves }\end{array}$ & Flu, malaria & $\begin{array}{l}\text { Ringworms, scabies, } \\
\text { blotch, eczema, tine } \\
\text { infections }\end{array}$ & {$[12]$} \\
\hline & India & $\begin{array}{l}\text { Stem, bark, leaves, seed, } \\
\text { root leaves, flower the } \\
\text { whole plant, leaves }\end{array}$ & $\begin{array}{l}\text { Diabetes, hemorrhoids, inguinal hernia, intestinal } \\
\text { parasitosis, syphilis, uterus disorder, helminthiasis } \\
\text { constipation, fungal infection diabetes }\end{array}$ & $\begin{array}{l}\text { Skin diseases, } \\
\text { ringworm }\end{array}$ & $\begin{array}{l}{[12,} \\
42]\end{array}$ \\
\hline & Nigeria & $\begin{array}{l}\text { Stem, leaves, root whole } \\
\text { plant }\end{array}$ & $\begin{array}{l}\text { Constipation, diarrhoea, respiratory tract } \\
\text { infection, body and abdominal pain, stress, } \\
\text { convulsion, diabetes }\end{array}$ & $\begin{array}{l}\text { Wound, skin } \\
\text { diseases, burns, } \\
\text { toothache, dermal } \\
\text { infections }\end{array}$ & [12] \\
\hline & Philippines & $\begin{array}{l}\text { Stem, bark, leaves seed, } \\
\text { root leaves, flower } \\
\text { leaves }\end{array}$ & $\begin{array}{l}\text { Hemorrhoids, inguinal hernia, syphilis, intestinal } \\
\text { parasitosis, diabetes, uterus disorder, } \\
\text { helminthiasis, constipation, fungal infections }\end{array}$ & $\begin{array}{l}\text { Skin diseases, } \\
\text { wound }\end{array}$ & $\begin{array}{l}{[12,} \\
43]\end{array}$ \\
\hline & $\begin{array}{l}\text { Sierra } \\
\text { Leone }\end{array}$ & Leaves & Abortion pain, facilitate delivery & - & [12] \\
\hline & Thailand & Leaves & Constipation, flatulence, inflammation & $\begin{array}{l}\text { Abscesses, wounds, } \\
\text { ringworm, itching }\end{array}$ & $\begin{array}{l}{[33,} \\
44]\end{array}$ \\
\hline & Togo & Whole plant & Diabetes & - & {$[12]$} \\
\hline \multirow{8}{*}{$\begin{array}{l}\text { Senna alexandrina } \\
\text { Mill. }\end{array}$} & Cyprus & Fruit & Constipation & - & [45] \\
\hline & Djibouti & Leaves & Constipation, injuries & Skin diseases & [46] \\
\hline & Egypt & Leaves & Constipation & - & [47] \\
\hline & Pakistan & Leaves, pod & $\begin{array}{c}\text { Constipation, rheumatism, backache, asthma, } \\
\text { anaemia typhoid fever, jaundice, pneumonia, } \\
\text { leprosy }\end{array}$ & Wound, pimples & [48] \\
\hline & Qatar & Leaves & Constipation, stomach cramps & - & [49] \\
\hline & Sudan & Leaves, fruits & Constipation, git-disorders & - & [50] \\
\hline & Thailand & Leaf pod & Constipation stomach pain & - & {$[33]$} \\
\hline & UAE & Leaves & Constipation, stomach cramps & - & [49] \\
\hline $\begin{array}{l}\text { Senna auriculata } \\
\text { (L.) Roxb. }\end{array}$ & India & Flower leaves & Diabetes & - & [51] \\
\hline
\end{tabular}


TABle 1: Continued.

\begin{tabular}{|c|c|c|c|c|c|}
\hline Senna species & $\begin{array}{l}\text { Country/ } \\
\text { culture }\end{array}$ & Part of plant & Internal usage & External usage & Ref \\
\hline $\begin{array}{l}\text { Senna } \\
\text { didymobotrya } \\
\text { (Fresen.) } \\
\text { H.S.Irwin \& } \\
\text { Barneby }\end{array}$ & $\begin{array}{l}\text { South } \\
\text { Africa }\end{array}$ & Leaves & Blood coagulation & - & {$[52]$} \\
\hline $\begin{array}{l}\text { Senna fruticosa } \\
\text { (Mill.) H.S.Irwin } \\
\text { \& Barneby }\end{array}$ & Panama & Stem, leaves & - & Body ache & [53] \\
\hline $\begin{array}{l}\text { Senna garrettiana } \\
\text { (Craib) H.S.Irwin } \\
\text { \& Barneby }\end{array}$ & Thailand & Heartwood & Constipation, cough, emmenagogue & - & [33] \\
\hline $\begin{array}{l}\text { Senna hirsuta (L.) } \\
\text { H.S.Irwin \& } \\
\text { Barneby }\end{array}$ & Thailand & Debarked stem & Fever, muscle spasm, poisoning, drunkenness & - & $\begin{array}{l}{[33,} \\
44]\end{array}$ \\
\hline \multirow{8}{*}{ Senna italica Mill. } & Bahrain & Leaves, seed & Constipation, stomach cramps & - & [49] \\
\hline & Djibouti & Leaves & Constipation & - & [46] \\
\hline & Egypt & Leaves & Constipation, bacterial infection, tumors & - & [47] \\
\hline & Iran & Leaves & Constipation, obesity, hemorrhoids & - & {$[54]$} \\
\hline & Pakistan & Leaves & Backache joints pain, headache, migraine & - & [55] \\
\hline & Qatar & Leaves, seed & Constipation, stomach cramps & - & [49] \\
\hline & $\begin{array}{c}\text { Saudi } \\
\text { Arabia }\end{array}$ & Leaves, seed & Constipation, stomach cramps & - & {$[49]$} \\
\hline & UAE & Leaves, seed & Constipation, stomach cramps & - & {$[49]$} \\
\hline $\begin{array}{l}\text { Senna } \\
\text { multiglandulosa } \\
\text { (Jacq.) H.S.Irwin } \\
\text { \& Barneby }\end{array}$ & Peru & Not specified & - & $\begin{array}{l}\text { Wound disinfectant } \\
\text { agent }\end{array}$ & {$[56]$} \\
\hline \multirow{7}{*}{$\begin{array}{l}\text { Senna occidentalis } \\
\text { (L.) Link }\end{array}$} & Bolivia & Root, seed & Dysentery & Bath, ringworm & {$[39]$} \\
\hline & Cuba & Not specified & $\begin{array}{c}\text { Liver pain, rheumatism, arthrosis, catarrh, } \\
\text { muscular pain, hemorrhoids, pneumonia, venereal } \\
\text { diseases, impotence }\end{array}$ & - & [41] \\
\hline & Guatemala & Leaves, aerial part & Fever, measles, chickenpox & - & {$[57]$} \\
\hline & India & Leaves, root seed & $\begin{array}{l}\text { Respiratory diseases, cough, constipation, malaria, } \\
\text { diabetes, indigestion, urinary disorder }\end{array}$ & $\begin{array}{l}\text { Skin problems, skin } \\
\text { disorders, pimples }\end{array}$ & $\begin{array}{l}{[42,} \\
58, \\
59]\end{array}$ \\
\hline & Tanzania & Root & Spasms, malaria, helminthiasis & - & [60] \\
\hline & Thailand & Leaves, fruit & Diarrhoea & - & [44] \\
\hline & Uganda & Leaves & Malaria & - & {$[35]$} \\
\hline \multirow{3}{*}{$\begin{array}{l}\text { Senna petersiana } \\
\text { (Bolle) Lock }\end{array}$} & $\begin{array}{l}\text { Eastern } \\
\text { Africa }\end{array}$ & Not specified & Flatulence & - & {$[61]$} \\
\hline & $\begin{array}{l}\text { Tropical } \\
\text { Africa }\end{array}$ & Not specified & Constipation, gonorrhoea & - & {$[61]$} \\
\hline & $\begin{array}{l}\text { South } \\
\text { Africa }\end{array}$ & Seed & $\begin{array}{l}\text { Venereal diseases, infertility constipation, } \\
\text { gonorrhoea }\end{array}$ & - & $\begin{array}{l}{[61,} \\
62]\end{array}$ \\
\hline $\begin{array}{l}\text { Senna siamea } \\
\text { (Lam.) H.S.Irwin } \\
\text { \& Barneby }\end{array}$ & Thailand & Leaves, flower & Constipation, insomnia hypertension & - & $\begin{array}{l}{[33,} \\
44]\end{array}$ \\
\hline \multirow{2}{*}{$\begin{array}{l}\text { Senna singueana } \\
\text { (Delile) Lock }\end{array}$} & Sudan & Root & Constipation & - & [63] \\
\hline & Tanzania & Root & Diabetes & - & [64] \\
\hline
\end{tabular}


TABLE 1: Continued.

\begin{tabular}{|c|c|c|c|c|c|}
\hline Senna species & $\begin{array}{l}\text { Country/ } \\
\text { culture }\end{array}$ & Part of plant & Internal usage & External usage & Ref \\
\hline \multirow[t]{2}{*}{$\begin{array}{l}\text { Senna sophera (L.) } \\
\text { Roxb. }\end{array}$} & Bangladesh & Leaves root & $\begin{array}{l}\text { Dyspepsia, asthma, bronchitis, hiccup, gonorrhoea } \\
\text { dyspepsia }\end{array}$ & - & $\begin{array}{l}{[37} \\
38, \\
65]\end{array}$ \\
\hline & India & Bark & Respiratory disorders & - & [42] \\
\hline $\begin{array}{l}\text { Senna timoriensis } \\
\text { (DC.) H.S.Irwin \& } \\
\text { Barneby }\end{array}$ & Thailand & Heartwood & Stimulate menstruation & - & [33] \\
\hline \multirow{3}{*}{$\begin{array}{l}\text { Senna tora (L.) } \\
\text { Roxb. }\end{array}$} & China & Not specified & $\begin{array}{c}\text { Stomach disorders, liver diseases, poor eyesight, } \\
\text { weakness, diuretic }\end{array}$ & - & [66] \\
\hline & Thailand & Seed leaves & $\begin{array}{c}\text { Constipation, urethral stones, diuretic, } \\
\text { constipation, insomnia }\end{array}$ & - & $\begin{array}{l}{[33,} \\
44]\end{array}$ \\
\hline & India & Seed leaves & & $\begin{array}{c}\text { Rheumatic swelling } \\
\text { and pain, skin } \\
\text { diseases }\end{array}$ & $\begin{array}{l}{[42,} \\
67]\end{array}$ \\
\hline $\begin{array}{l}\text { Senna uniflora } \\
\text { (Mill.) H.S.Irwin } \\
\text { \& Barneby }\end{array}$ & Cuba & Not specified & Bleeding, rheumatism, arthrosis & - & [41] \\
\hline
\end{tabular}

[74] in leaves identified compounds like isolated $7^{\prime}$-multijuguinone and $12^{\prime}$-hydroxy- $7^{\prime}$-multijuguinone. Vargas Rechia et al. [75] extracted from seed (aqueous) extract compounds, viz., galactomannan and $\mathrm{O}$-acetyl-glucuronoarabinoxylan. Abegaz et al. [76] separated anthraquinones, emodin, floribundone-1, torosanin- $9^{\prime}, 10^{\prime}$-quinone, anhydrophlegmacin, and 9-(physcion- $7^{\prime}$-yl)-5,10-dihydroxy-2methoxy-7-methyl-1,4-anthraquinone from Senna multiglandulosa (Jacq.) H.S.Irwin \& Barneby.

Alemayehu and Abegaz [77] reported the presence of physcion, torosachrysone, floribundone-1, anhydrophlegmacin, and 9-(physcion- ${ }^{\prime}$-yl)-5,10-dihydroxy-2-methyl-7methoxy-1,4-anthraquinone (isosengulone) from the seeds of S. multiglandulosa.

Essien et al. [78] identified the following volatile oils from the fruits of S. hirsuta and S. occidentalis by GC-MS analysis. Compounds identified in S. hirsuta are as follows: $\alpha$-pinene, germacrene, camphene, selinene, $\beta$-pinene, valencene, viridiflorene, 2 -tridecanone, $\mathrm{p}$-cymene, $\alpha$-muurolene, limonene, 1,8-cineole, (Z,Z)- $\alpha$-earnesene, $\gamma$-terpinene, $\beta$ bisabolene, trans- $\gamma$-cadinene, $\delta$-cadinene, methyl chavicol, (E)- $\alpha$-bisabolene, isothymol methyl ether, occidentalol, methyl thymol, caryophyllene oxide, bornyl acetate, cedrol, 1,10-di-epicubenol, $\alpha$-copaene, 1-epi-cubenol, cyperene, $\tau$ cadinol, $\beta$-caryophyllene, $\alpha$-cadinol, 2,5-dimethoxy-pcymene, valerianol, $\alpha$-humulene, cyperotundone, pentadecanal, benzyl benzoate, and $\gamma$-muurolene. Compounds identified in S. occidentalis are as follows: $\alpha$-pinene, selinene, $\beta$-pinene, valencene, myrcene, $\alpha$-selinene, $\alpha$-phellandrene, viridiflorene, $\delta$-3-carene, $\mathrm{p}$-cymene, limonene, $\beta$-himachalene, $\beta$-bisabolene, terpinolene, 1,8-cineole, linalool, 7-epi$\alpha$-selinene, $\alpha$-terpineol, $\delta$-cadinene, methyl chavicol, caryophyllene oxide, bornyl acetate, myrtenyl acetate, humulene epoxide II, $\alpha$-terpinyl acetate, $\alpha$-copaene, 1 -epi-cubenol, daucene, $\gamma$-eudesmol, cyperene, $\tau$-cadinol, $\beta$-caryophyllene, valerianol, trans- $\alpha$-bergamotene, (Z)-6,7-dihydrofarnesol, $\alpha$-humulene, $\alpha$-patchoulene, alloaromadendrene, $\gamma$-himachalene, and $\gamma$-muurolene.

Maia et al. [79] from methanolic extracts of S. gardneri and Senna georgica H.S.Irwin \& Barneby separated compounds, viz., vanillic acid, 3,4-dihydroxybenzoic acid, syringic acid, dihydromyricetin, rutin glucoside, quercetin diglucoside, rutin pentoside, kaempferol rhamnodiglucoside, quercetin glucoarabinoside, kaempferol diglucoside, ellagic acid, rutin, oxyresveratrol, methoxy oxyresveratrol, quercetin glucoside, rubrofusarin tetraglucoside, quercitrin, kaempferol rhamnoglucoside, rubrofusarin triglucoside, rubrofusarin gentobioside, myricetin, quercetin, rubrofusarin glucoside, and emodin.

Monteiro et al. [80] reported the preliminary investigation on the qualitative phytochemicals present in Senna cana (Nees \& Mart.) H.S.Irwin \& Barn and Senna pendula (Willd.) H.S.Irwin \& Barneby and reported the presence of saponins, anthraquinones, triterpenoids, steroids, flavonols, flavones, tannins, and xanthones.

Barba et al. [81] extracted different compounds from the leaves of Senna corymbosa (Lam.) H.S.Irwin \& Barneby and roots of Senna lindheimeriana (Scheele) H.S.Irwin \& Barneby. They were chrysophanol, methoxyhydroquinone, emodin, 5,7' -biphyscion (floribundone-l), physcion, p-hydroxybenzaldehyde, hydroquinone monomethyl ether, 3-hydroxy-4-methoxyphenol, $\beta$-sitosterol, stigmasterol, and linoleic acid in $S$. corymbose; while $S$. lindheimeriana had chrysophanol, xanthorin, chrysophanol 8-methyl ether, emodin, questin, physcion, 1-hydroxy-3-methyl-2,6,7,8-tetramethoxy-9,10anthraquinone, $3,4,3^{\prime} 5^{\prime}$-tetrahydroxystilbene (piceatannol), $4,2^{\prime}, 4^{\prime}$-trihydroxychalcone (isoliquiritigenin), 2,4,5-trimethoxyphenol, betulinic acid, and stigmasterol.

Zavala-Sánchez et al. [82] analyzed the GC-MS result from the Senna crotalarioides (Kunth) H.S.Irwin \& Barneby 
leaf (chloroform) extracts and reported the following compounds. 1-ocyacosanol, 1-triacontanol, palmitic acid, betasitosterol, neophytadiene, 1-hexacosanol, and stigmasterol.

Alemayehu et al. [83] from the pods of Senna didymobotrya (Fresen.) H.S.Irwin \& Barneby isolated compounds, namely, knipholone, emodin, chrysophanol, 10-hydroxy-10-(physcion$7^{\prime}$-yl)-chrysophanol anthrone, physcion, and 5,10-dihydroxy2-methyl-9-(physcion- $7^{\prime}$-yl)-1,4-anthraquinone.

Ochieng et al. [84] reported that the root extracts (ethyl acetate) resulted in nataloemodin-8-methyl ether, obtusifolin, 1,6-di-O-methylemodin, chrysophanol, physcion, physcion-10,10'-bianthrone, chrysophanol-10,10' -bianthrone, and stigmasterol. Rao et al. [85] extracted compounds, namely, kaempferol 3-O- $\alpha$-L-rhamnopyranosyl $(1 \rightarrow 2)-\alpha$-Lrhamnopyranoside, kaempferol 3-O-rutinoside, and rutin from the flowers of $S$. hirsuta.

Silva et al. [86] identified the following compounds from S. gardneri, Senna macranthera (Collad.) H.S.Irwin \& Barneby, Senna splendida (Vogel) H.S.Irwin \& Barneby, and Senna trachypus (Benth.) H.S.Irwin \& Barneby through GC-MS. S. gardneri containing succinic acid, glyceric acid, $\beta$-caryophyllene, malic acid, pyroglutamic acid, 3-hydroxy3-methylglutaric acid, 3,4-dihydroxy benzoic acid, citric acid, neophytadiene, gluconic acid, hexadecanoic acid, linolenic acid methyl ester, phytol, quercetin, $\alpha$-linolenic acid, linoleic acid, stearic acid, $\alpha$-tocopherol, eicosanoic acid, squalene, tetracosanoic acid, $\beta$-sitosterol, stigmasterol, 1triacontanol. S. macranthera contains succinic acid, $\beta$-caryophyllene, malic acid, pyroglutamic acid, eicosanoic acid, hexadecanoic acid, docosanoic acid, $\alpha$-linolenic acid, phytol, linoleic acid, stearic acid, chrysin, squalene, trans-catechin, $\beta$-tocopherol, $\alpha$-tocopherol, quercetin, stigmasterol, $\beta$-sitosterol, $\beta$-amyrin, 1 -triacontanol, and $\alpha$-amyrin.

S. splendida contains succinic acid, glyceric acid, pentanedioic acid, pyroglutamic acid, 3-hydroxy-3-methylglutaric acid, stearic acid, galactonic acid, gluconic acid, hexadecanoic acid, linoleic acid, $\alpha$-tocopherol, linolenic acid methyl ester, phytol, $\alpha$-linolenic acid, docosanoic acid, squalene, tetracosanoic acid, stigmasterol, $\beta$-sitosterol, quercetin, $\beta$-amyrin, 1 triacontanol, $\alpha$-amyrin. $S$. trachypus contains succinic acid, linoleic acid, hexadecanoic acid, neophytadiene, linolenic acid ethyl ester, $\alpha$-linolenic acid, galactonic acid, gluconic acid, eicosanoic acid, phytol, stearic acid, stigmasterol, $\beta$-sitosterol, docosanoic acid, squalene, tetracosanoic acid, $\alpha$-tocopherol, quercetin, $\beta$-amyrin, 1-triacontanol, and triacontanoic acid. Gololo et al. [87] identified the phytol (3,7,11,15-tetramethyl-2-hexadecen-1-ol); 1,2-benzenedicarboxylic acid, mono (2-ethylheptyl) ester; n-tetracontane; 13-docosenamide; squalene $(2,6,10,14,18,22$-hexamethyltetracosane),1-heptacosanol; $\alpha$-tocopherol- $\beta$-D-mannoside; 1,2-epoxynonadecane; stigmasterol; $\gamma$-sitosterol and lupeol from hexane extract of Senna italica Mill. leaves through GC-MS analysis.

Khalaf et al. [88] used aerial parts and isolated physcion, emodin, 2-methoxy-emodin-6-O-D-glucopyranoside, quercetin 3-O-L-rhamnopyranosyl-(16)-D-glucopyranoside (rutin), 1-hydroxy-2-acetyl-3-methyl-6-hydroxy-8-methoxynaphthalene (tinnevellin), and 1,6,8-trihydroxy-3-methoxy-9,10dioxo-9,10-dihydroanthracene. Similarly, Madkour et al. [89] identified n-hexadecanoic acid, (Z,Z,Z)9,12,15-octadecadienoic acid, vitamin E, from hexane extract and 3-methyl-4-oxopentanoic acid, (E)-stilbene, and 2,6-di-tert-butylphenol from methylene chloride extract by GC-MS analysis. Mokgotho et al. [90] extracted 3,4',5-trihydroxystilbene (resveratrol) from aqueous extracts of the roots.

Alemayehu et al. [91] isolated 1,8,1', $8^{\prime}$-tetrahydroxy- $6^{\prime}$ -methoxy-3,3' -dimethyl-(10,10' -bianthracen)- $9,9^{\prime}$-dione (or chrysophanol-physcion), 1,8, $1^{\prime}, 8^{\prime}$-tetrahydroxy- $7^{\prime}$ methoxy-3,3 $3^{\prime}$-dimethyl-(10,10 ${ }^{\prime}$-bianthracen)- $9,9^{\prime}$-dione (or chrysophanol- isophyscion-10,10' -bianthrone) and 1,8, $1^{\prime}, 8^{\prime}$ -tetrahydroxy- $7,7^{\prime}$-dimethoxy-3,3' -dimethyl-(10,10' -bianthracen)-9, $9^{\prime}$-dione (or isophyscion-10,10' -bianthrone) from the leaves and root bark of Senna longiracemosa (Vatke) Lock. Branco et al. [92] communicated the presence of rubrofusarin (5,6-dihydroxy-8-methoxy-2-methylbenzo[g]cromen-4-one, 1) in S. macranthera. Klika et al. [93] confirmed the $\left(2 \mathrm{R}, 3 \mathrm{~S}, 4 \mathrm{~S}, 2^{\prime \prime} \mathrm{R}, 3^{\prime \prime} \mathrm{S}\right)$-guibourtinidol- $(4 \alpha \rightarrow 8)$-catechin (procyanidin) in root isolates.

Pires et al. [94] isolated mannose and galactose from the endosperm of $S$. macranthera seeds. Messana et al. [95] isolated 10-demethylflavasperone-10-sulphate, 10demethylflavasperone, 10 -demethylflavasperone-10-O- $\beta$-Dapiofuranosyl- $(1 \rightarrow 6)-O-\beta$-D-glucopyranoside, and cassiapyrone-10-sulphate (7-methyl-10-demethylflavasperone-10-suophate); quinquangulin-6-O- $\beta$-D-apiofuranosyl$(\mathrm{l} \rightarrow 6)-O-\beta$-D-glucopyranoside, rubrofusarin-6-O- $\beta$-D-glucopyranoside, quinquangulin-6-O- $\beta$-D-glucopyranoside and chrysophanol dimethyl ether, chrysophanol, physcion, cis-3, $3^{\prime}, 5,5^{\prime}$-tetrahydroxy-4-methoxystilbene, trans-3, $3^{\prime}$ $, 5,5^{\prime}$-tetrahydroxy-4-methoxystilbene, and cassiaside B from the root methanolic extracts [96]. de Macedo et al. [97] reported the presence of bianthrone glycoside, namely, martianine $1 \quad\left(10,10^{\prime}\right.$-il-chrysophanol-10-oxi$10,10^{\prime}$-bi-glucosyl) from the stalks of Senna martiana (Benth.) H.S.Irwin \& Barneby.

Graham et al. [98] isolated quinquangulin and rubrofusarin from the stem and fruit extract (methanolic) of Senna obliqua (G.Don) H.S.Irwin \& Barneby.

Pang et al. [99] communicated extractions from seeds of $S$. obtusifolia and those included obtusifolin-2-O- $\beta-\mathrm{D}-\left(6^{\prime}-O-\alpha\right.$, $\beta$-unsaturated butyryl)-glucopyranoside (1) and epi-9-dehydroxyeurotinone- $\beta$-D-glucopyranoside. Saidu et al. [100] described the existence of cardenolides, flavonoids, saponins, alkaloids and anthraquinones in the leaves of S. occidentalis.

Javaid et al. [101] extracted 1,3-benzenedicarboxylic acid, bis(2-ethylhexyl) ester, 9,10-dimethyltricyclo [4.2.1.1(2,5)]decane-9,10-diol, 2(2-hydroxy-2-propyl)-5methyl-cyclohexanol, 1,2-benzenedicarboxylic acid mono(2-ethylhexyl) ester, 7-hydroxy-3,7-dimethyl-octanal, and 5,6,6-trimethyl5-(3-oxobut-1-enyl)-1-oxaspiro[2.5]octan-4-one from the aerial parts. Kim et al. [102] isolated $\mathrm{N}$-methylmorpholine from the seeds.

Kumar et al. [103] identified rutin, quercetin, kaempferol, catechin, ferulic acid, gallic acid, caffeic acid, and coumaric acid using LC-MS (liquid chromatography-mass spectrometry). 
Li et al. [104] isolated cycloccidentalic acids A and B, cycloccidentalisides I-V, quercetin, luteolin, eriodictyol, robtein, chrysoeriol, 3-methylquercetin, 7,4'-dihydroxy-3' -methoxyflavone, 7,3',4' -trihydroxyflavone, 3-methoxy-7,3' , $4^{\prime}$-trihydroxyflavone, chrysoeriol 5-methyl ether, $2^{\prime}, 3,4^{\prime}, 4$ tetrahydroxychalcone, ajugasterone C, 20-hydroxyecdysone 2-acetate, 20-hydroxyecdysone 3-acetate, calonysterone, and poststerone. S. F. Li and S. L. Li [105] isolated cycloccidentalic acid $\mathrm{C}$ and cycloccidentaliside VI.

Ogunwande et al. [106] identified the (E)-geranyl acetone, hexahydrofarnesylacetone, and (E)-phytol acetate through GC-MS. Qin et al. [107] extracted nor-sesquiterpene, 3-isopropyl-1,6-dimethoxy-5-methyl-naphthalen7-ol, and 2,7-dihydroxy-4-isopropyl-6-methyl-naphthalene-1-carbaldehyde. Singh et al. [108] reported the isolation of emodin, rhamnetin 3-neohesperidoside, chrysophanol, physcion, cassiollin, quercetin, 5,7,2',4' -tetrahydroxyfavanol, $\beta$-sitosterol, and chrysophanol.

Tshikalange et al. [109] extracted luteolin from the seeds of S. petersiana. Gamal-Eldeen et al. [110] isolated 7-acetonyl-5-hydroxy-2-methylchromone (petersinone 1), 7-(propan-2' -ol-1' -yl)-5-hydroxy-2-methylchromone (petersinone 2), 5-methyl-3-(propan- $2^{\prime}$-on- $1^{\prime}$-yl) benzoic acid (petersinone 3), 5-(methoxymethyl)-3-(propan-2' -ol-1' -yl) benzoic acid (petersinone 4), glyceryl-1-tetracosanoate, and sistosterol-3- $\beta$-D-glycoside from the leaves. Coetzee et al. [111] extracted cassiaflavan- $(4 \alpha \rightarrow 8)$-epicatechin, cassiaflavan- $(4 \alpha \rightarrow 8)$-epigallocatechin, cassiaflavan- $(4 \beta \rightarrow 8)$-epicatechin, cassiaflavan- $(4 \beta \rightarrow 8)$-epigallocatechin, cassiaflavan$(4 \beta \rightarrow 8)$-gallocatechin, ent-cassiaflavan- $(4 \beta \rightarrow 8)$-epicatechin, and cassiaflavan- $(4 \alpha \rightarrow 6)$-epicatechin from the bark. Ajiboye et al. [112] isolated $\beta$-elemene, phytol, caryophyllene oxide chrysophanol, 3-oxo-methyl ester, $\alpha$-humulene, $\beta$-caryophyllene, rhein, emodin, and $\alpha$-copaene from the leaves of Senna podocarpa (Guill. \& Perr.) Lock.

Malmir et al. [113] isolated rhein, emodin, chrysophanol, physcion, and sennosides A and B from the hydroethanol extracts of leaves and roots. Genta-Jouve et al. [114] isolated schoepfins A and D from Senna quinquangulata, while Ogura et al. [115] isolated quinquangulin.

Mena-Rejón et al. [116] isolated 8,9-dihydroxy-3-methoxy-2,2,6-trimethyl-(2H)-anthracen-1-one (racemochrysone) from Senna racemosa (Mill.) H.S.Irwin \& Barneby bark extracts (hexane extract). Sansores-Peraza et al. [117] isolated cassine and inositol methyl ether from the leaves. Dos Santos et al. [118] extracted compounds from the wood of Senna reticulata (Willd.) H.S.Irwin \& Barneby, and they include chrysophanol, emodin, physcion, aloe-emodin, 1,3,8-trihydroxyanthraquinone, 3-methoxy-1,6,8-trihydroxyanthraquinone, chrysophanol-10,10' -bianthrone, stigmasterol, $\alpha$ and $\beta$-amyrin, $\beta$-sitosterol, and kaempferol. Barbosa et al. [119] isolated chrysophanol, physcion, quinquangulin, and rubrofusarin from the roots of S. rugosa.

Alemayehu et al. [120] isolated chrysophanol, physcion, emodin, floribundone-1,5, $7^{\prime}$-physcion-fallacinol, $5,7^{\prime}$-physcion-physcion- $10^{\prime}-\mathrm{C}$ - $\alpha$-arabinopyranoside from the stem bark of S. septemtrionalis. Similarly from the pods, Alemayehu et al. [121] isolated bianthraquinone, 5,7' ${ }^{\prime}$-phys- cion-fallacinol $\quad\left(1,1^{\prime}, 8,8^{\prime}\right.$,-tetrahydroxy-6,6 $6^{\prime}$-dimethoxy-3methyl-3' -hydroxymethylene-5, $7^{\prime}$-bianthracene- $9,9^{\prime}, 10,10^{\prime}$ -tetraone) chrysophanol, physcion, torosachrysone, emodin, floribundone-1, and torosanin- $9^{\prime}, 10^{\prime}$-quinone. Ingkaninan et al. [122] isolated luteolin, cassia chromone (5-acetonyl-7hydroxy-2-methylchromone), 4-(trans)-acetyl, 3,6,8-trihydroxy-3-methyldihydronaphthalenone, 5-acetonyl-7-hydroxy2-hydroxymethyl-chromone, and 4-(cis)-acetyl-3,6,8-trihydroxy-3-methyldihydronaphthalenone from the leaves of $S$. siamea.

The leaves are also reported to contain barakol [123], cassiarins A and B [124], and chrobisiamone A [125].

The floral parts of Senna plants species are reported to have cassiarins C-E, 10,11-dihydroanhydrobarakol [126], and cassibiphenols $A$ and B [127]. The compounds such as $1,1^{\prime}, 3,8,8^{\prime}$-pentahydroxy-3',6-dimethyl [2,2' -bianthracene]$9,9^{\prime}, 10,10^{\prime}$-tetrone, 7-chloro-1,1' $, 6,8,8^{\prime}$-pentahydroxy-3,3' -dimethyl [2,2' -bianthracene $]-9,9^{\prime}, 10,10^{\prime}$-tetrone, emodin, cassiamin A, chrysophanol, friedelin, physcion, and cycloart25 -en-3 $\beta, 24$-diol were isolated from the root $[128,129]$.

The stems of Senna plant species are identified with physcion, chrysophanol, betulinic acid, lupeol, and emodin $[130,131]$. In other studies, Lü et al. [132-134] reported the extraction of chrysophanol, 1-[( $\beta$-D-glucopyranosyl$(1 \rightarrow 6)-O-\beta$-D-glucopyranosyl)oxy]-8-hydroxyl-3-methy-

9,10-anthraquinone, chrysophanol-1-O-beta-D-glucopyranoside [132], sucrose, $\beta$-sitosterol, n-octacosanol, 2 methyl-5-2' -hydroxypropyl)-7-hydroxy-chromone- $2^{\prime}-\mathrm{O}-\beta$ D-glucopyranoside, piceatannol [133], and 1,8,10-trihydroxyl-1-O- $\beta$-D-glucopyranosyl-3-methyl-10-C (S)- $\beta$-Dglucopyranosyl-anthrone-9 [134] from stem. $\mathrm{Hu}$ et al. [135] isolated siamchromones A-G, 7-hydroxy-2-methyl-5(2-oxopropyl)-4H-chromen-4-one, O-methylalloptaeroxylin, perforatic acid, uncinoside A, peucenin-7-methyl ether, 8-methyleugenitol, urachromone A, 11-hydroxy-sec-O-glucosylhamaudol, sec-O-glucosylhamaudol, barakol, 4-cisacety1-3,6,8-trihydroxy-3-methyldihydronaphthalenone,

and 2-methyl-5-(2' -hydroxypropy1)-7-hydroxychromone$2^{\prime}$-O-D-glucopyranoside from the stem. In an independent work, Ledwani and Singh [136] reported the isolation of 1,8-dihydroxy-3-methyl anthraquinone and cassiamin from stem. Li et al. [137] isolate 6-hydroxy-7-methoxy-3-(4methoxyphenyl)-2H-chromen-2-one, 7-hydroxy-6-methoxy-3-(4-methoxyphenyl)-2H-chromen-2-one, piceatanno1, $2,2^{\prime}, 3,3^{\prime}$-tetrahydroxyldiphenylethylene, candenatenin E, kaempferol, quercetin, and nonin A from the stems.

Thengyai et al. [138] isolated lupeol, $\beta$-amyrin, $\alpha$ amyrin, betulin, betulinic acid, and scopoletin from the stem bark.

Baez et al. [139] isolated rutin, quercetin, 5,7-dimethoxyrutin, aglycon 5,7-dimethoxyquercetin, D-3-O-methylchiro-inositol, and piceatannol from roots of Senna skinneri (Benth.) H.S.Irwin \& Barneby. Also, Baez et al. [140] isolated 5,7-di-O-methylrutin and 5,7-di-O-methylquercetin from $S$. skinneri and quercetin and rutin from Senna wislizeni (A.Gray) H.S.Irwin \& Barneby. Alemayehu et al. [141] separated different compounds from the seeds of $S$. sophera, and these included presengulone [9-(6' methoxy- $3^{\prime}$-methyl- $3^{\prime}, 8^{\prime}$ 
, $9^{\prime}$-trihydroxy-1 $1^{\prime}$-oxo- $1^{\prime}, 2^{\prime}, 3^{\prime}, 4^{\prime}$-tetrahydro-anthracene- $7^{\prime}$ yl)-5,10-dihydroxy-2-methoxy-7-methyl-1,4-anthraquinone], physcion bianthrone, xanthorin, floribundone-1, isosengulone, sengulone, and anhydrophlegmacin-9,10-quinones A2 and B2. Kharat et al. [142] extracted hexahydroxydiphenic acid and kaempferol from methanolic extract of leaves.

Malhotra and Misra [143] isolated 1,3,6,8-tetrahydroxy 2-methyl 7-vinyl anthraquinone (sopheranin), 3-sitosterol, chrysophanol, physcion, and emodin from the roots and flowers. Mondal et al. [144] isolated 2-(3,4-dihydroxy-phenyl)-3,5-dihydroxy-7-methoxy-chromen-4-one.

Mushtaq et al. [145] isolated palmitic acid, palmitoleic acid, oleic acid, phytol, neophytadiene, and solasodine from S. sophera and S. tora. S. spectabilis is one of plant widely studied and reported. Selegato et al. [11] have reviewed the chemical aspects of S. spectabilis. Silva et al. [146] isolated caffeine, lupeol, $\alpha$-amyrin, $\beta$-amyrin, cycloeucalenol, friedelin, ursolic, oleanolic, and betulinic acids, sitosterol, and stigmasterol and their respective glucosides from the leaves. Lim et al. [147] isolated $(+)$-spectaline and iso-6-spectaline from the leaves.

For this plant, flowers are recognized by (-)-cassine, $(-)$-cassine, (-)-spectaline, and iso-6-spectaline [148-150]. Sriphong et al. [151] isolated 3(R)-benzoyloxy-2(R)methyl-6(R)-(11' -oxododecyl)-piperidine, 5-hydroxy-2methyl-6-(11' -oxododecyl)-pyridine, 5-hydroxy-2-methyl6-(11'-oxododecyl)-pyridine $\mathrm{N}$-oxide, and (-)-cassine from the flowers. Viegas Junior et al. [152] isolated (-)-7-hydroxycassine), (-)-cassine, (-)-spectaline, (-)-3-O-acetylspectaline, $(-)-7$-hydroxyspectaline and (-)-iso-6-spectaline, $\beta$-sitosterol, luteolin, 3-methoxyluteolin, betulinic acid, and transcinnamic acid from the green fruits and flowers, whereas few other researchers reported piperidine alkaloid (-)-3-Oacetylspectaline, (-)-3-O-acetyl-spectalin, (-)-spectaline cassine, (-)-3-O-acetylcassine, iso-6-cassine, (-)-3-O-acetylspectaline, (-)-cassine, and (-)-spectaline [153-157].

Maia et al. [79] isolated quercetin diglucoside from the leaves, methoxy oxyresveratrol from the roots, quercetin-3O-rhamnoside- $4^{\prime}$-O-glucoside from the flowers $(2.885 \mathrm{~g} /$ $\mathrm{kg}$ ), while the bark of $S$. splendida had quercetin rhamnoside. Valencia et al. [158] isolated 5-(3-formyl-4-hydroxyfenoxy)-2-hydroxybenzaldehyde from stems and leaves of Senna stipulacea (Aiton) H.S.Irwin \& Barneby.

El-Sawi and Sleem [159] isolated quercetin 3-O-glucoside 7-O-rahmnoside, quercetin, and rutin from the leaves of S. surattensis. Anu and Madhusudana [160] isolated kleinioxanthrone- 1 and 2 from the aerial sections of $S$. tora [161] while roots had kleinioxanthrone-3 and 4. elHalawany et al. [162] isolated torachrysone $8-O-[\beta$-D-glucopyranosyl $(1 \rightarrow 3)-O-\beta$-D-glucopyranosyl $(1 \rightarrow 6)-O-\beta$-D -glucopyranoside], toralactone $9-O-[\beta$-D-glucopyranosyl- $(1 \rightarrow 3)$ $O-\beta$-D-glucopyranosyl-( $1 \rightarrow 6)-O-\beta$-D-glucopyranoside], aurantio-obtusin 6-O-b-D-glucoside, torachrysone 8-O-b-Dgentiobioside, toralactone 9-O-b-D-gentiobioside, 6hydroxymusizin 8-O-b-D-glucoside, torachrysone tetraglucoside, rubrofusarin triglucoside, and chrysophanol triglucoside from ethanolic extract of the seed. In another work, Fathalla et al. [163] identified chrysophanol, chrysarobin, 10hydroxy-5-methoxy-2-methyl-1,4-anthracenedione, rubrofu- sarin, parietin, griseoxanthone- $\mathrm{B}$, isotorachrysone, and cumbiasin B from the seeds through GC-MS. Lee et al. [164] isolated rubrofusarin-6-O- $\beta$-D-gentiobioside, cassiaside, and toralactone-9-O- $\beta$-D-gentiobioside from the seeds.

Hatano et al. [165] isolated rubrofusarin-6-O- $\beta$-gentiobioside, cassiaside, cassiaside $\mathrm{C}$, chrysophanol-1-O- $\beta$ tetraglucoside, torosachrysone-8-O- $\beta$-gentiobioside, cassiaside $\mathrm{C} 2$, rubrofusarin triglucoside, torachrysone tetraglucoside, demethylflavasperone gentiobioside, norrubrofusarin gentiobioside, torachrysone gentiobioside, and torachrysone apioglucoside from the seeds. Lee et al. $[166,167]$ extracted emodin, 7-methoxy-obtusifolin, chrysoobtusin, obtusin, aurantio-obtusin, chrysophanol, obtusifolin, physcion, cassiaside, rubrofusarin-6-O-gentiobiosideol, obtusifolin-2-glucoside, cassitoroside, toralactone-9-O-gentiobioside, chryso-obtusin-2-O-glucoside, physcion-8-O-gentiobioside, glucoaurantio-obtusin, and alaternin $2-O-\beta$-D-glucopyranoside from the seeds. In an independent study, Park and Kim [168] isolated chryso-obtusin-6-glucoside, norrubrofusarin-6-glucoside, and obtusifolin2 -glucoside, using seeds. Cherng et al. [169] extracted aloe-emodin, emodin, chrysophanol, and rhein. Hyun et al. [170] extracted emodin, alaternin, gluco-aurantioobtusin, glucoobtusifolin, cassiaside, cassitoroside, chrysophanol triglucoside, toralactone gentiobioside, questin, and 2-hydroxyemodin 1methylether from the methanol extract. Jimenez-Coello et al. [171] isolated (8-hydroxymethylen)-trieicosanyl acetate from the Senna villosa (Mill.) H.S.Irwin \& Barneby. Guzmán et al. [172] isolated (8-hydroxymethylen)-trieicosanyl acetate from the leaf extract (chloroform extract).

The chemical structures of some representative phytochemical compounds with therapeutic potencies in Senna plants are represented in Figure 2.

\section{Antioxidant Activity of Senna Plants}

Antioxidants are chemical compounds which are naturally present in food and also in human body [173-175]. These substances play a vital role for preventing cell damage caused by oxidative destruction as a result of free radical generation [176-178].

According to the literature, there are different pathways to acting as antioxidant agents $[179,180]$ :

(1) Inhibiting the spread of free radicals or peroxide radicals by exchange of one or more protons

(2) Reducing or blocking free radical formations with help of "metal chelating agents"

(3) Reduction in reactive oxygen species (ROS) formation

(4) Decreasing cellular ROS creation by hindering the oxidant enzymes

(5) Influencing the complete antioxidant mechanism in the body by synergies of different antioxidant-rich ingredients

ROS are considered causative for various detrimental effects and persistent diseases like cancer, cardiovascular 
$\mathrm{HO}$<smiles>CC(=O)CCCCCCCCCCC1CCCCN1</smiles>

cassine<smiles>Oc1cc(O)c2c(c1)O[C@H](c1ccc(O)c(O)c1)[C@H](O)C2</smiles>

epicatechin<smiles></smiles>

quercimeritrin<smiles>O=c1cc(-c2ccc(O)cc2)oc2cc(O)c(O)c(O)c12</smiles><smiles>Cc1cc(O)c2c(c1)C(=O)c1cccc(O)c1C2=O</smiles>

chrysophanol<smiles>COc1cc(O)c2c(c1)C(=O)c1cc(C)cc(O)c1C2=O</smiles>

physcion<smiles>O=C(O)c1cc(O)c2c(c1)C(=O)c1cccc(O)c1C2=O</smiles>

rhein<smiles>Cc1cc(O)c2c(c1)C(=O)c1cc(O)cc(O)c1C2=O</smiles>

emodin<smiles></smiles>

proanthocyanidins<smiles>C[C@H]1O[C@H](OC[C@H]2O[C@H](Oc3c(-c4ccc(O)c(O)c4)oc4cc(O)cc(O)c4c3=O)[C@@H](O)[C@H](O)[C@H]2O)[C@H](O)C(O)[C@@H]1O</smiles><smiles>CCC(C=CC(C)C(C)C)C1CCC2C3CC=C4C[C@@H](O)CC[C@]4(C)C3CCC12C</smiles>

FIgURE 2: Chemical structures of mostly identified phytochemical compounds in Senna plants.

diseases (CVD), neurodegenerative dysfunction, like Alzheimer's, Parkinson's, and Huntington's diseases, sepsis, and diabetes [181-183].

The antioxidant activity of Senna genus was correlated with phenolic and flavonoid content which includes chemical compounds such as catechins, proanthocyanidins, scutellarein, rutin, quercimeritrin, kaempferol glycosides, rhein, chrysophanol, aloe-emodin, and physcion [184-186].

Neutralization of free radicals by the contained polyphenols justifies the antioxidant activities of the genus Senna. These polyphenols also quench singlet, and triplet oxygen, or decompose peroxides [187]. The antioxidant capacity and total polyphenol content of genus Senna were investigated by conducting both in vitro and in vivo experiments (Figure 3).

Commonly used in vitro techniques for determining the antioxidant activities of extracts are DPPH (2,2-diphenyl-1picrylhydrazyl radical) and FRAP (ferric reducing antioxidant power) assay. The literature study indicates that various species under Senna genus were investigated using different methodologies, and they are indicated in Table 2. According to the study of Silva et al. [188] with four species of Senna from northeast Brazil, some of the phenolic compounds such as anthraquinones and flavonoids which are detected in the phytochemical screening especially in root extracts more than other parts can act as radical scavengers by donating hydrogen. They also mentioned that root extract of $S$. trachypus had a higher radical scavenging activity level than two standards (butylated hydroxyanisole (BHA) and quercetin) used in the assays.

Campos et al. [185] examined the chemical makeup of Senna velutina (Vogel) H.S.Irwin \& Barneby leaf extracts (ethanol) and antioxidant activities with the DPPH method. In this study, $\mathrm{IC}_{50}$ (minimum sample concentration needed for scavenging 50 percent free radicals) values of the extract of $S$. velutina leaf extract; ascorbic acid and butylated hydroxytoluene (BHT) were found $(6.3 \mu \mathrm{g} / \mathrm{mL}, 2.6 \mu \mathrm{g} / \mathrm{mL}$, and $21.3 \mu \mathrm{g} / \mathrm{mL}$, respectively). This indicates that the antioxidant activity of $S$. velutina leaves is higher with a 3.5 -fold than BHT but lower than ascorbic acid according to these results.

Ita and Ndukwe [189] studied the antioxidant activity of S. alata roots in different in vitro models. They used three different solvents such as acetone, ethanol, and water for 


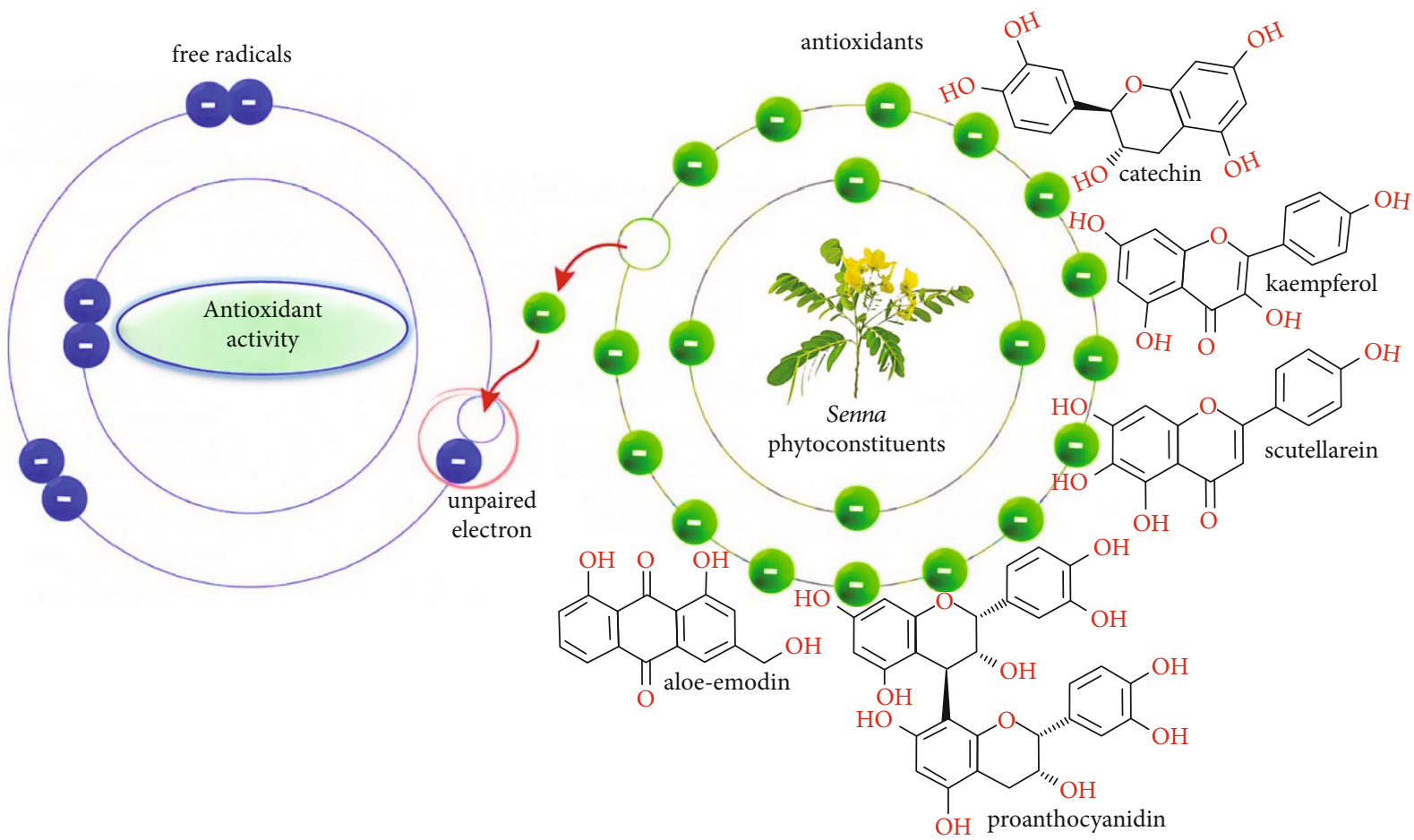

Figure 3: Antioxidant activity of bioactive compounds of Senna plants. The antioxidant bioactive molecules contained in Senna species neutralize free radicals by releasing electrons.

extraction and measured its ferric reducing power, DPPH, ABTS $\quad\left(2,2^{\prime}\right.$-azino-bis(3-ethylbenzothiazoline-6-sulfonic acid) radical-scavenging abilities, and metal chelating activity to determine antioxidant properties of roots. Researchers stated that ethanol extract had high amounts of total phenolics and flavonoids with values of $78.21 \mathrm{mg}$ gallic acid equivalent (GAE)/g and $39.29 \mathrm{mg}$ quercetin equivalent (QE)/g and exhibited the best antioxidant capacity in terms of DPPH and ABTS protocols. Besides, the aqueous extract showed more potential in metal chelating and reducing power. Khalaf et al. [88] analyzed the phenolic compounds, antioxidant, antimicrobial, and anticancer activities of $S$. italica aerial parts extracted using ethyl acetate and n-butanol. The researchers isolated and identified six compounds from this plant as they did bioguided fractionation. The names of these compounds are as follows: quercetin 3-O- $\alpha$-L-rhamnopyranosyl-( $1 \rightarrow 6)$ - $\beta$-D-glucopyranoside (rutin), physcion, emodin, 1-hydroxy-2-acetyl-3-methyl-6-hydroxy-8-methoxynaphthalene (tinnevellin), 2-methoxy-emodin-6-O- $\beta$ D-glucopyranoside, and 1,6,8-trihydroxy-3-methoxy-9,10dioxo-9,10-dihydroanthracene. Antioxidant activity was measured with ABTS method, and the ethyl acetate and nbutanol extracts showed $82.9 \%$ and $85.7 \%$ inhibition against ABTS radical, respectively, in comparison with ascorbic acid (89.2\% inhibition). According to the literature, anthraquinone compounds which are already in this plant are given to their antioxidant potentials. Therefore, the researchers said that these anthraquinone-rich extracts (ethyl acetate and n-butanol) might be the reasons behind the high antiradical capacity. At last, it is noted that the aerial parts of
S. italica may possess antioxidant activity and can serve as natural sources of antimicrobial and anticancer factors.

Phaiphan and Baharin [190] focused on determining effects of various extraction methods on some bioactive properties of S. siamea leaf. Researchers focused the study on comparing the solvent extraction with that of ultrasound-assisted extraction with regard to total phenolic content and antioxidant and antibacterial activity. In solvent extraction and ultrasound-assisted extraction (UAE), ethanol/water mixture (49\%) and ethanol/water mixture (40\%) were used, respectively, under the optimized conditions which were predetermined. The study showed that extracts from the ultrasound-assisted extraction had higher yield, total phenolic content (TPC), and antioxidant activities than those acquired from the solvent extraction. Furthermore, UAE extracts had greater antibacterial activity compared to solvent extracts. This can be attributed to the fact that the cavitational effect caused by ultrasound resulted in a more porous cell wall causing more release of phenolic bioactive in the solvent. It is evident from the literature that higher concentrations of bioactive have a direct correlation with antioxidant activity and antimicrobial activity. Similarly, Laghari et al. [191] investigated the comparison between 5 different extraction methods (microwave, Soxhlet, marination, reflux, and sonication) during the extraction of flavonoids to evaluate the antioxidative properties of $S$. alexandrina. As a result of this study, a greater quantity of flavonoids was obtained with microwave extraction in the aqueous ethanol (70\%) fractions of S. alexandrina flowers and leaves. 


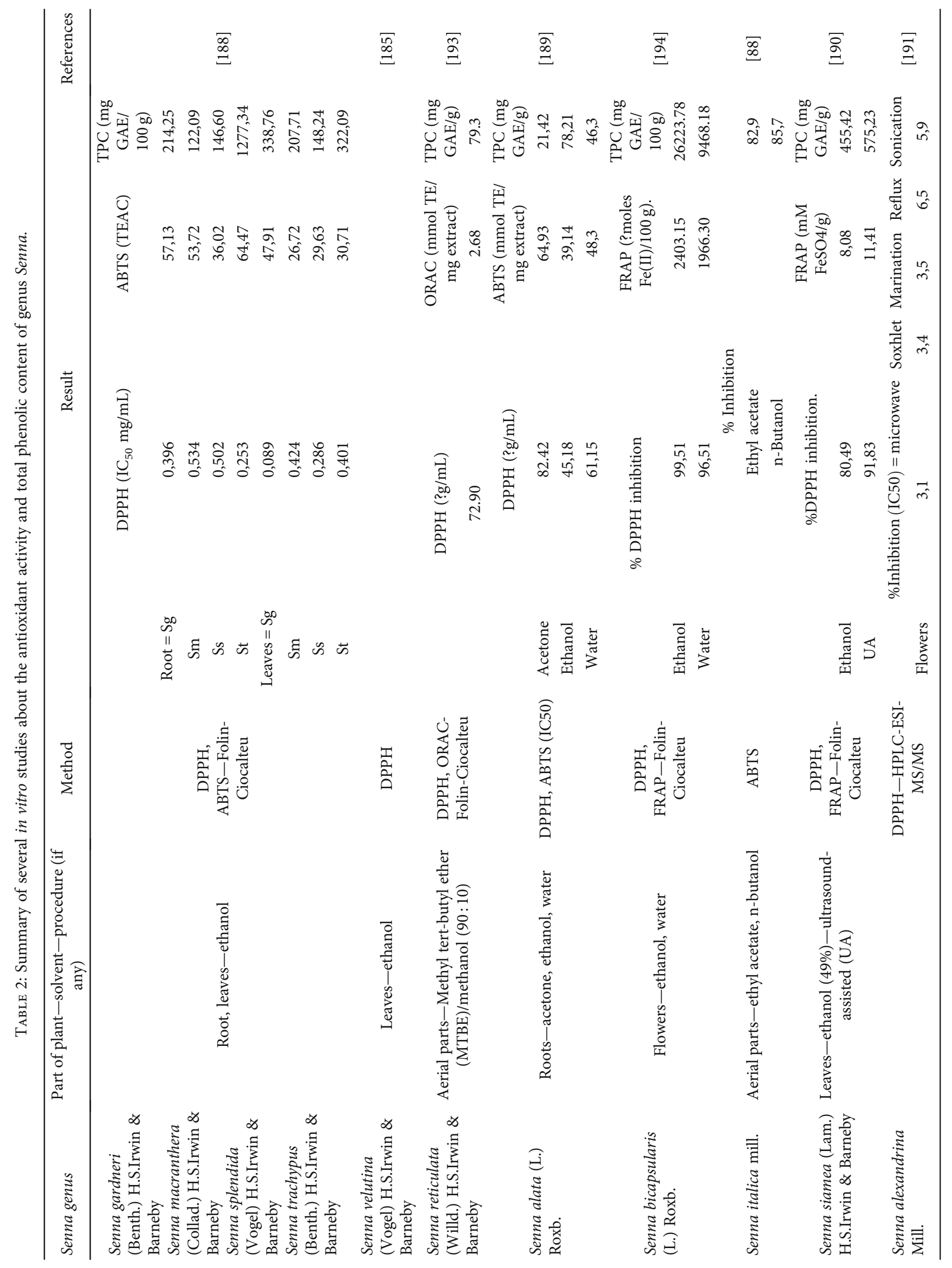




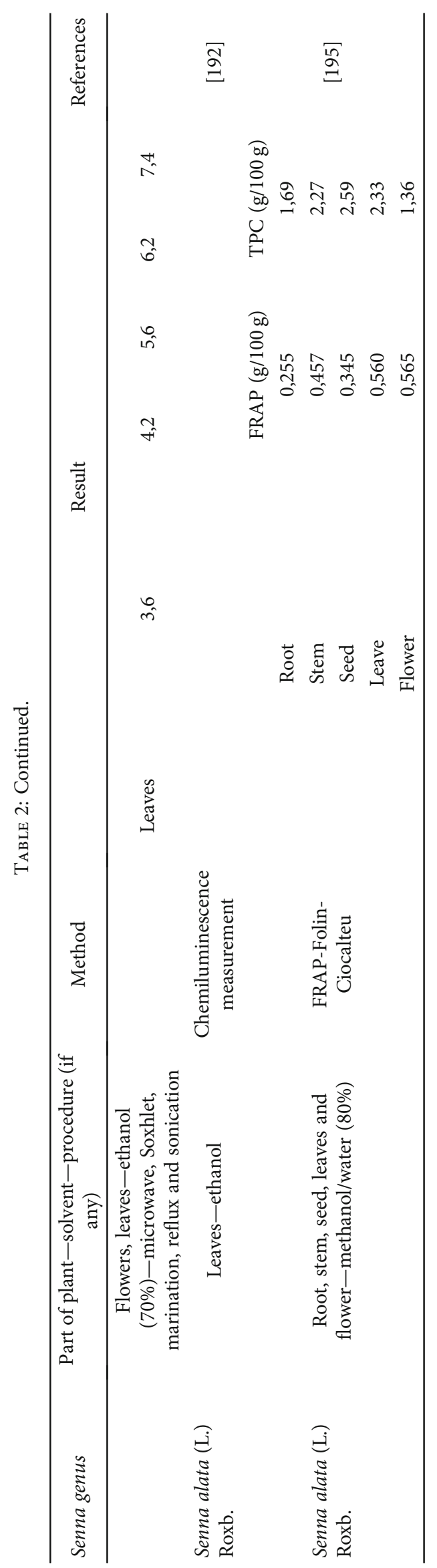


In some of the studies, the antioxidant activity of some plants is compared with each other. In a study, five different medicinal plants (S. alata, Eleusine indica (L.) Gaertn., Eremomastax speciosa (Hochst.) Cufod., Carica papaya L., and Polyscias fulva (Hiern) Harms) collected from Cameroon were examined according to their scavenger activities against superoxide anion and hydrogen peroxide [192]. The results show that $S$. alata plant extracts at less than $12.5 \mu \mathrm{g}$ had the best scavenger activity with a $67 \%$ reduction in luminol-amplified chemiluminescence signal.

Navarro et al. [193] obtained and characterized (UPLCDAD-EST-TQ-MS) phenolic extracts from Petiveria alliaceae L., Phyllanthus niruri L., and S. reticulata. Researchers also evaluated the antioxidant potential via conducting DPPH and ORAC (oxygen radical absorbance capacity) assay, and TPC was measured by the Folin-Ciocalteu method. Correlation analysis was carried out as well. It was reported that $P$. niruri has the highest phenolic content with 328.8 GAE/g, followed by $S$. reticulata with $79.3 \mathrm{GAE} / \mathrm{g}$. In addition, $P$. niruri exhibited the best DPPH and ORAC values among these three plants. About the phenolic acid's characterization, for $S$. reticulata, the main compound was ferulic acid (52.6\%) followed by 4-hydroxybenzoic acid, caffeic acid, vanillic acid, p-coumaric acid, and protocatechuic acid. S. reticulata had $\mathrm{IC}_{50}$ of $72.9 \mu \mathrm{g} / \mathrm{mL}$ for $\mathrm{DPPH}$ and $2.68 \mathrm{mmol}$ Trolox equivalents (TE)/g for ORAC. It was concluded that as TPC and UPLC increased ORAC values increased indicating a strong correlation.

Mak et al. [194] investigated the antioxidant capacity and antibacterial properties of ethanolic and distilled water extracts of hibiscus (Hibiscus rosa-sinensis L.) and S. bicapsularis flower. DPPH radical scavenging activity and FRAP were used as antioxidant assay while total phenolic content was analyzed by using the Folin-Ciocalteu method. DPPH inhibition values were $99.51 \pm 0.2$ for ethanol extracts and $96.51 \pm 0.3$ for aqueous extracts. The FRAP values found in the study were like $2403.15 \pm 307.3 \mu \mathrm{mol} \mathrm{Fe}$ (II) $/ 100 \mathrm{~g}$ for ethanol extract and 1966.30 \pm 12.7 for aqueous extract. Total phenolics were also determined in the study, and results are as follows: $26223.78 \pm 450.3 \mathrm{mg} \mathrm{GAE} / 100 \mathrm{~g}$ for ethanol extract and $9468.18 \pm 91.9 \mathrm{mg}$ GAE/100 $\mathrm{g}$ for aqueous extract. Researchers stated that these results were significantly different from each other and the other hibiscus flower extracts. Similarly, too many studies in literature, Cassia flower extracts (ethanolic) exhibited the highest TPC, total flavonoid, and flavonol content, which in turn had the highest DPPH radical scavenging activity. In addition to that, they suggested that all hibiscus and cassia flowers-because of their significant antioxidant activities-can be used as a natural preservative in formulations of new and creative functional products or nutraceuticals.

Channa et al. [195] studied medicinal properties, biochemical parameters, and antibacterial activity of S. alata's various sections such as roots, stem, seed, leaves, and flower. To analyze the antioxidant capacity, the FRAP method was chosen and $80 \%$ methanol-water was used as a solvent. Researchers noted that the seeds were found rich in phenolic compounds compared to other parts. The seeds of $S$. alata contained a sufficient amount of total flavonoid whereas the leaves of the plant were quite rich in tannins. However, flowers were found the strongest antioxidative content. As a result, researchers suggested that these extracts have important potential for health benefits, so the plant needs to be isolated and test in detail.

Madubunyi and Ode [196] investigated the antioxidant potential of the $S$. singueana leaves with an in vivo malondialdehyde test. Malondialdehyde is an oxidative stress marker which is the end product of lipid peroxidation in the cells. In this study, all doses $(0.25,0.50$, and $1.00 \mathrm{~g} / \mathrm{kg}$ feed) of $S$. singueana extract significantly decreased malondialdehyde (MDA) level in the blood samples of test rats in comparison to the control group up to day 56. Similar to that study, treating rats using the methanolic extract of $S$. singueana root extracts was able to decrease malondialdehyde levels, the same as aspartate aminotransferase, alanine aminotransferase, and bilirubin level which are the indices of liver damage and lipid peroxidation, in all tissues especially in the liver and kidney [197].

\section{Anti-infectious Activity of Senna Plants}

7.1. Antibacterial and Antifungal. The most studied genus Senna for its anti-infectious activity was found to be $S$. alata. Different parts of S. alata are used as a vermicide, astringent, purgative, and expectorant and for treating skin diseases such as eczema, pruritus, itching, ulcers, scabies, and especially ringworm [198, 199]. Other species having antimicrobial activity are S. spectabilis, S. alexandrina, S. occidentalis, S. podocarpa, S. tora, S. racemosa, and S. siamea. The bioactive substances that provide bioactivity to genus Senna are steroids, flavonoids, anthraquinones, anthrones, and miscellaneous other compounds. They are located in the leaves, stems, roots, flowers, bark, seeds, and fruits.

Especially antibacterial and antifungal activities of Senna extracts are obtained from the extraction of leaves mostly. In the studies generally, minimum inhibitory concentration (MIC) is calculated which is described as the smallest concentration of sample necessary to prevent microbial growth. The MIC value of $100-200 \mu \mathrm{g} / \mathrm{mL}$ is generally acceptable for plant materials [200]. Although the extracts of the parts of the genus Senna could not reach such MIC values, when the bioactive compounds are isolated from the extracts, MIC values decrease, and the antimicrobial properties increase [201]. Some of these bioactive components include stigmasterol, beta-sitosterol, kaempferol, luteolin, santal, alatonal, aloe-emodin, alquinone, chrysophanol, emodin, physcion, rhein, alarone, benzoquinone, coumarin, ellagitannin, naphthalene, phenolic acid, purine, xanthone, and cassine [202]. Anti-infectious effects of genus Senna are presented in Table 3.

The antifungal and antibacterial activity of the genus Senna varies depending on the species of the plant, the species of the microorganism, and the factors that affect the yield of the extraction process, such as the extraction method, the solvent used, the portion of the plant, and the secondary metabolite.

Ogunjobi and Abiala [203] investigated in vitro antimicrobial effect of different solvent extracts of $S$. alata leaves 


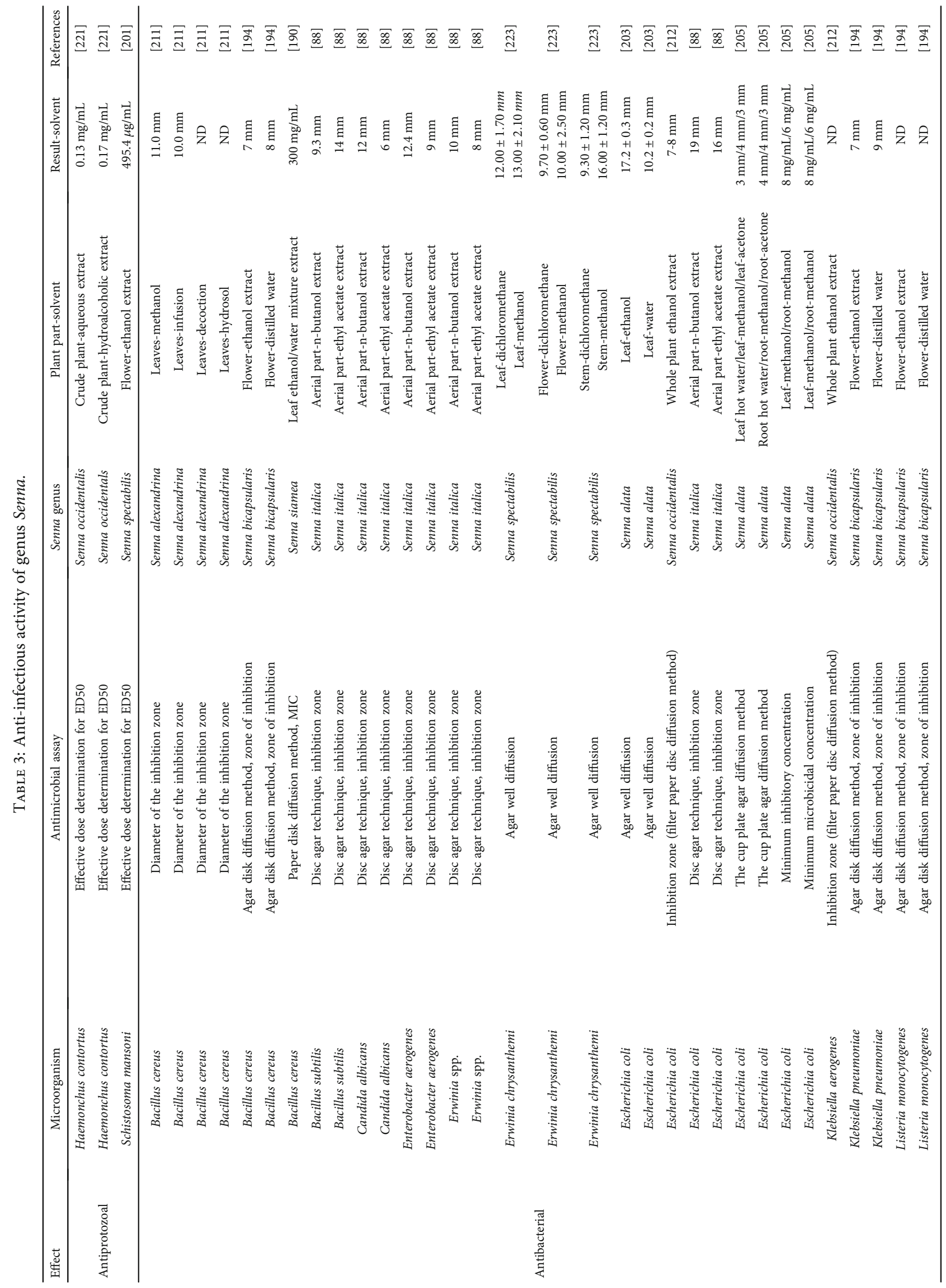




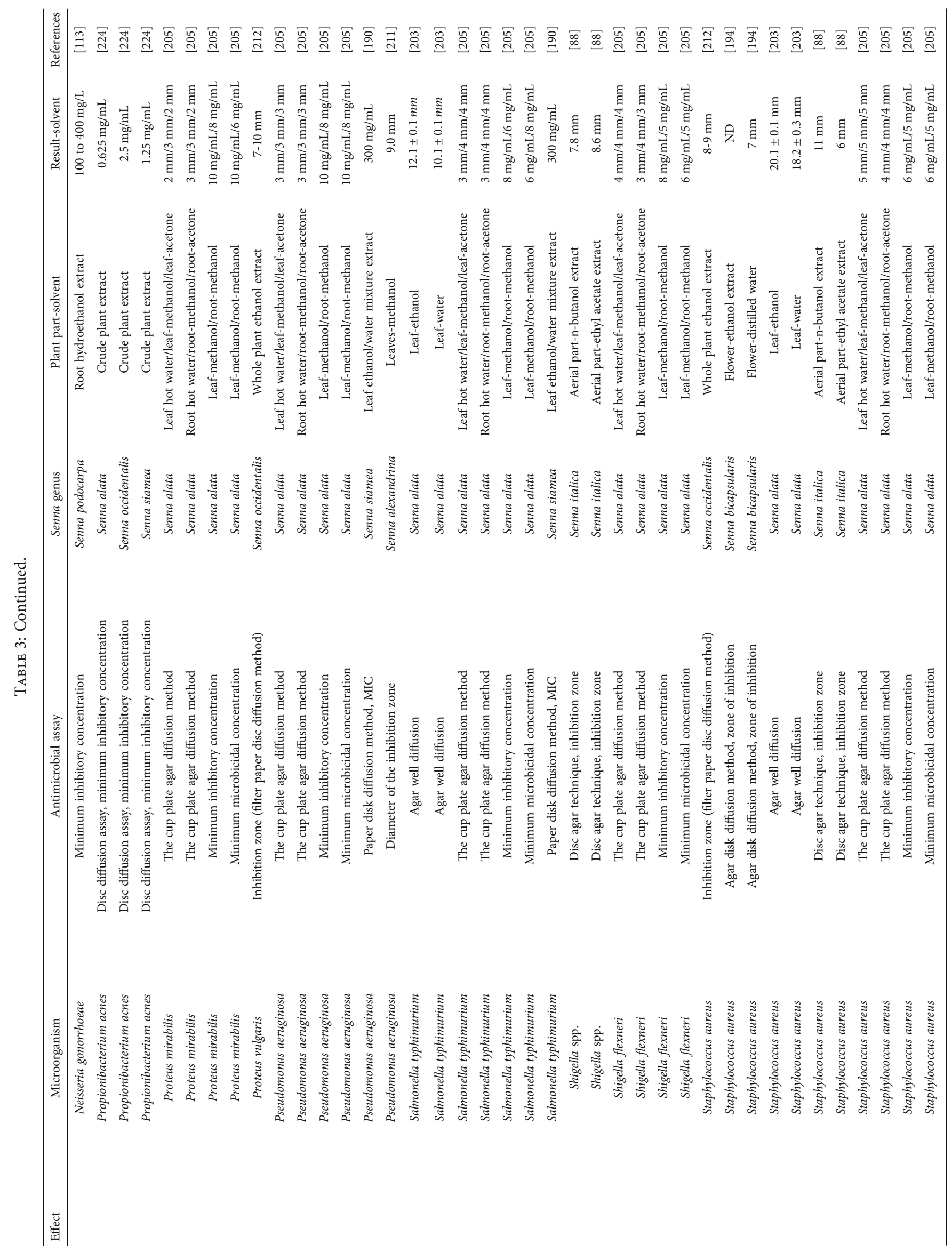




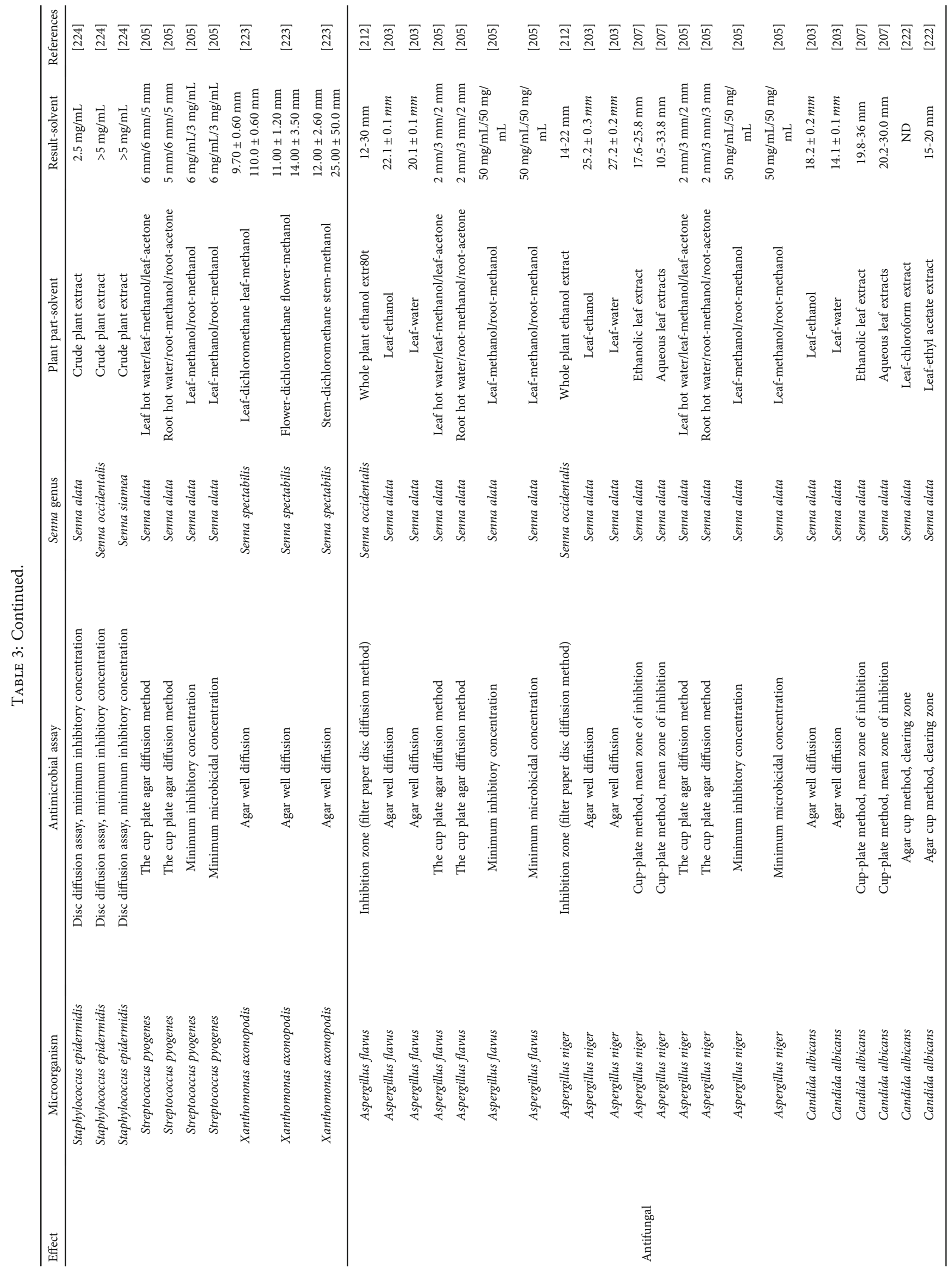




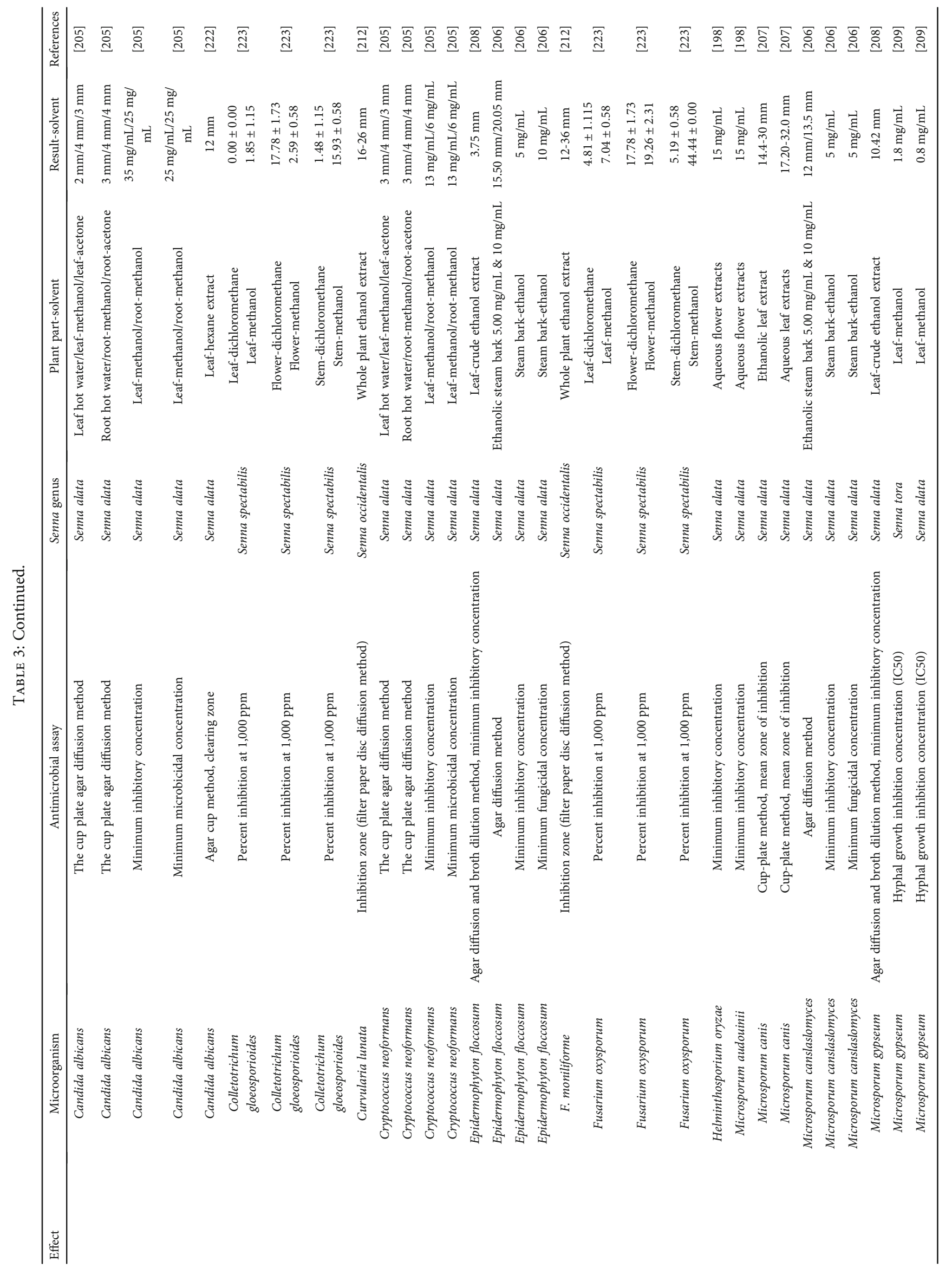




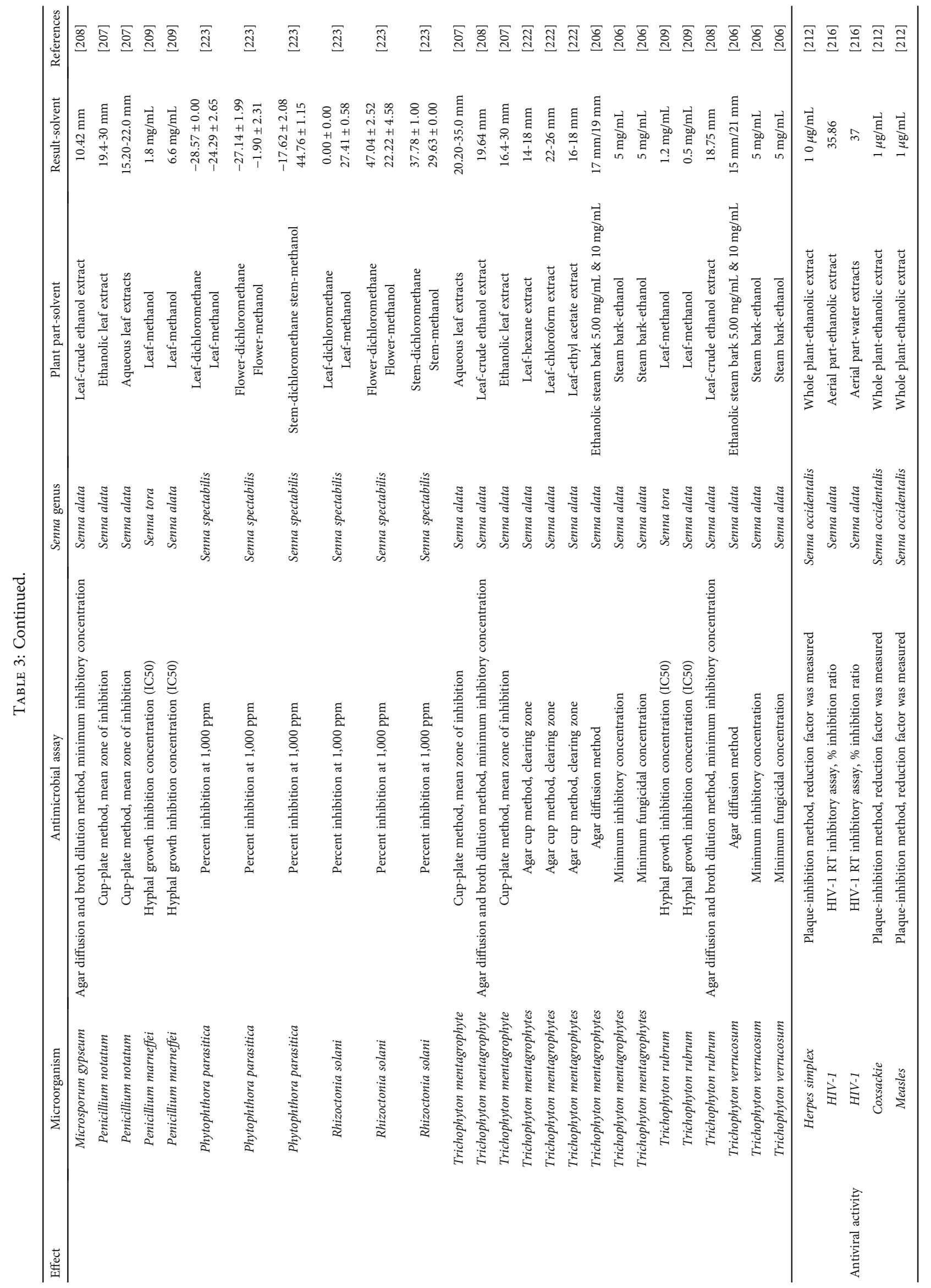




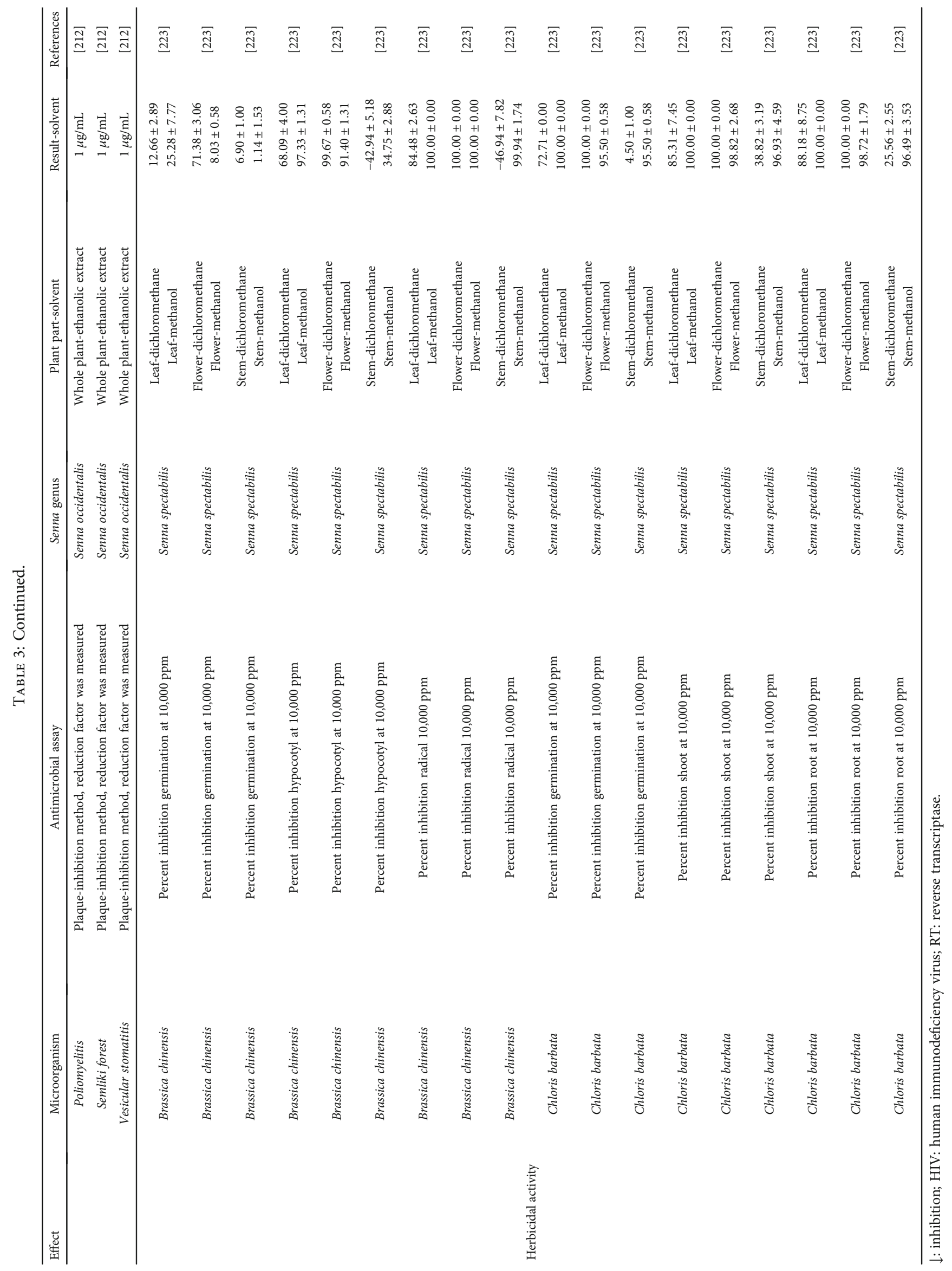


by using the agar well diffusion method. Except for Aspergillus niger inhibition, ethanol extract of $S$. alata showed a more inhibition zone than water extract. The best antimicrobial properties of $S$. alata ethanolic extract were shown in $A$. niger with a $25.2 \mathrm{~mm}$ zone of inhibition, and the least was Salmonella typhimurium with a $12.1 \mathrm{~mm}$ inhibition zone. Escherichia coli and Candida albicans had similar inhibition zone with $17.2 \mathrm{~mm}$ and $18.2 \mathrm{~mm}$. In addition, ethanol extract of $S$. alata demonstrated effective antimicrobial activity of Staphylococcus aureus and Aspergillus flavus with $20.1 \mathrm{~mm}$ and $22.1 \mathrm{~mm}$ zone of inhibition. S. alata water extract observed the best effective antimicrobial characteristics against $A$. niger and $A$. flavus with $27.2 \mathrm{~mm}$ and 20.1 . The other zone of inhibition was followed by $S$. aureus with $18.2 \mathrm{~mm}$ and $C$. albicans with $14.1 \mathrm{~mm}$. The least effective antimicrobial activity was of aqueous extracts of $S$. alata against E. coli and $S$. typhimurium having inhibition zones of $10.2 \mathrm{~mm}$ and $10.1 \mathrm{~mm}$, respectively.

Makinde et al. [204] research was about the methanolwater extract of $S$. alata leaves, and extract was assessed for antimicrobial activity by using a disc diffusion method (in vitro assay). The results indicated that $S$. alata leaves are more effective against fungi. S. alata phenolics and terpenoids, alkaloid salt, alkaloid base, and aqueous extract showed antimicrobial activity against Microsporum canis, Blastomyces dermatitidis, Trichophyton mentagrophytes, C. albicans, and A. flavus with $10-30 \mathrm{~mm}$ zone of inhibition. Phenolics and terpenoids, alkaloid salt, and alkaloid base extract of $S$. alata leaves had provided $5 \mathrm{~mm}$ of inhibition of S. aureus, Corynebacterium parvum, Nocardia asteroides, and Clostridium septicum; however, the aqueous extract had not shown antimicrobial activity of these bacteria. Phenolic and terpenoids and aqueous extract of $S$. alata leaf had 5-10 mm inhibition zone of Dermatophilus congolensis. Alkaloid salt and alkaloid base S. alata extract's inhibition zone of $D$. congolensis was $10-20 \mathrm{~mm}$ and $20-30 \mathrm{~mm}$. Besides, S. alata antimicrobial activity was not observed against Proteus vulgaris and Bacillus pumilus.

Ehiowemwenguan et al. [205] examined the S. alata leaves and roots antimicrobial effect by using the cup plate agar diffusion method. Except for Streptococcus pyogenes, all inhibition zone is less than $5 \mathrm{~mm}$; moreover, hot water extract, methanol extract, and acetone extract $S$. alata root and leaves did not differentiate among their inhibition zone. $S$. pyogenes had the highest zone inhibition at 5-6 $\mathrm{mm}$ both root and leaf extract independent of solvent type. S. alata root and leaves exhibited antimicrobial and antifungal reaction against E. coli, Proteus mirabilis, Pseudomonas aeruginosa, Salmonella typhi, Shigella flexneri, S. aureus, A. flavus, A. niger, C. albicans, and Cryptococcus neoformans. $S$. alata root extract's MIC level was changed $(5-8 \mathrm{mg} / \mathrm{mL})$ for bacteria species except for $S$. pyogenes $(3 \mathrm{mg} / \mathrm{mL})$; however, fungi needed more concentration, approximately 25$50 \mathrm{mg} / \mathrm{mL}$ for inhibition except for C. neoformans $(6 \mathrm{mg} /$ $\mathrm{mL})$. The results of MIC level of leaves for bacteria were similar to root extract; yet, MIC range was between 6 and $10 \mathrm{mg} /$ $\mathrm{mL}$ for bacteria. The leaf extract MIC was $35-50 \mathrm{mg} / \mathrm{mL}$ except C. neoformans $(13 \mathrm{mg} / \mathrm{mL})$. The minimum microbial concentration of $S$. alata leaf extract for bacteria was determined between 6 and $10 \mathrm{mg} / \mathrm{mL}$, and fungi had more minimum microbial concentration at $25-50 \mathrm{mg} / \mathrm{mL}$ except C. neoformans $(13 \mathrm{mg} / \mathrm{mL})$. The minimum microbial concentration of root extract results was similar to leaf extract except for $S$. pyogenes $(3 \mathrm{mg} / \mathrm{mL})$ and $C$. neoformans $(6 \mathrm{mg} / \mathrm{mL})$.

Channa et al. [195] also detected antibacterial activity in root, stem, seeds, leaves, and flower extracts (methanol, ethanol, and water) of $S$. alata. In this study, a good diffusion method was used, and the results were between 8 and $34 \mathrm{~mm}$. The least inhibition zone, $8 \mathrm{~mm}$, was observed against $S$. aureus and Klebsiella pneumoniae by root-methanol, root-ethanol, leave-ethanol, stem-ethanol, and stemwater extraction. The maximum inhibition zone was observed against E. coli by leaves-methanol extraction. Furthermore, the results showed that flowers and leaves of $S$. alata possess antibacterial activity as compared to commercial drugs such as ciprofloxacin, penicillin, ampicillin, tetracycline, and gentamicin.

Sule et al. [206] experimented to determine in vitro antifungal activities of $S$. alata crude stem bark extract by using the agar diffusion method. Zones of inhibition were observed at $5 \mathrm{mg} / \mathrm{mL}$ and $10 \mathrm{mg} / \mathrm{mL}$ ethanol solvent of $S$. alata crude steam bark except for T. mentagrophytes. T. mentagrophytes has the highest inhibition zone with $17 \mathrm{~mm}$ at $5 \mathrm{mg} / \mathrm{mL}$ concentration. The inhibition zone followed the order as Epidermophyton floccosum with $15.5 \mathrm{~mm}$, Trichophyton verrucosum with $15.0 \mathrm{~mm}$, and Microsporum canslaslomyces with $12.0 \mathrm{~mm}$ at $5 \mathrm{mg} / \mathrm{mL}$ concentration. T. verrucosum and E. floccosum showed the best inhibition of zone with $21.0 \mathrm{~mm}$ and $20.5 \mathrm{~mm}$ at $10 \mathrm{mg} / \mathrm{mL}$ concentration. $M$. canslaslomyces had again the least zone of inhibition with $13.50 \mathrm{~mm}$ at a concentration of $10 \mathrm{mg}$ / $\mathrm{mL}$. However, a concentration of $10 \mathrm{mg} / \mathrm{mL}$ was effective against T. mentagrophytes with $19 \mathrm{~mm}$ inhibition of the zone. In addition, T. mentagrophytes was the only fungi that affected the inhibition at $2.5 \mathrm{mg} / \mathrm{mL}$ concentration with $10 \mathrm{~mm}$ zone. The MIC was evaluated at $5 \mathrm{mg} / \mathrm{mL}$ for all fungi. Minimum $5 \mathrm{mg} / \mathrm{mL}$ fungicidal concentration was appropriate for inhibition of fungi, except E. floccosum. The minimum fungicidal concentration of E. floccosum was determined at $10.0 \mathrm{mg} / \mathrm{mL}$.

Abubacker et al. [198] conducted a study for in vitro antifungal properties of $S$. alata aqueous flower extracts, using three different fungal groups including fungi that produce aflatoxin (A. flavus and Aspergillus parasiticus), plant pathogenic fungi (Fusarium oxysporum and Helminthosporium oryzae), and human pathogenic fungi (C. albicans and Microsporum audouinii). The results highlighted the strong antifungal activity of $S$. alata. While $15 \mathrm{mg} / \mathrm{mL}$ of flower extract concentration provides $100 \%$ inhibition of all the fungus, $10 \mathrm{mg} / \mathrm{mL}$ was enough in inhibiting A. flavus. The MIC values of the flower extract of $S$. alata ranged from 5.75 to $8.0 \mathrm{mg} / \mathrm{mL}$.

In a different investigation, Timothy et al. [207] assessed leaf extracts of $S$. alata (aqueous and ethanol) against five pathogenic fungi which are C. albicans, M. canis, T. mentagrophyte, Penicillium notatum, and A. niger. According to the calculated zones of inhibition, there was no inhibition 
for water extract of leaves whereas ethanol extracts exhibited inhibition for all tested microorganisms. Furthermore, MIC of ethanol extracts for all tested fungi was lower than the water extract indicating that ethanol extract includes more bioactive compounds than the water extract. The reason ethanol is being more effective than the water was told to be because of the presence of anthraquinone which is not found in the water extraction. Intense antifungal activities of $S$. alata were depicted from the study outcomes.

Wuthi-udomlert et al. [208] remarked on the importance of anthraquinone derivatives in the in vitro evaluation. Anthraquinone glycosides including emodin, rhein, and chrysophanol found in S. alata are the source of laxative effects. In the study, extraction of leaves is obtained in five different ways using anthraquinone aglycone, anthraquinone glycoside, anthraquinone aglycone from glycosidic fraction, crude ethanol, and anthraquinone aglycone from crude ethanol extract. Extraction yields were monitored by thin-layer chromatography, and the highest yield is obtained from crude ethanol extraction which was $34.94 \% \mathrm{w} / \mathrm{w}$. As a result of the in vitro antifungal activity against Trichophyton rubrum, T. mentagrophytes, E. floccosum, and Microsporum gypseum by diffusion and broth dilution methods, anthraquinone aglycone from glycosidic fraction presented greater activity among five different extracts.

Phongpaichit et al.'s [209] experiment was about antifungal activities of $S$. alata and S. tora. Except Penicillium marnef$f e i, 10 \mathrm{mg} / \mathrm{mL}$ methanolic extract obtained from leaves of $S$. alata and S. tora were enough in inhibiting all the M. gypseum, and T. rubrum. $10 \mathrm{mg} / \mathrm{mL}$ S. alata leaves inhibited only $77 \%$ of $P$. marneffei; still, $S$. tora extract was sufficient to inhibit all $P$. marneffei. In addition, $\mathrm{IC}_{50}$ result of T. rubrum followed the order as $S$. alata at $0.5 \mathrm{mg} / \mathrm{mL}$ and $S$. tora at $1.2 \mathrm{mg} / \mathrm{mL}$. $S$. alata with $0.8 \mathrm{mg} / \mathrm{mL} \mathrm{IC}_{50}$ value was the best inhibition for M. gypseum; also $S$. tora have an $\mathrm{IC}_{50}$ value at $1.8 \mathrm{mg} / \mathrm{mL}$. The $\mathrm{IC}_{50}$ values of $P$. marneffei of $S$. alata and $S$. tora were $6.6 \mathrm{mg} / \mathrm{mL}$ and $1.8 \mathrm{mg} / \mathrm{mL}$, respectively.

Malmir et al. [113] drew attention to the bioactive substance called "rhein" isolated from S. podocarpa root hydroethanol extract. In their study, $S$. podocarpa root extracts were evaluated for in vitro anti-Neisseria gonorrhoeae activity. Gonorrhoea is a widespread sexually transmitted infectious disease induced by $N$. gonorrhoeae bacterium infection. $N$. gonorrhoeae infects the mucous membranes of the reproductive organs that include the fallopian tubes, uterus, and cervix in women, while in men and boys it infects the urethra. N. gonorrhea can also harm the mucous membranes of the mouth, throat, and eyes [210]. S. podocarpa root demonstrated anti-N. gonorrhoeae activity against all strains. MIC ranged from 100 to $400 \mathrm{mg} / \mathrm{L}$. The most active fractions having $50-100 \mathrm{mg} / \mathrm{L}$ MIC values, had rhein, emodin, chrysophanol, and physician as their key compounds as detected by LC-UV/DAD cochromatography with reference standards. Among all the isolates, rhein (MIC: $3.13 \mathrm{mg} / \mathrm{L}$ against all test strains) was the most effective. In addition to rhein, Sansores-Peraza et al. [117] highlighted the antibacterial and antifungal activity of cassine, isolated from S. racemosa, with MIC of $2.5 \mathrm{mg} / \mathrm{mL}$ against S. aureus and Bacillus subtilis and $5.0 \mathrm{mg} / \mathrm{mL}$ for C. albicans.
Albayrak et al. [211] indicated that infusion of S. alexandrina leaves is the only herb that has antibacterial effect against Bacillus cereus among infusions of eight plants in Turkey which are Foeniculum vulgare Mill. (fennel), Pimpinella anisum L. (anise), Laurus nobilis L. (laurel), Tilia $\times$ europaea L. (linden tea), Urtica dioica L. (nettle), Petroselinum crispum (Mill.) Fuss (parsley), and Anethum graveolens L. (dill). In the study, they extracted $S$. alexandrina leaves by four methods which are methanol extraction, infusion, decoction, and hydrosol. The in vitro antimicrobial activities of $S$. alexandrina leaves were evaluated, and the results showed that infusion of Senna leaves has antibacterial effect against $B$. cereus and methanol extracts of Senna have antibacterial activity against $B$. cereus and $P$. aeruginosa.

As a result of in vitro antibacterial analysis conducted by Jain et al. [212], although Klebsiella aerogenes exhibited resistance to all extracts, ethanol extracts of flowers and pods of S. occidentalis provide inhibition of growth of E. coli and $P$. vulgaris. In addition, a descending sort among bioactive compounds according to the antibacterial activities against test bacteria which are E. coli, K. aerogenes, P. vulgaris, and $S$. aureus was reported as anthraquinones $>$ sennosides $>$ flavonoids. Antifungal activity of ethanol extracts of S. occidentalis was found to be higher than the antibacterial activity. Among the metabolite-rich fractions, the maximum inhibition was shown by sennosides against A. flavus, followed by anthraquinones and flavonoids against Curvularia lunata.

7.2. Antiviral. Antiviral activity of genus Senna is generally found quite low; however, the extraction yield and the isolation of bioactive compounds provide an increase in the antiviral activity.

Jain et al. [212] investigated the antimicrobial, antitumor, and antiviral activity of ethanol extracts of S. occidentalis. They conducted in vitro analysis for antiviral and in vivo analysis for antitumor activity. The antiviral activity against Herpes simplex was quite inadequate; the reduction factor of titre was found $10 \mu \mathrm{g} / \mathrm{mL}$. In addition, S. occidentalis did not exhibit any antitumor activity or cytotoxicity.

Ogbole et al. [213] highlighted the antiviral agents that $S$. siamea includes which are lupenone, lupeol, betulinic acid, chrysophanol, physicon, and $\beta$-sitosterol glucoside. Among tested anthraquinones and triterpenoids, lupeol was the most effective constituent against poliovirus having $0.014 \mu \mathrm{g} / \mathrm{mL}$ of $\mathrm{IC}_{50}$ value. Antipoliovirus, antitobacco mosaic virus, and anti-HIV-1 effects were observed in the extract of $S$. siamea stem bark $[135,214]$.

Another genus which is analyzed for the antiviral activity is S. alata. Shaheen et al. [215] determined the antiviral activity of methanol, chloroform, ethyl acetate, n-butanol, and aqueous extracts of $S$. alata by in vitro and in vivo experiments. The results justified the antiviral activity of Senna; all extracts exhibited antiviral effects against cardiac coxsackievirus $\mathrm{B} 3$. As a result of in vitro analysis, the therapeutic index varied between 0.2 and 12. In vivo, virus titer values were between $0 \log _{10}$ and $2.5 \log _{10}$. Both in vitro and in vivo analyses exhibited that the most effective extracts against cardiac coxsackievirus B3 were aqueous extracts. 


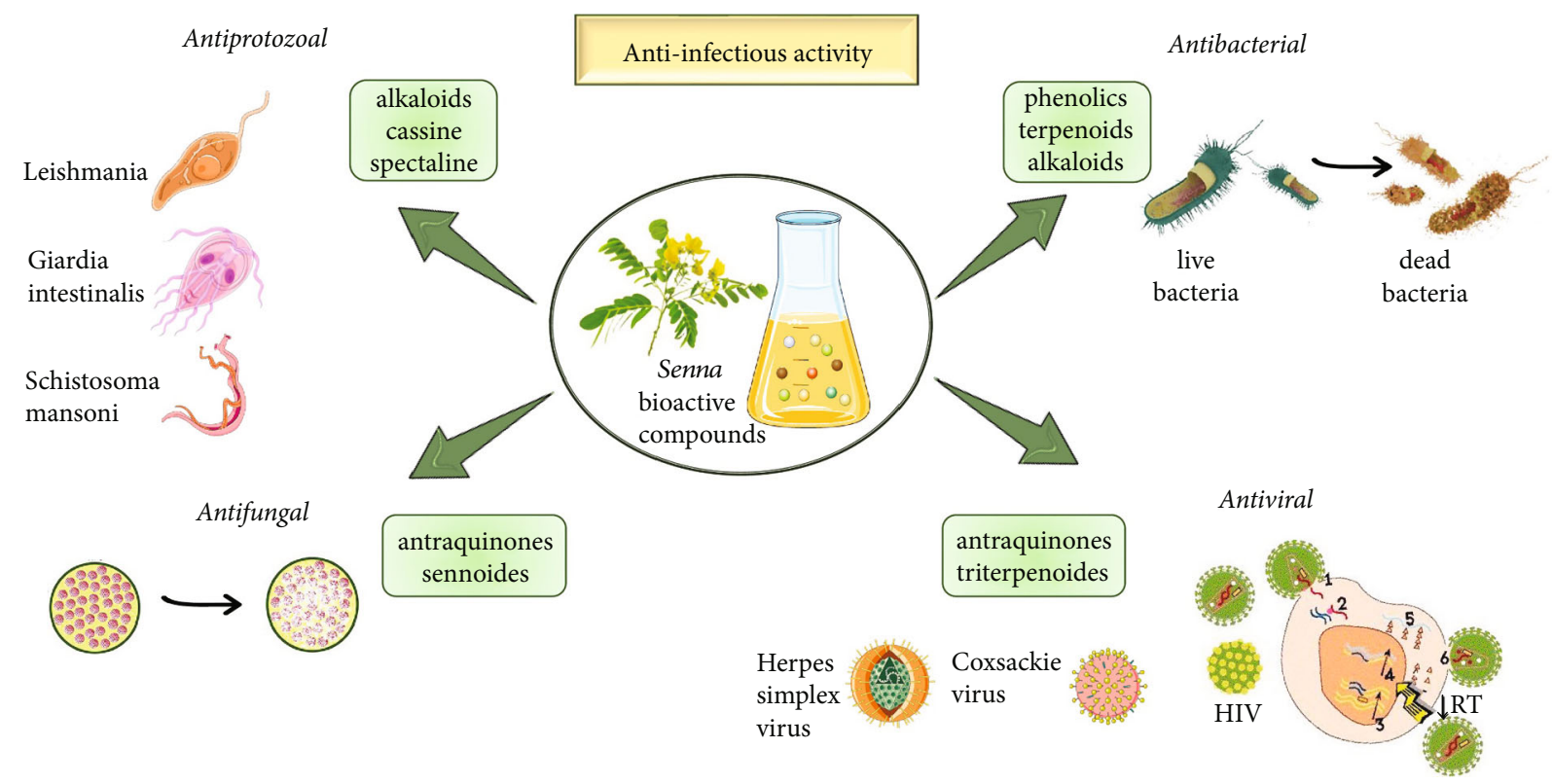

Figure 4: Anti-infectious properties of the most representative bioactive compounds of Senna plants. Botanical molecules such us alkaloids, sennoides, anthraquinones, phenolics, terpenoids, alkaloids, and triterpenoids have anti-infectious activity against bacteria, fungus, protozoa, and viruses (HIV, Coxsackie, and Herpes simplex).

Woradulayapinij et al. [216] investigated in vitro HIV-1 reverse transcriptase inhibitory activity of ethanol and water extracts of aerial part of S. alata. Even though the results were quite close to each other, water extract depicted higher activity than the ethanol extract; inhibition ratios were 37 and $35.86 \%$ for water and ethanol extracts, respectively.

7.3. Antiprotozoal. Numerous studies reported antiprotozoal activities of genus Senna. de Castro et al. [201] conducted a study about the schistosomicidal activity of S. spectabilis flower extracts. Schistosoma is an intestinal parasite that causes a chronic disease called Schistosomiasis. The disease has been reported in 78 countries; especially, $90 \%$ of the cases have been reported in Africa where access to safe drinking water is a challenge. According to the WHO [217], at least 229 million people needed the treatment of Schistosoma in 2018. de Castro et al. [201] extracted and isolated (-)-cassine and (-)-spectaline substances from S. spectabilis flowers. In vitro activity of extracts, their fractions, and the mixture of (-)-cassine and (-)-spectaline against S. mansoni worms were analyzed. Obtained data indicated that the mixture of (-)-cassine and (-)-spectaline exhibited a multitarget mechanism against the excretory activity, tegument lesions, and neuromotor activity. It also showed a toxic effect on the larval period of cercariae. Therefore, S. spectabilis flower extracts (-)-cassine and (-)-spectaline have a great potential for their schistosomicidal activity. Furthermore, de Albuquerque Melo et al. [218] mentioned about leishmanicidal activity of $S$. spectabilis and the two major alkaloidal metabolites (-)-cassine/(-)-spectaline. Caamal-Fuentes et al. [219] studied antiprotozoal properties of S. racemosa against Giardia intestinalis and observed that methanolic extracts of S. racemosa bark in both in vitro and in vivo experiments had activity against $G$. intestinalis $[219,220]$. Eguale et al.
[221] mentioned the in vitro anthelmintic activity of S. occidentalis, and the extract concentration required to inhibit $50 \%$ (ED50) of the eggs of Haemonchus contortus was found to be $0.13 \mathrm{mg} / \mathrm{mL}$ and $0.17 \mathrm{mg} / \mathrm{mL}$ for aqueous and hydroalcoholic extracts, respectively.

A scheme with anti-infectious properties of Senna plants is summarized in Figure 4.

7.4. Other Biological Properties. Villaseñor et al. [222] also conducted research on $S$. alata leaf extracts with hexane, chloroform, and ethyl acetate to investigate antimutagenic, antifungal, analgesic, anti-inflammatory, and hypoglycemic activities. Chloroform extract exhibited a reduction in the mutagenic activity of tetracycline by $65.8 \%$ at a dosage of $2 \mathrm{mg} / 20 \mathrm{~g}$ mouse as a result of the in vivo analysis. Against fungi, T. mentagrophytes chloroform extract was the most effective. The hexane extract was having the highest analgesic property which provides a decrease of $59.9 \%$ at a dosage of $5 \mathrm{mg} / 20 \mathrm{~g}$ mouse among other extracts. The analgesic activity of hexane extract was similar to the activity of mefenamic acid which is a widely known analgesic. For the antiinflammatory activity, all three extracts are observed hourly, for three hours. At the end of three hours, hexane and ethyl acetate extracts demonstrated $65.5 \%$ and $68.2 \%$ inhibition, respectively, at a dosage of $5 \mathrm{mg} / 20 \mathrm{~g}$ mouse. Ethyl acetate extract also showed hypoglycemic activity more effectively than the other extracts by providing a $56.7 \%$ reduction in blood glucose level.

\section{Clinical Studies}

Health-promoting effects of Senna and its other species have been evaluated by a large number of researchers around the world while clinical trials have been conducted in limited 
cases (Table 4). Therefore, in this section, we are presenting quantified data on Senna and its clinical trials (previous and latest).

Mcnicol [225] performed a clinical experiment to evaluate the activity of tablets prepared using Senna (standardized preparation) on human bowel function and its possible side effects. The experiment was carried out in two phases: (a) first is the administration of the drug to 52 ward patients; (b) the drug was administered to 126 volunteer medical students. The Senna tablets were prepared in two different batches. The results demonstrated that the mean values for "speed of action" of Senna preparation (3 tablets) were recorded as 9.7 hours with ward patients and 12.15 hours among student volunteers, respectively. The frequency of griping, looseness of stool, and multiple bowel movements in ward patients have been recorded in dose-dependent patterns (increased with rising dosage). In addition, results confirmed that there is no significant difference between male and female responses. Thamlikitkul et al. [226] performed a randomized controlled experiment to evaluate the efficacy of $S$. alata against constipation. A total of 80 candidates participated in this study, and the differences observed between both groups (placebo \& mist. Alba; and placebo \& S. alata) were statistically highly significant $(p<0.001)$.

Kinnunen et al. [227] evaluated the safety and efficacy profile of laxatives containing Senna in treating constipation patients using lactulose as standard medication. The present study was carried out in a total of 30 patients (mainly bedridden due to degenerative diseases, age: 65-94 years). One week run-in without laxatives was followed by 5 weeks (a) of a daily dose of $14.8 \mathrm{mg}(20 \mathrm{~mL})$ laxative plus Senna or $20.1 \mathrm{mg}(30 \mathrm{~mL})$ lactulose and (b) crossed medicines (5-week period). The results indicated that bulk laxative plus Senna ( $14.8 \mathrm{mg}$ dose) when given daily resulted in significantly $(p<0.005)$ more frequent bowel habits (4.5 vs. $2.2-19 /$ week $)$ compared to that of lactulose (daily dose of $14.8 \mathrm{mg}$ ). In other words, bulk laxative plus Senna produced efficiently treated constipation patients.

Damodaran and Venkataraman [228] from India reported the therapeutic effectiveness of $S$. alata leaves against Pityriasis versicolor in humans. The study was completed among 200 candidates (age: 16-60 years) of Tamil Nadu (Indian State) within 10 years. Different concentrations of plant extract $(80 \%, 90 \%$, and $100 \%)$ were used at affected areas (trunk, neck, hands, and face) of the body. The results indicated that $S$. alata leaf extract could be employed as a herbal remedy having no side effects, for curing $P$. versicolor.

Ramesh et al. [229] carried out a controlled comparative study of Misrakasneham (Ayurvedic formulation) and laxative Senna tablets (purified Senna extract) against opioidinduced constipation. Misrakasneham (a combination of 21 different types of herbs, castor oil, purified butter, and milk) is a centuries-old Ayurvedic medicine. The present study was conducted in 50 patients with advanced cancer aged 15 years and categorized into two groups (25 each). The first group received Misrakasneham while the second group received Senna tablets in three steps during the 14day study. The results demonstrated that $85 \%$ of the Misra- kasneham group and 69\% of the laxative Senna group had satisfactory bowel movements with no statistical difference $(p>0.2)$. In addition, Misrakasneham data showed interesting results in terms of efficacy and was recommended as a possible candidate for opioid-induced constipation.

van Gorkom et al. [230] reported the effects of sennosides on histology of colonic mucosa and bowel preparation. In this experiment, a total of 171 candidates participated who were further split into two groups: (a) $n=84$ candidates treated with $1 \mathrm{~mL} / \mathrm{kg}$ of a syrup containing $2 \mathrm{mg} / \mathrm{mL}$ sennosides $\mathrm{A}$ and $\mathrm{B}$ and $3-5 \mathrm{~L}$ of a lavage solution and (b) $n=87$ candidates treated with 3-5 L of lavage solution. The results demonstrated that both groups showed no difference in tolerance or quality of bowel preparation. In addition, group a $(10 / 19)$ also showed a rapid increase of mononuclear infiltrate in the lamina propria compared to group b $(2 / 21)$, respectively $(p=0.0005)$.

\section{Safety and Side Effects}

In traditional medicine, the leaves of Senna traditionally are used as laxatives in the form of pellets prepared with dried figs and plums. The anthraquinone laxatives like Senna are extremely useful drugs, but appropriate usage is highly important, although most of the reported side effects are mild and transit.

Senna is generally safe and well tolerated but can cause adverse events when it is used in high doses and for a long period (Figure 5). Most of the adverse effects are mild and transient. The liver injury, including hepatotoxicity, has been reported in several case studies when Senna has been used prolonged, and the symptoms were mild-to-moderate in severity and solved rapidly with discontinuation [243-245]. In all cases, the correlation between side effects was explained by abuse of Senna in laxative purpose.

Derivatives of sennosides present in the leaves and pods may affect increasing irritability on the intestinal mucosa, which could cause abdominal pain and spasm in a sensitive person. It can also lead to diarrhoea, intensification of menstrual bleeding, and dark urine. It is recommended to take herbal tea or capsules/tablets/syrup of Senna in the evening before sleep, as effects start 6 to 12 hours later. Also, drugs that contain Senna are available in the form of rectal suppositories.

The prolonged use of Senna causing the spasm is the sign that it is necessary to stop future taken. In rare cases, vomiting and nausea may occur. Chronic use of Senna and other laxative herbs leads to increased potassium excretion, resulting in spasms, muscle weakness, and heart failure. However, in very well-explained patient conditions, these types of herbal drugs should be avoided. However, the full safety profile of these herbals is controversial like the opponent attitude of FDA and EMA regarding their consumption in some vulnerable groups of people.

\section{Therapeutic Perspectives and Clinical Gaps}

Traditional and modern medicines, in case of decreasing the intestine motility, take into consideration two classes of 
TABle 4: Summary of some clinical trials conducted on Senna spp.

\begin{tabular}{|c|c|c|c|}
\hline Samples & Type of study/findings/results & Country & Ref \\
\hline Senna alata (L.) Roxb. & $\begin{array}{l}\text { Randomized controlled trial } \\
\text { Trial registration: TCTR0180828004 } \\
\text { Evaluating the use and safety of } S \text {. alata on bowel function recovery among women with } \\
\text { gynecologic cancer } \\
90 \text { women candidates diagnosed with gynecologic cancer were randomly assigned to } \\
\text { postoperative consumption ( } 45 \text { with } S \text {. alata tea and } 45 \text { with warm water) } \\
\text { Usage of } S \text {. alata significantly reduced the time of first passage of flatus (mean difference: } \\
-8.5 \mathrm{~h} ; 95 \% \text { confidence interval: }-3.7,-13.4 \mathrm{~h} \text { ) and time of first defecation (mean difference: } \\
-19.8 \mathrm{~h} \text {; } 95 \% \text { confidence interval: }-11.2,-28.5 \mathrm{~h} \text { ) compared with the controls } \\
\text { The use of } S \text {. alata showed a positive impact during the postoperative care of gynecologic } \\
\text { cancer patients }\end{array}$ & Thailand & [231] \\
\hline Senna & $\begin{array}{l}\text { Randomized controlled and crossover study } \\
\text { Assessing the efficacy and safety of Senna versus polyethylene glycol in treating constipation } \\
\text { in children }\end{array}$ & Mexico & [232] \\
\hline Senna & $\begin{array}{l}\text { Comparative study } \\
\text { Evaluating of Senna and other oral bowel medicines for treating constipation in pediatric } \\
\text { oncology patients getting opioids } \\
\text { The results of 5-year investigation demonstrated that } 41.8 \%(n=245) \text { had blood cancer, } \\
50.3 \%(n=295) \text { had solid cancer, and } 7.9 \%(n=46) \text { had brain cancer out of } 586 \text { matched } \\
\text { samples (age: } 0-20 \text { years, ave. age: } 11.5 \text { years) } \\
\text { Initializing Senna therapy, over another oral bowel medication, reduced the subsequent risk } \\
\text { of surrogate markers of problematic constipation. Adjusted effect of Senna on enema } \\
\text { (hazard ratio, } 0.31 ; 95 \% \text { confidence interval, } 0.11-0.91) \text {, abdominal radiographic imaging } \\
\text { (hazard ratio, } 0.74 ; 95 \% \text { confidence interval, } 0.55-0.98) \text {, and escalation of oral bowel } \\
\text { medicine (hazard ratio, } 0.78 ; 95 \% \text { confidence interval, } 0.59-1.03) \text { were recorded }\end{array}$ & Philadelphia & [233] \\
\hline
\end{tabular}

Control single-blinded randomized study

Assessing the efficacy and safety of gum chewing added to high dose Senna before

colonoscopy promotes bowel cleaning

129 candidates participated and were further divided into two groups

(a) $n=65$ patients treated with Senna solution $(150 \mathrm{~mL})$ and sennoside tablet $(80 \mathrm{mg})$ daily

for 3 days before the colonoscopy

Senna

(b) $n=64$ patients were additionally advised to chew sugarless gum half an hour (three

Turkey times) daily for 3 days

The results demonstrated that gum chewing enhanced colonoscopy bowel preparation quality and is considered a physiologically sound, safe, and impassive part of the colonoscopy bowel preparation. The gum chewing group showed better cleaning compared to other groups

Placebo-controlled, double-blinded, randomized study

Evaluating the use of Senna with docusate for constipation after pelvic surgery 96 candidates completed a baseline seven-day bowel diary pre- and postsurgery. After pelvic

Senna surgery, candidates were divided into two groups: (a) $n=45$ in the placebo group and (b)

$$
n=48 \text { in Senna }(8.6 \mathrm{mg}) \text { with docusate }(50 \mathrm{mg}) \text { group. }
$$

The findings demonstrated that the use of Senna with docusate decreases the time to first bowel movement in those undergoing pelvic surgery than placebo ( 3.00 vs. 4.05 days; $p=$ $0.001)$. 
TABLE 4: Continued.

\begin{tabular}{ccc}
\hline Samples & Type of study/findings/results & Country \\
\hline Case study & Ref \\
Case of a 31-year-old female patient who, after prolonged ingestion of Senna extract, \\
developed severe weight loss, cyclic oedema, and dyspepsia, accompanied by an \\
asymptomatic increase in markers of liver and muscle damage, dyslipidemia, \\
electromyographic alterations, and mitochondrial myopathy in the muscle biopsy \\
This clinical case is of particular significance, given that Senna is widely used for its \\
pharmacological properties, with failure to consider its potentially toxic effects
\end{tabular}

\section{Single-blinded randomized study}

The effectiveness of Senna tables and sodium phosphate solution for bowel preparation before colonoscopy was examined for its efficiency

A total of 134 candidates were treated with Senna tablets $(180 \mathrm{mg})$ and sodium phosphate solution $(95 \mathrm{~mL})$ on the day before colonoscopy

Senna

The results demonstrated that the mean cleanliness scores in the four segments of the colon

(rectum, sigmoid segments, descending colon, and transverse colon) except the cecum were higher in the sodium phosphate group than in the Senna group (7.9 vs. 8.3, 8.0 vs. 8.5, 7.9 vs. $8.5,7.9$ vs. 8.2 , and 7.2 vs. 6.9 , respectively)

The taste of Senna was more effective compared to sodium phosphate solutions

\begin{tabular}{|c|c|c|c|}
\hline Senna tora (L.) Roxb. & $\begin{array}{l}\text { Experimental study } \\
\text { Supplementation of } S \text {. tora fibre on the serum lipid profile of diabetic Korean patients was } \\
\text { evaluated. } S \text {. tora fibre supplement of a combination of soluble fibre extracted from } S \text {. tora } \\
(2 \mathrm{~g}) \text {, alpha-tocopherol }(200 \mathrm{mg}) \text {, ascorbic acid ( } 500 \mathrm{mg}) \text {, and maltodextrin }(300 \mathrm{mg}) \text { was } \\
\text { prepared in a pack and given to a total of } 15 \text { candidates } 2 \text { packs per day up to } 2 \text { months } \\
\text { The results demonstrated that } S \text {. tora fibre products were safe for consumption and } \\
\text { additionally provided the necessary amount of dietary fibre for helping in the maintenance } \\
\text { of lipid status in diabetic (type II) patients }\end{array}$ & Korea & [238] \\
\hline Senna & $\begin{array}{l}\text { Controlled randomized single-blinded study } \\
\text { Evaluating efficiency and acceptability of high dose Senna tablets and its comparison with } \\
\text { standard polyethylene glycol in adult patients } \\
192 \text { patients participated and were treated into two groups: (a) } n=91 \text { in polyethylene glycol } \\
\text { group and (b) } n=101 \text { in Senna group } \\
\text { The Senna tablet group showed acceptable results for colon cleansing and tolerance } \\
\text { compared to the polyethylene glycol group }(p<0.001)\end{array}$ & - & [239] \\
\hline Senna & $\begin{array}{l}\text { Controlled study } \\
\text { Highly purified Senna extract was evaluated against cell proliferation, crypt length in the } \\
\text { entire colon and gene expression (p53 and bcl-2). } 171 \text { patients ( } 84 \text { with sennoside- } \\
\text { containing syrup and } 87 \text { without sennoside-containing syrup) were included } \\
15 \text { patients with Senna and } 17 \text { without Senna from } 32 \text { randomized patients were used for } \\
\text { biopsies } \\
\text { Proliferation activity in four areas of colon and gene expression (p53 and bcl-2) was } \\
\text { evaluated by using 5-bromo- } 2^{\prime} \text {-deoxyuridine labelling, immunohistochemistry, and } \\
\text { immunohistochemical } \\
\text { The results demonstrated that crypts were shorter in the Senna group than without Senna } \\
\text { group in the transverse and sigmoid colon. In the entire colon, the labelling index was higher } \\
\text { in the Senna group than without the Senna group. In addition, bcl-2 expression was higher } \\
\text { in both groups when crypts were shorter and proliferation was enhanced while no difference } \\
\text { was recorded in p53 expression }\end{array}$ & Netherlands & [240] \\
\hline
\end{tabular}


TABLE 4: Continued.

Samples
A double-blinded, double-dummy, randomized, and controlled trial
Trial registration: NCT01695850

curative substances: drugs that increase the volume of the gut contents and facilitate mass flow [246, 247]. Among herbal substances, here, we have substances rich in sugars (dried plums and figs) and herbals with mucus, such as flax seeds. Another approach is medicines that contain substances that have a mild irritant effect on the intestinal mucosa to promote intestinal motility [248, 249]. Among these remedies are the species from the genus Senna.

Genus Senna is well recognized as the most used laxative herbal treatment, also available without a prescription. Even before we knew its composition, Senna was used for centuries in phytotherapy for the same purpose. The main type of Senna genus used in medicine is S. alexandrina, known in commerce as Alexandria Senna, and Tinnevelly Senna [250]. Senna plants are widely used herbal medicine in the treatment of functional constipation. As the beneficial parts of the plant in phytotherapy, both the mature pods and the dried leaves are used. They contain natural chemical compounds, called anthraquinone, which are glycoside derivatives of anthracene, and the major compounds are sennosides $\mathrm{A}$ and $\mathrm{B}$, which are available in the market [251]. The sennosides A and B have been broken down by the bacterial flora in the colon and result in the production of the main active metabolites rhein and rheinanthrone [252]. The working of anthraquinones includes the hindrance of $\mathrm{NaCl}$ absorption in the colon and the stimulation of $\mathrm{Cl}$ secretion, by inhibiting the $\left(\mathrm{Na}^{+}, \mathrm{K}^{+}\right)$-ATPase [253].

Additionally, S. alexandrina is used in case of bowel irritable colon, as a pretreatment before diagnostic tests like colonoscopy [254] and as a supplement for weight reduction [255]. While the treatment with active compounds from genus Senna is widely used in different laxative drugs taken orally in liquid or solid dosage forms, in the form of instant tea and herbal tea, however, there are controversies in their usage.

European Medical Agency (EMA) reference the use of Senna [256] only in cases of periodical constipation, while long term is not recommended due to acute dehydration which is followed by loss of electrolytes. Also, EMA do not recommend Senna in case of pregnancy, breast feeding, dehydration, different forms of intestinal obstructions, ulcers, and ulcerative colitis, inflammatory bowel disease including Crohn's disease, pain and spasm in stomach, unknown etiology, and rectal bleeding.

EMA does not recommend using the Senna as a laxative treatment in children under 12, but off-label use has been reported (Figure 5). On the other hand, the USA Food and Drug Administration (FDA) prescribes $17.2 \mathrm{mg}$ (7.5 to $30 \mathrm{mg}$ ) per day for people 12 years and older and $8.5 \mathrm{mg}$ for children under 12 and allowing the usage of botanical laxatives containing Senna in children under 12. Based on a recently published review on Senna side effects as a longterm therapy in children by Vilanova-Sanchez et al. [257], Senna can be a safely employed option in treating functional constipation in children. However, more evidences are needed to confirm this conclusion and to change the attitude of EMA, who recently revised the herbal monography of Senna still stated that Senna is not recommended for children under 12 years [256].

Although some researches of Senna have found that it is effective in a short-term usage of constipation treatment in pregnancy [258-260] and does not have the teratogenic potential [261], intake of Senna during the pregnancy is allowed only in some countries like the USA.

Senna is still contraindicated by EMA recommendation because of experimental data that indicated possibly a 


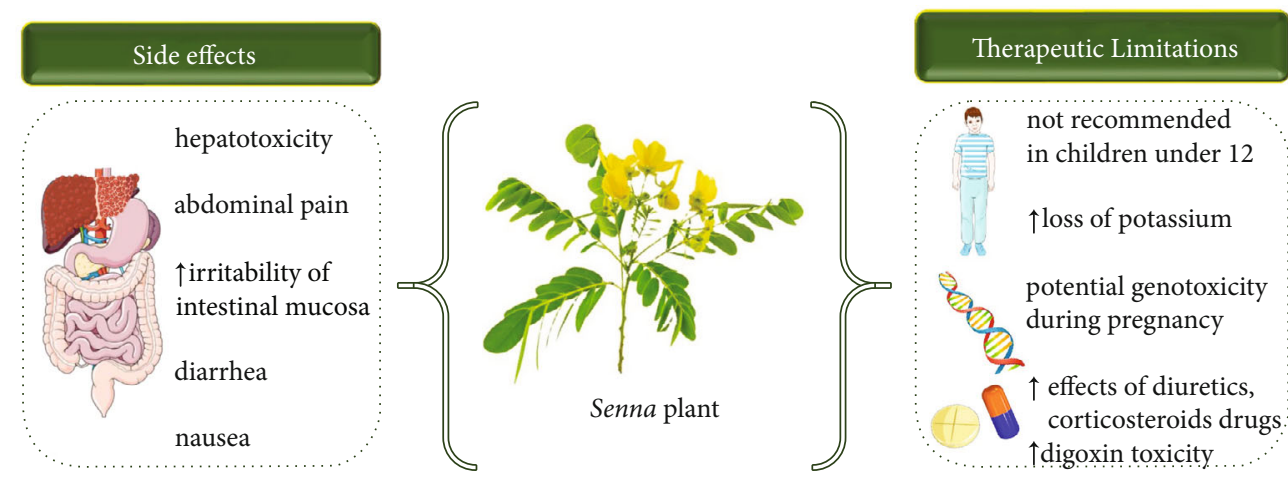

FIgURE 5: Summarized scheme with side effects and clinical therapeutic limitations of Senna plant.

genotoxic risk of several anthranoids, e.g., emodin and aloeemodin [262]. While the use of Senna in breastfeeding women is not recommended, there is evidence that anthraquinone drugs in lactating mothers do not carry a risk of producing a laxative effect in the infant [263-265]. However, there are available data from other studies in which laxative effect on the bowels was observed in infants [258]. Despite controversial findings, still, the official recommendation is to avoid the use of it.

Senna should not be used for a longer period, no longer than 1-2 weeks, nor with medicines that lead to loss of potassium (diuretics, cardiotonic drugs, and corticosteroids). The caution should be exercised when used with antiarrhythmic and cardiotonic drugs and medicinal products inducing QTprolongation, as it may potentiate their effect. All of these effects are correlated with hypokalemia [266, 267]. It has been found that usage of sennosides and digoxin in combination is linked with a modestly increased risk of digoxin toxicity in heart failure patients [268].

Particular attention, based on the animal studies, should be exerted in the patients with kidney and liver disorders during chronic use of Senna-based products [269]. Additionally, studies performed on rats showed that long-term administration of extracts of Senna does not promote gastrointestinal, liver, kidney, or adrenal tumors in the rats [270-272].

\section{Concluding Remarks}

This review showed that various parts of the Senna plant such as roots, stem, leaves, and seeds are traditionally used to treat many ailments and its extract has antioxidant, antimicrobial, and important health-promoting activities. These biological activities are attributed to the many phytochemicals contained in the genus Senna. Epicatechin, proanthocyanidins, scutellarein, rutin, and sennoides are just a few bioactive compounds of the genus Senna that are responsible for their bioactivity. Numerous studies in vitro and in vivo have been performed to establish the anti-infective and antioxidant properties of Senna extracts. Studies on the consumption of Senna over a period have shown that Senna is safe, but chronic use has adverse and limiting effects in medical practice. Among them, the laxative disease is a condition related to the massive use of Senna-based laxatives with an increased loss of potassium ions and the possibility of interaction with other drugs prescribed for heart disease. Based on the analysis of the studies selected in the study, this review opens new therapeutic perspectives of the Senna plant for antioxidant and especially anti-infective effects in the digestive tract.

\section{Data Availability}

The data supporting this review are from previously reported studies and datasets, which have been cited. The processed data are available from the corresponding authors upon request.

\section{Conflicts of Interest}

The authors declare that they have no known competing financial interests or personal relationships that could have appeared to influence the work reported in this paper.

\section{References}

[1] N. Azani, M. Babineau, C. D. Bailey et al., "A new subfamily classification of the Leguminosae based on a taxonomically comprehensive phylogeny: the legume phylogeny working group (LPWG)," Taxon, vol. 66, no. 1, pp. 44-77, 2017.

[2] F. O. Robbiati, A. Anton, B. Marazzi, M. Vásquez-Cruz, and R. H. Fortunato, "The evolutionary history of Senna ser. Aphyllae (Leguminosae-Caesalpinioideae), an endemic clade of southern South America," Plant Systematics and Evolution, vol. 303, no. 10, pp. 1351-1366, 2017.

[3] J. Bradley Morris, B. D. Tonnis, and M. L. Wang, "Variability for Sennoside a and B concentrations in eight Senna species," Industrial Crops and Products, vol. 139, article 111489, 2019.

[4] H. S. Irwin and R. C. Barneby, The American cassiinaea synoptical revision of leguminosae tribe cassieae subtribe cassiinae in the New World, New York Botanical Garden Bronx, New York USA, 1982.

[5] B. Marazzi, P. K. Endress, L. P. . Queiroz, and E. Conti, "Phylogenetic relationships within Senna (Leguminosae, Cassiinae) based on three chloroplast DNA regions: patterns in the evolution of floral symmetry and extrafloral nectaries," American Journal of Botany, vol. 93, no. 2, pp. 288-303, 2006.

[6] L. Acharya, A. K. Mukherjee, and P. C. Panda, "Separation of the genera in the subtribe Cassiinae (Leguminosae: 
Caesalpinioidae) using molecular markers," Acta Botânica Brasílica, vol. 25, no. 1, pp. 223-233, 2011.

[7] B. Marazzi and M. J. Sanderson, "Large-scale patterns of diversification in the widespread legume genus Senna and the evolutionary role of extrafloral nectaries," Evolution: International Journal of Organic Evolution, vol. 64, no. 12, pp. 3570-3592, 2010.

[8] M. O. Rahman, M. Z. Rahman, and A. Begum, "Numerical taxonomy of the genus Senna mill. from Bangladesh," Bangladesh Journal of Plant Taxonomy, vol. 20, no. 1, pp. 7783, 2013.

[9] H. A. Spiller, M. L. Winter, J. A. Weber, E. P. Krenzelok, D. L. Anderson, and M. L. Ryan, "Skin breakdown and blisters from Senna-containing laxatives in young children," Annals of Pharmacotherapy, vol. 37, no. 5, pp. 636-639, 2003.

[10] M. A. Nassar, H. R. Ramadan, and H. M. Ibrahim, "Morphological characteristics of vegetative and reproductive growth of Senna occidentalis (L.) link (Caesalpiniaceae)," Research Journal of Agriculture and Biological Sciences, vol. 7, no. 2, pp. 260-270, 2011.

[11] D. M. Selegato, A. F. Monteiro, N. C. Vieira et al., "Update: biological and chemical aspects of Senna spectabilis," Journal of the Brazilian Chemical Society, vol. 28, no. 3, pp. 415-426, 2017.

[12] O. S. Oladeji, F. E. Adelowo, A. P. Oluyori, and D. T. Bankole, "Ethnobotanical description and biological activities of Senna alata," Evidence-based Complementary and Alternative Medicine, vol. 2020, Article ID 2580259, 2020.

[13] A. Farid, D. Kamel, S. Abdelwahab Montaser, M. Mohamed Ahmed, M. el Amir, and A. el Amir, "Synergetic role of Senna and Fennel extracts as antioxidant, anti-inflammatory and anti-mutagenic agents in irradiated human blood lymphocyte cultures," Journal of Radiation Research and Applied Science, vol. 13, no. 1, pp. 191-199, 2020.

[14] G. Nambirajan, K. Karunanidhi, A. Ganesan et al., "Evaluation of antidiabetic activity of bud and flower of Avaram Senna (Cassia auriculata L.) in high fat diet and streptozotocin induced diabetic rats," Biomedicine \& Pharmacotherapy, vol. 108, pp. 1495-1506, 2018.

[15] R. O. Malematja, V. P. Bagla, I. Njanje et al., "Potential hypoglycaemic and antiobesity effects of Senna italica leaf acetone extract," Evidence-based Complementary and Alternative Medicine, vol. 2018, Article ID 5101656, 2018.

[16] T. PlantList2021, http://www.theplantlist.org/.

[17] M. Heinrich, G. Appendino, T. Efferth et al., "Best practice in research - overcoming common challenges in phytopharmacological research," Journal of Ethnopharmacology, vol. 246, article 112230, 2020.

[18] L. Fernandez-Pacella, "Morfología polínica de especies del género Senna (Fabaceae) del Sureste del Iberá, Corrientes, Argentina," Argentina. Revista de Biología Tropical, vol. 62, no. 2, pp. 769-782, 2014.

[19] D. A. Carvalho and P. E. Oliveira, "Biologia reprodutiva e polinização de Senna sylvestris (Vell.) H.S. Irwin \& Barneby (Leguminosae, Caesalpinioideae)," Brazilian Journal of Botany, vol. 26, no. 3, pp. 319-328, 2003.

[20] M. Heil and D. McKey, "Protective ant-plant interactions as model systems in ecological and evolutionary research," Annual Review of Ecology, Evolution, and Systematics, vol. 34, no. 1, pp. 425-553, 2003.
[21] S. L. Jothy, A. Torey, I. Darah et al., "Cassia spectabilis (DC) Irwin et barn: a promising traditional herb in health improvement," Molecules, vol. 17, no. 9, pp. 10292-10305, 2012.

[22] F. O. Robbiati, L. D. Amarilla, A. M. Anton, and R. H. Fortunato, "Phenotypic variation in arid and semi-arid zones of southern South America: the case of Senna series Aphyllae (Fabaceae, Caesalpinioideae)," Botanical Journal of the Linnean Society, vol. 183, no. 3, pp. 454-473, 2017.

[23] J. M. P. Cordeiro and L. P. Felix, "Intra- and interspecific karyotypic variations of the genus Senna mill. (Fabaceae, Caesalpinioideae)," Acta Botânica Brasílica, vol. 32, no. 1, pp. 128134, 2018.

[24] K. F. Resende, L. C. Davide, and G. A. Torres, "Chromosome number and meiosis in populations of Senna species (Caesalpinioideae - Fabaceae) from Southeast Brazil," Caryologia, vol. 66, no. 1, pp. 1-5, 2013.

[25] A. Rice, L. Glick, S. Abadi et al., "The chromosome counts database (CCDB)-a community resource of plant chromosome numbers," New Phytologist, vol. 206, no. 1, pp. 19-26, 2015.

[26] K. Resende, C. Prado, L. Davide, and G. Torres, "Polyploidy and apomixis in accessions of Senna rugosa (G.Don) H.S.Irwin \& Barneby," Turkish Journal of Biology, vol. 38, no. 4, pp. 510-515, 2014.

[27] L. P. Matos, K. L. Barreto, A. S. Conceição, L. P. Queiroz, and M. J. Andrade, Análise citogenética em 16 espécies dos gêneros Senna Mill. e Cassia L.(Leguminosae), com ênfase nas espécies ocorrentes na Bahia. XV Semic-Seminário de Iniciação Científica, Universidade Estadual de Feira de Santana, Feira de Santana, 2011.

[28] S. Singh, S. K. Singh, and A. Yadav, "A review on Cassia species: pharmacological, traditional and medicinal aspects in various countries," American Journal of Phytomedicine and Clinical Therapeutics, vol. 1, no. 3, pp. 291-312, 2013.

[29] B. Y. Abubakar, A. K. Adamu, A. A. Ambi, and F. G. Nuru, "Taxonomic delimitation of species of Senna and Cassia in Ahmadu Bello University, Zaria," Trends in Science and Technology Journal, vol. 3, no. 2, pp. 448-495, 2018.

[30] M. O. Soladoye, M. A. Onakoya, E. C. Chukwuma, and M. A. Sonibare, "Morphometric study of the genus Senna Mill. in South-Western Nigeria," African Journal of Plant Science, vol. 4, no. 3, pp. 044-052, 2010.

[31] T. Jaca and G. Condy, "Senna didymobotrya," The Flowering Plants of Africa, vol. 65, pp. 68-75, 2017.

[32] K. Larsen, Leguminosae-Caesalpinioideae. Flora of Thailand, The Chutima Press, 1984.

[33] P. Monkheang, R. Sudmoon, T. Tanee, K. Noikotr, N. Bletter, and A. Chaveerach, "Species diversity, usages, molecular markers and barcode of medicinal Senna species (Fabaceae, Caesalpinioideae) in Thailand," Journal of Medicinal Plant Research, vol. 5, no. 26, pp. 6173-6181, 2011.

[34] J. B. Okullo, J. Obua, J. R. Kaboggoza, and J. R. Aluma, “Traditional agroforestry systems, tree uses and management in northern Uganda," Uganda Journal of Agricultural Sciences, vol. 8, pp. 5-12, 2003.

[35] P. Ssegawa and J. M. Kasenene, "Medicinal plant diversity and uses in the Sango bay area, southern Uganda," Journal of Ethnopharmacology, vol. 113, no. 3, pp. 521-540, 2007.

[36] B. C. Kalita, H. Tag, B. J. Gogoi, and P. K. Hui, "Diversity and traditional uses of some poisonous plants of Arunachal 
Pradesh," International Journal of Advance Research and Innovative Ideas in Education, vol. 3, no. 1, pp. 755-763, 2017.

[37] U. Hossain and M. O. Rahman, "Ethnobotanical uses and informant consensus factor of medicinal plants in Barisal district, Bangladesh," Bangladesh Journal of Plant Taxonomy, vol. 25, no. 2, pp. 241-255, 2018.

[38] A. H. Rahman, M. C. Biswas, A. K. Islam, and A. T. Zaman, "Assessment of traditional medicinal plants used by local people of Monirampur Upazilla under Jessore district of Bangladesh," Wudpecker Journal of Medicinal Plants, vol. 2, pp. 99-109, 2013.

[39] Z. Hajdu and J. Hohmann, "An ethnopharmacological survey of the traditional medicine utilized in the community of Porvenir, Bajo Paragua Indian reservation, Bolivia," Journal of Ethnopharmacology, vol. 139, no. 3, pp. 838-857, 2012.

[40] J. A. Castro, B. P. Brasileiro, D. H. Lyra, D. de Almeida Pereira, and J. L. Chaves, "Ethnobotanical study of traditional uses of medicinal plants: the flora of caatinga in the community of Cravolândia-BA, Brazil," Journal of Medicinal Plant Research, vol. 5, no. 10, pp. 1905-1917, 2011.

[41] J. H. Cano and G. Volpato, "Herbal mixtures in the traditional medicine of eastern Cuba," Journal of Ethnopharmacology, vol. 90, no. 2-3, pp. 293-316, 2004.

[42] S. Kar, D. Das, A. Das, and B. K. Datta, "Ethnomedicinal uses of some legumes in Tripura, India," Pleione, vol. 13, no. 2, pp. 258-268, 2019.

[43] L. Balinado and M. Chan, "An ethnomedicinal study of plants and traditional health care practices in district 7 , Cavite, Philippines," in 2017 International Conference on Chemical, Agricultural, Biological and Medical Sciences (CABMS-17), Manila (Philippines), 2017.

[44] N. Sutjaritjai, P. Wangpakapattanawong, H. Balslev, and A. Inta, "Traditional uses of Leguminosae among the Karen in Thailand," Plants, vol. 8, no. 12, p. 600, 2019.

[45] R. Karousou and S. Deirmentzoglou, "The herbal market of Cyprus: traditional links and cultural exchanges," Journal of Ethnopharmacology, vol. 133, no. 1, pp. 191-203, 2011.

[46] A. Hassan-Abdallah, A. Merito, S. Hassan et al., "Medicinal plants and their uses by the people in the region of Randa, Djibouti," Journal of Ethnopharmacology, vol. 148, no. 2, pp. 701-713, 2013.

[47] T. Mahmoud and S. Gairola, "Traditional knowledge and use of medicinal plants in the Eastern Desert of Egypt: a case study from Wadi El-Gemal National Park," Journal of Medicinal Plants, vol. 1, no. 6, pp. 10-17, 2013.

[48] S. Z. Husain, R. N. Malik, M. Javaid, and S. A. Bibi, "Ethonobotanical properties and uses of medicinal plants of Morgah Biodiversity Park, Rawalpindi," Pakistan Journal of Botany, vol. 40, no. 5, pp. 1897-1911, 2008.

[49] P. C. Phondani, A. Bhatt, E. Elsarrag, and Y. A. Horr, "Ethnobotanical magnitude towards sustainable utilization of wild foliage in Arabian Desert," Journal of Traditional and Complementary Medicine, vol. 6, no. 3, pp. 209-218, 2016.

[50] M. G. E. Karar and N. Kuhnert, "Herbal drugs from Sudan: traditional uses and phytoconstituents," Pharmacognosy Reviews, vol. 11, no. 22, pp. 83-103, 2017.

[51] M. Manoranjotham, T. Ramaraj, and M. Kamaraj, “An edthnobotanical study on traditional uses of medicinal plants in Musiri taluk, Tiruchirappalli District, Tamil Nadu," Journal of Applied and Advanced Research, vol. 1, no. 3, pp. 16-24, 2016.

[52] S. Semenya, M. Potgieter, M. Tshisikhawe, S. Shava, and A. Maroyi, "Medicinal utilization of exotic plants by Bapedi traditional healers to treat human ailments in Limpopo province, South Africa," Journal of Ethnopharmacology, vol. 144, no. 3, pp. 646-655, 2012.

[53] M. Gupta, P. N. Solís, A. I. Calderón et al., "Medical ethnobotany of the Teribes of Bocas del Toro, Panama," Journal of Ethnopharmacology, vol. 96, no. 3, pp. 389-401, 2005.

[54] M. S. Amiri and M. R. Joharchi, "Ethnobotanical investigation of traditional medicinal plants commercialized in the markets of Mashhad, Iran," Avicenna Journal of Phytomedicine, vol. 3, no. 3, pp. 254-271, 2013.

[55] R. Qureshi, G. R. Bhatti, and R. A. Memon, "Ethnomedicinal uses of herbs from northern part of Nara desert Pakistan," Pakistan Journal of Botany, vol. 42, no. 2, pp. 839-851, 2010.

[56] G. B. Hammond, I. D. Fernández, L. F. Villegas, and A. J. Vaisberg, "A survey of traditional medicinal plants from the Callejon de Huaylas, Department of Ancash, Peru," Journal of Ethnopharmacology, vol. 61, no. 1, pp. 17-30, 1998.

[57] J. Kufer, H. Förther, E. Pöll, and M. Heinrich, "Historical and modern medicinal plant uses-the example of the Ch'orti 'Maya and Ladinos in eastern Guatemala," Journal of Pharmacy and Pharmacology, vol. 57, no. 9, pp. 1127-1152, 2005.

[58] J. Rani, "Ethanobotanical survey and traditional uses of medicinal plants in Jind district of Haryana India," Plant Archives, vol. 19, no. 1, pp. 1241-1247, 2019.

[59] G. Yaseen, M. Ahmad, S. Shinwari et al., "Medicinal plant diversity used for livelihood of public health in deserts and arid regions of Sindh-Pakistan," Pakistan Journal of Botany, vol. 51, no. 2, pp. 2409-2419, 2019.

[60] M. J. Moshi, D. F. Otieno, and A. Weisheit, "Ethnomedicine of the Kagera region, north western Tanzania. Part 3: plants used in traditional medicine in Kikuku village, Muleba District," Journal of Ethnobiology and Ethnomedicine, vol. 8, no. 1, pp. 1-11, 2012.

[61] T. E. Tshikalange, The traditional use of medicinal plants to treat sexually transmitted diseases, University of Pretoria, 2006.

[62] N. A. Masevhe, L. J. McGaw, and J. N. Eloff, "The traditional use of plants to manage candidiasis and related infections in Venda, South Africa," Journal of Ethnopharmacology, vol. 168, pp. 364-372, 2015.

[63] M. Sobeh, M. Mahmoud, R. Hasan, H. Cheng, A. el-Shazly, and M. Wink, "Senna singueana: antioxidant, hepatoprotective, antiapoptotic properties and phytochemical profiling of a methanol bark extract," Molecules, vol. 22, no. 9, p. 1502, 2017.

[64] L. K. Keter and P. C. Mutiso, "Ethnobotanical studies of medicinal plants used by traditional health practitioners in the management of diabetes in lower Eastern Province, Kenya," Journal of Ethnopharmacology, vol. 139, no. 1, pp. 74-80, 2012.

[65] A. Rahman and M. A. Keya, "Traditional medicinal plants used by local people at the village Sabgram under Sadar Upazila of Bogra district Bangladesh," Research in Plant Sciences, vol. 3, no. 2, pp. 31-37, 2015.

[66] Y. Fu, J. C. Yang, A. B. Cunningham et al., "A billion cups: the diversity, traditional uses, safety issues and potential of 
Chinese herbal teas," Journal of Ethnopharmacology, vol. 222, pp. 217-228, 2018.

[67] S. S. M. Pattnaik and L. Behera, "Traditional use of herbal medicines against rheumatism by the tribals of Bargarh district in Odisha (India) by sk sen1_ mr pattnaik2 and $1 \mathrm{~m}$ behera3," Life Sciences Leaflets, vol. 51, pp. 59-68, 2014.

[68] S. Ahmed and A. M. Shohael, "In silico studies of four anthraquinones of Senna alata $L$. as potential antifungal compounds," Pharmacology, vol. 2, pp. 259-268, 2019.

[69] E. E. Essien, T. M. Walker, I. A. Ogunwande, A. Bansal, W. N. Setzer, and O. Ekundayo, "Volatile constituents, antimicrobial and cytotoxicity potentials of Three Senna Species from Nigeria," Journal of Essential Oil-Bearing Plants, vol. 14, no. 6, pp. 722-730, 2011.

[70] F. Epifano, S. Fiorito, M. Locatelli, V. A. Taddeo, and S. Genovese, "Screening for novel plant sources of prenyloxyanthraquinones: Senna alexandrina Mill. and Aloe vera (L.) Burm. F," Natural Product Research, vol. 29, no. 2, pp. 180-184, 2015.

[71] S. I. Ahmed, M. Q. Hayat, M. Tahir et al., "Pharmacologically active flavonoids from the anticancer, antioxidant and antimicrobial extracts of Cassia angustifolia Vahl," BMC Complementary Medicine and Therapies, vol. 16, no. 1, p. 460, 2016.

[72] D. Arrieta-Baez, R. Roman, R. Vazquez-Duhalt, and M. Jiménez-Estrada, "Peroxidase-mediated transformation of hydroxy-9,10-anthraquinones," Phytochemistry, vol. 60, no. 6, pp. 567-572, 2002.

[73] W. Francisco, M. Pivatto, A. Danuello et al., "Pyridine alkaloids from Senna multijuga As acetylcholinesterase inhibitors," Journal of Natural Products, vol. 75, no. 3, pp. 408-413, 2012.

[74] M. A. R. Serrano, M. Pivatto, W. Francisco et al., "Acetylcholinesterase inhibitory pyridine alkaloids of the leaves of Senna multijuga," Journal of Natural Products, vol. 73, no. 3, pp. 482-484, 2010.

[75] C. G. Vargas Rechia, M. R. Sierakowski, J. L. M. S. Ganter, and F. Reicher, "Polysaccharides from the seeds of Senna multijuga," International Journal of Biological Macromolecules, vol. 17, no. 6, pp. 409-412, 1995.

[76] B. M. Abegaz, M. Bezabeh, G. Alemayehu, and H. Duddeck, "Anthraquinones from Senna multiglandulosa," Phytochemistry, vol. 35, no. 2, pp. 465-468, 1994.

[77] G. Alemayehu and B. M. Abegaz, "Bianthraquinones from the seeds of Senna multiglandulosa," Phytochemistry, vol. 41, no. 3, pp. 919-921, 1996.

[78] E. E. Essien, P. S. Thomas, R. Ascrizzi, W. N. Setzer, and G. Flamini, "Senna occidentalis(L.) link and Senna hirsuta (L.) H. S. Irwin \& Barneby: constituents of fruit essential oils and antimicrobial activity," Natural Product Research, vol. 33, no. 11, pp. 1637-1640, 2019.

[79] I. R. . O. Maia, M. T. S. Trevisan, M. G. . V. Silva, A. Breuer, and R. W. Owen, "Characterization and quantitation of polyphenolic compounds in Senna gardneriand S. Georgicafrom the northeast of Brazil," Natural Product Communications, vol. 13, no. 11, article 1934578X1801301, 2018.

[80] J. A. Monteiro, J. M. Ferreira Júnior, I. R. Oliveira et al., "Bioactivity and toxicity of Senna cana and Senna pendula extracts," Biochemistry Research International, vol. 2018, Article ID 8074306, 2018.

[81] B. Barba, J. G. Díaz, and W. Herz, "Anthraquinones and other constituents of two Senna species," Phytochemistry, vol. 31, no. 12, pp. 4374-4375, 1992.
[82] M. Á. Zavala-Sánchez, J. L. Rodríguez-Chávez, R. FigueroaBrito et al., "Bioactivity of 1-octacosanol from Senna crotalarioides (Fabaceae: Caesalpinioideae) to control Spodoptera frugiperda (Lepidoptera: Noctuidae)," Florida Entomologist, vol. 102, no. 4, pp. 731-737, 2019.

[83] G. Alemayehu, A. Hailu, and B. M. Abegaz, "Bianthraquinones from Senna didymobotrya," Phytochemistry, vol. 42, no. 5, pp. 1423-1425, 1996.

[84] C. O. Ochieng, A. Shrivastava, U. Chaturvedi et al., "Effects of Senna didymobotrya root extract and compounds on Tritoninduced hyperlipidaemic rats and differentiation of 3T3-Li preadipocytes," Natural Products Journal, vol. 3, no. 3, pp. 212-217, 2013.

[85] K. V. Rao, A. G. Damu, B. Jayaprakasam, and D. Gunasekar, "Flavonol glycosides from Cassiahirsuta," Journal of Natural Products, vol. 62, no. 2, pp. 305-306, 1999.

[86] J. G. Silva, A. A. Silva, I. D. Coutinho, C. O. Pessoa, A. J. Cavalheiro, and M. G. Silva, "Chemical profile and cytotoxic activity of leaf extracts from Senna spp. from northeast of Brazil," Journal of the Brazilian Chemical Society, vol. 27, no. 10, pp. 1872-1880, 2016.

[87] S. S. Gololo, N. S. Mapfumari, L. S. Sethoga, M. T. Olivier, L. J. Shai, and M. A. Mogale, "Identification of phytochemical constituents within the $\mathrm{n}$-hexane leaf extract of Senna italica (mill) using gas chromatography-mass spectrometry (GCMS) analysis," Journal of Pharmaceutical Sciences and Research, vol. 8, no. 10, pp. 1141-1143, 2016.

[88] O. M. Khalaf, M. A. Ghareeb, A. M. Saad, H. M. F. Madkour, A. K. el-Ziaty, and M. S. Abdel-Aziz, "Phenolic constituents, antimicrobial, antioxidant, and anticancer activities of ethyl acetate andn-butanol extracts of Senna italica," Acta Chromatographica, vol. 31, no. 2, pp. 138-145, 2019.

[89] H. M. Madkour, M. A. Ghareeb, M. S. Abdel-Aziz et al., "Gas chromatography-mass spectrometry analysis, antimicrobial, anticancer and antioxidant activities of n-hexane and methylene chloride extracts of Senna italica," Journal of Applied Pharmaceutical Science, vol. 7, no. 6, pp. 023-032, 2017.

[90] M. P. Mokgotho, S. S. Gololo, P. Masoko et al., "Isolation and chemical structural characterisation of a compound with antioxidant activity from the roots of Senna italica," Evidence-based Complementary and Alternative Medicine, vol. 2013, Article ID 519174, 2013.

[91] G. Alemayehu, B. Abegaz, G. Snatzke, and H. Duddeck, "Bianthrones from Senna longiracemosa," Phytochemistry, vol. 32, no. 5, pp. 1273-1277, 1993.

[92] A. Branco, A. C. Pinto, R. Braz-Filho, E. F. Silva, N. F. Grynberg, and A. Echevarria, "Rubrofusarina, um policetídeo natural inibidor da topoisomerase II- $\alpha$ humana," Brazilian Journal of Pharmacognosy, vol. 18, pp. 703-708, 2008.

[93] K. D. Klika, I. Ricarte, M. T. S. Trevisan, M. G. de Vasconcelos Silva, and R. W. Owen, " $(2 R *, 3 S *, 4 S *, 2$ " $R *, 3$ " $S *$ )-Guibourtinidol-( $4 \alpha->8)$-catechin, a biflavanoid procyanidin of the proguibourtinidin group from Senna macranthera: its relative stereochemistry and conformation," Tetrahedron: Asymmetry, vol. 26, no. 5-6, pp. 247-250, 2015.

[94] L. Pires, P. A. J. Gorin, F. Reicher, and M. R. Sierakowski, “An active heparinoid obtained by sulphation of a galactomannan extracted from the endosperm of Senna macranthera seeds," Carbohydrate Polymers, vol. 46, no. 2, pp. 165-169, 2001.

[95] I. Messana, F. Ferrari, M. S. Cavalcanti, and E. Gacs Baitz, "New naphthopyrone derivatives from Cassia pudibunda," Heterocycles, vol. 31, no. 10, p. 1847, 1990. 
[96] I. Messana, F. Ferrari, M. S. B. Cavalcanti, and G. Morace, "An anthraquinone and three naphthopyrone derivatives from Cassia pudibunda," Phytochemistry, vol. 30, no. 2, pp. 708-710, 1991.

[97] E. M. S. de Macedo, H. J. Wiggers, M. G. V. Silva, R. BrazFilho, A. D. Andricopulo, and C. A. Montanari, "A new bianthron glycoside as inhibitor of Trypanosoma cruzi glyceraldehyde 3-phosphate dehydrogenase activity," Journal of the Brazilian Chemical Society, vol. 20, no. 5, pp. 947-953, 2009.

[98] J. G. Graham, H. Zhang, S. L. Pendland et al., "Antimycobacterial naphthopyrones from Senna obliqua," Journal of Natural Products, vol. 67, no. 2, pp. 225-227, 2004.

[99] X. Pang, L. M. Wang, Y. C. Zhang et al., "New anthraquinone and eurotinone analogue from the seeds of Senna obtusifolia and their inhibitory effects on human organic anion transporters 1 and 3," Natural Product Research, vol. 33, no. 23, pp. 3409-3416, 2019.

[100] A. N. Saidu, E. O. Aina, A. Mann, and U. I. Leje, "The effect of aqueous extract of Senna occidentalis leaves on rats infected with salmonella typhi," Australian Journal of Basic and Applied Sciences, vol. 5, no. 12, pp. 1863-1867, 2011.

[101] A. Javaid, H. Qudsia, and A. Shoaib, "Bioassays guided fractionation of Senna occidentalis for identification of natural antifungal constituents against Macrophomina phaseolina," Planta Daninha, vol. 35, 2017.

[102] H. L. Kim, B. J. Camp, and R. D. Grigsby, "Isolation of Nmethylmorpholine from the seeds of Cassia occidentalis $\mathrm{L}$. (coffee Senna)," Journal of Agricultural and Food Chemistry, vol. 19, no. 1, pp. 198-199, 1971.

[103] N. Kumar, G. Singh, S. Singh, and A. Singh, "Standardization and simultaneous quantification of flavonoids and phenolic contents in Cassia occidentalis using liquid chromatography triple quadrupole mass spectrometry (LC-MS/MS)," Research Journal of Chemistry and Environment, vol. 21, no. 1, pp. 1-8, 2017.

[104] S. F. Li, Y. T. di, R. H. Luo et al., "Cycloartane triterpenoids from Cassia occidentalis," Planta Medica, vol. 78, no. 8, pp. 821-827, 2012.

[105] S. F. Li and S. L. Li, "Cycloartane triterpenoid and its glucoside isolated from Cassia occidentalis," Chinese Journal of Natural Medicines, vol. 15, no. 12, pp. 950-954, 2017.

[106] I. A. Ogunwande, N. O. Avoseh, G. Flamini et al., "Essential oils from the leaves of six medicinal plants of Nigeria," Natural Product Communications, vol. 8, no. 2, pp. 243-248, 2013.

[107] R. X. Qin, Q. Zuo, X. H. Huang et al., "A new norsesquiterpene from Cassia occidentalis and its bioactivity," China Journal of Chinese Materia Medica, vol. 41, no. 23, pp. 4389-4392, 2016.

[108] H. Singh, P. Chahal, A. Mishra, and A. K. Mishra, "An up-todate review on chemistry and biological activities of Senna occidentalis (L.) link family: Leguminosae," Advances in Traditional Medicine, vol. 20, no. 3, pp. 263-278, 2020.

[109] T. E. Tshikalange, J. J. M. Meyer, and A. A. Hussein, "Antimicrobial activity, toxicity and the isolation of a bioactive compound from plants used to treat sexually transmitted diseases," Journal of Ethnopharmacology, vol. 96, no. 3, pp. 515-519, 2005.

[110] A. M. Gamal-Eldeen, P. C. Djemgou, M. Tchuendem, B. T. Ngadjui, P. Tane, and H. Toshifumi, "Anti-cancer and immunostimulatory activity of chromones and other constituents from Cassia petersiana," Zeitschrift fur Naturforschung
- Section C Journal of Biosciences, vol. 62, no. 5-6, pp. 331338, 2007.

[111] J. Coetzee, L. Mciteka, E. Malan, and D. Ferreira, "Structure and synthesis of the first procassinidin dimers based on epicatechin, and gallo- and epigallo-catechin," Phytochemistry, vol. 53, no. 7, pp. 795-804, 2000.

[112] B. O. Ajiboye, O. A. Ojo, B. Fatoba et al., "In vitro antioxidant and enzyme inhibitory properties of the n-butanol fraction of Senna podocarpa (Guill. and Perr.) leaf," Journal of Basic and Clinical Physiology and Pharmacology, vol. 31, no. 1, 2020.

[113] M. Malmir, E. Ferreira, R. Serrano, E. T. Gomes, M. Caniça, and O. Silva, "In vitro anti- Neisseria gonorrhoeae activity of Senna podocarpa root extracts," Industrial Crops and Products, vol. 76, pp. 467-471, 2015.

[114] G. Genta-Jouve, L. Weinberg, V. Cocandeau, Y. Maestro, O. P. Thomas, and S. Holderith, "Revising the absolute configurations of coatlines via density functional theory calculations of electronic circular dichroism spectra," Chirality, vol. 25, no. 3, pp. 180-184, 2013.

[115] M. Ogura, G. A. Cordell, and N. R. Farnsworth, "Quinquangulin, a new naphthopyrone from Cassia quinquangulata (Leguminosae)," Lloydia, vol. 40, no. 4, pp. 347-351, 1977.

[116] G. J. Mena-Rejóna, K. Pérez-Rivas, P. Sansorez-Peraza, T. Rios, and L. Quijano, "Racemochrysone, a dihydroanthracenone from Senna racemosa," Zeitschrift fur Naturforschung - Section C Journal of Biosciences, vol. 57, no. 9-10, pp. 777779, 2002.

[117] P. Sansores-Peraza, M. Rosado-Vallado, W. Brito-Loeza, G. J. Mena-Rejón, and L. Quijano, "Cassine, an antimicrobial alkaloid from Senna racemosa," Fitoterapia, vol. 71, no. 6, pp. 690-692, 2000.

[118] R. N. Dos Santos, M. G. D. V. Silva, and R. Braz Filho, "Constituintes químicos do caule de Senna reticulata Willd. (Leguminoseae): chemical constituents isolated from the wood of Senna reticulata Willd," Quimica Nova, vol. 31, no. 8, pp. 1979-1981, 2008.

[119] F. G. Barbosa, M. . C. F. de Oliveira, R. Braz-Filho, and E. R. Silveira, "Anthraquinones and naphthopyrones from Senna rugosa," Biochemical Systematics and Ecology, vol. 32, no. 3, pp. 363-365, 2004.

[120] G. Alemayehu, L. Adane, and B. M. Abegaz, "A new bianthracene C-arabinopyranoside from Senna septemtrionalis," Natural Product Communications, vol. 5, no. 5, pp. 747-750, 2010.

[121] G. Alemayehu, B. Woldeyesus, and B. M. Abegaz, "(+)-Floribundone 3 from the pods of Senna septemtrionalis," Bulletin of the Chemical Society of Ethiopia, vol. 11, no. 1, pp. 25-29, 1997.

[122] K. Ingkaninan, A. P. Ijzerman, and R. Verpoorte, "Luteolin, a compound with adenosine A1Receptor-binding activity, and chromone and dihydronaphthalenone constituents from Senna siamea," Journal of Natural Products, vol. 63, no. 3, pp. 315-317, 2000.

[123] A. P. Sakunpak, J. I. Suksaeree, C. H. Monton, and P. A. Pathompak, "Development and quantitative determination of barakol in Senna siamea leaf extract by TLC-image analysis method," International Journal of Pharmacy and Pharmaceutical Sciences, vol. 6, no. 3, pp. 267-270, 2014.

[124] H. Morita, S. Oshimi, Y. Hirasawa et al., "Cassiarins a and B, novel antiplasmodial alkaloids from Cassia siamea," Organic Letters, vol. 9, no. 18, pp. 3691-3693, 2007. 
[125] S. Oshimi, Y. Tomizawa, Y. Hirasawa et al., "Chrobisiamone a, a new bischromone from Cassia siamea and a biomimetic transformation of 5-acetonyl-7-hydroxy-2-methylchromone into cassiarin a," Bioorganic and Medicinal Chemistry Letters, vol. 18, no. 13, pp. 3761-3763, 2008.

[126] S. Oshimi, J. Deguchi, Y. Hirasawa et al., "Cassiarins C-E, antiplasmodial alkaloids from the flowers of Cassia siamea," Journal of Natural Products, vol. 72, no. 10, pp. 1899-1901, 2009.

[127] J. Deguchi, T. Sasaki, Y. Hirasawa et al., "Two novel tetracycles, cassibiphenols a and B from the flowers of Cassia siamea," Tetrahedron Letters, vol. 55, no. 7, pp. 1362-1365, 2014.

[128] J. Koyama, I. Morita, K. Tagahara, and M. Aqil, "Bianthraquinones from Cassia siamea," Phytochemistry, vol. 56, no. 8, pp. 849-851, 2001.

[129] D. Kumar, A. Karmase, S. Jagtap, R. Shekhar, and K. K. Bhutani, "Pancreatic lipase inhibitory activity of cassiamin a, a bianthraquinone from Cassia siamea," Natural Product Communications, vol. 8, no. 2, pp. 195-198, 2013.

[130] O. O. Ogbole, T. E. Akinleye, T. O. C. Faleye, and A. J. Adeniji, "Enterovirus inhibiting activities of two Lupane triterpenoids and anthraquinones from senna siamea stem bark against three serotypes of echovirus," Acta Pharmaceutica Sciencia, vol. 57, no. 3, pp. 105-115, 2019.

[131] E. O. Ajaiyeoba, J. S. Ashidi, L. C. Okpako, P. J. Houghton, and C. W. Wright, "Antiplasmodial compounds from Cassia siamea stem bark extract," Phytotherapy Research, vol. 22, no. 2, pp. 254-255, 2008.

[132] T. S. Lü, Y. H. Yi, S. L. Mao et al., "Studies on the anthraquinones of Cassia siamea," Yao xue xue bao = Acta Pharmaceutica Sinica, vol. 36, no. 7, pp. 547-548, 2001.

[133] T. S. Lu, Y. H. Yi, S. L. Mao et al., "A new chromone glycoside from Cassia siamea Lam," Yaoxue Xuebao, vol. 38, no. 2, pp. 113-115, 2003.

[134] T. S. Lu, Y. H. Yi, Z. G. Zhang, Z. Q. Zhang, and N. Hua, “A new 10-hydroxyl anthrone glycoside from Cassia siamea Lam," Chinese Chemical Letters, vol. 13, no. 8, pp. 731-733, 2002.

[135] Q. F. Hu, B. Zhou, X. M. Gao et al., "s," Journal of Natural Products, vol. 75, no. 11, pp. 1909-1914, 2012.

[136] L. Ledwani and M. Singh, "Isolation and characterization of anthraquinones from the stem bark of Cassia species," Journal of the Indian Chemical Society, vol. 83, no. 4, pp. 383385, 2006.

[137] Y. K. Li, B. Zhou, X. X. Wu et al., "Phenolic compounds from Cassia siamea and their anti-tobacco mosaic virus activity," Chemistry of Natural Compounds, vol. 51, no. 1, pp. 50-53, 2015.

[138] S. Thengyai, P. Thiantongin, C. Sontimuang, C. Ovatlarnporn, and P. Puttarak, " $\alpha$-glucosidase and $\alpha$ -amylase inhibitory activities of medicinal plants in Thai antidiabetic recipes and bioactive compounds from Vitex glabrata R. Br. Stem bark," Journal of Herbal Medicine, vol. 19, p. 100302, 2020.

[139] D. A. Baez, L. G. Zepeda Vallejo, and M. Jimenez-estrada, "Phytochemical studies on Senna skinneri and Senna wislizeni," Natural Product Letters, vol. 13, no. 3, pp. 223-228, 1999.

[140] D. A. Baez, G. Z. Vallejo, P. C. Sánchez, M. B. Valle, R. R. Chilpa, and M. J. Estrada, "Use of the SOS-chromotest spot assay as a screening system for detecting genotoxic compounds in crude plant extracts," ATLA, Alternatives to Laboratory Animals, vol. 30, no. 1, pp. 87-92, 2002.

[141] G. Alemayehu, B. Abegaz, and W. Kraus, "A 1,4-anthraquinone-dihydroanthracenone dimer from Senna sophera," Phytochemistry, vol. 48, no. 4, pp. 699-702, 1998.

[142] A. R. Kharat, K. Kharat, M. Jadhav, and S. J. Makhija, “Antihyperglycemic, antihyperlipidemic and antioxidative evaluation of compounds from Senna sophera (L.) Roxb in streptozotocin-induced diabetic rats," Natural Product Research, vol. 33, no. 4, pp. 602-605, 2019.

[143] S. Malhotra and K. Misra, "A new anthraquinone fromCassia sopheraHeartwood," Planta Medica, vol. 46, no. 12, pp. 247249, 1982.

[144] A. Mondal, D. Rajalingam, and T. Kumar Maity, "Antiinflammatory effect of $O$-methylated flavonol 2-(3,4-dihydroxy- phenyl)-3,5-dihydroxy-7-methoxy-chromen-4-one obtained from Cassia sophera Linn in rats," Journal of Ethnopharmacology, vol. 147, no. 2, pp. 525-529, 2013.

[145] W. Mushtaq, Q. Ain, M. B. Siddiqui, H. Alharby, and K. R. Hakeem, "Allelochemicals change macromolecular content of some selected weeds," South African Journal of Botany, vol. 130, pp. 177-184, 2020.

[146] F. . O. Silva, Í. R. . Oliveira, M. G. . V. Silva, and R. Braz-Filho, "Constituintes químicos das folhas de Senna spectabilis (DC) Irwin \& Barneby var. excelsa (Schrad.) Irwin \& Barneby," Quimica Nova, vol. 33, no. 9, pp. 1874-1876, 2010.

[147] K. T. Lim, A. Amanah, N. J. Y. Chear, Z. Zahari, Z. Zainuddin, and M. I. Adenan, "Inhibitory effects of (+)-spectaline and iso-6-spectaline from Senna spectabilis on the growth and ultrastructure of human-infective species Trypanosoma brucei rhodesiense bloodstream form," Experimental Parasitology, vol. 184, pp. 57-66, 2018.

[148] K. A. B. S. da Silva, M. N. Manjavachi, A. F. Paszcuk et al., "Plant derived alkaloid (-)-cassine induces antiinflammatory and anti- hyperalgesics effects in both acute and chronic inflammatory and neuropathic pain models," Neuropharmacology, vol. 62, no. 2, pp. 967-977, 2012.

[149] M. Pivatto, L. R. Baccini, A. Sharma et al., "Antimalarial activity of piperidine alkaloids from Senna spectabilis and semisynthetic derivatives," Journal of the Brazilian Chemical Society, vol. 25, no. 10, pp. 1900-1906, 2014.

[150] F. O. Silva, M. G. V. Silva, G. S. Cerqueira et al., "Central nervous system effects of Iso-6-spectaline isolated from Senna spectabilis var. excelsa (schrad) in mice," Journal of Young Pharmacists, vol. 3, no. 3, pp. 232-236, 2011.

[151] L. Sriphong, U. Sotanaphun, S. Limsirichaikul, P. Wetwitayaklung, C. Chaichantipyuth, and S. Pummangura, "Cytotoxic alkaloids from the flowers of Senna spectabilis," Planta Medica, vol. 69, no. 11, pp. 10541056, 2003.

[152] C. Viegas Junior, M. Pivatto, A. D. Rezende, L. Hamerski, D. H. Silva, and V. D. Bolzani, "7-Hydroxycassine: a new 2,6-dialkylpiperidin-3-ol alkaloid and other constituents isolated from flowers and fruits of Senna spectabilis (Fabaceae)," Journal of the Brazilian Chemical Society, vol. 24, no. 2, pp. 230-235, 2013.

[153] M. Valli, A. H. Betti, A. Danuello et al., "Pyridinic analog of the natural product $(-)$-spectaline as potential adjuvant for the treatment of central nervous system disorders," Bioorganic and Medicinal Chemistry Letters, vol. 25, no. 10, pp. 2247-2250, 2015. 
[154] C. Viegas Jr., V. S. Bolzani, L. S. B. Pimentel et al., "New selective acetylcholinesterase inhibitors designed from natural piperidine alkaloids," Bioorganic and Medicinal Chemistry, vol. 13, no. 13, pp. 4184-4190, 2005.

[155] F. . O. Silva, M. G. . V. Silva, D. Feng, and R. M. de Freitas, "Evaluation of central nervous system effects of iso-6cassine isolated from Senna spectabilis var. excelsa (Schrad) in mice," Fitoterapia, vol. 82, no. 2, pp. 255-259, 2011.

[156] R. B. Lacerda, T. R. Freitas, M. M. Martins et al., "Isolation, leishmanicidal evaluation and molecular docking simulations of piperidine alkaloids from Senna spectabilis," Bioorganic and Medicinal Chemistry, vol. 26, no. 22, pp. 5816-5823, 2018.

[157] R. M. Pereira, G. Á. Ferreira-Silva, M. Pivatto et al., "Alkaloids derived from flowers of Senna spectabilis, (-)-cassine and (-)-spectaline, have antiproliferative activity on HepG2 cells for inducing cell cycle arrest in G1/S transition through ERK inactivation and downregulation of cyclin D1 expression," Toxicology In Vitro, vol. 31, pp. 86-92, 2016.

[158] E. Valencia, E. Valenzuela, E. Barros et al., "Estudio fitoquimico y actividad antialimentaria de Senna stipulaceae," Boletin de la Sociedad Chilena de Quimica, vol. 45, no. 2, pp. 297301, 2000.

[159] S. A. El-Sawi and A. A. Sleem, "Flavonoids and hepatoprotective activity of leaves of Senna Surattensis (Burm.f.) in CCl4 induced hepatotoxicity in rats," Australian Journal of Basic and Applied Sciences, vol. 4, no. 6, pp. 1326-1334, 2010.

[160] S. J. Anu and J. Madhusudana Rao, "Oxanthrone esters from the roots of Cassia kleinii," Phytochemistry, vol. 59, no. 4, pp. 425-427, 2002.

[161] S. J. Anu and J. M. Rao, "Oxanthrone esters from the aerial parts of Cassia kleinii," Phytochemistry, vol. 57, no. 4, pp. 583-585, 2001.

[162] A. M. el-Halawany, M. H. Chung, N. Nakamura, C. M. Ma, T. Nishihara, and M. Hattori, "Estrogenic and antiestrogenic activities of Cassia tora phenolic constituents," Chemical and Pharmaceutical Bulletin, vol. 55, no. 10, pp. 1476-1482, 2007.

[163] N. Fathalla, M. Bishr, A. Nasser Singab, and O. Salama, "GCMS and LC-MS identification of the phenolic compounds present in the ethyl acetate fraction obtained fromSenna tora,L. Roxb. Seeds," Natural Product Letters, vol. 33, no. 19, pp. 2878-2881, 2019.

[164] G. Y. Lee, D. S. Jang, Y. M. Lee, J. M. Kim, and J. S. Kim, "Naphthopyrone glucosides from the seeds of Cassia tora with inhibitory activity on advanced glycation end products (AGEs) formation," Archives of Pharmacal Research, vol. 29, no. 7, pp. 587-590, 2006.

[165] T. Hatano, H. Uebayashi, H. Ito, S. Shiota, T. Tsuchiya, and T. Yoshida, "Phenolic constituents of cassia seeds and antibacterial effect of some naphthalenes and anthraquinones on methicillin-resistant Staphylococcus aureus," Chemical and Pharmaceutical Bulletin, vol. 47, no. 8, pp. 1121-1127, 1999.

[166] G. Y. Lee, J. H. Kim, S. K. Choi, and Y. H. Kim, "Constituents of the seeds of Cassia tora with inhibitory activity on soluble expoxide hydrolease," Bioorganic and Medicinal Chemistry Letters, vol. 25, no. 22, pp. 5097-5101, 2015.

[167] H. J. Lee, J. S. Choi, J. H. Jung, and S. S. Kang, "Alaternin glucoside isomer from Cassia tora," Phytochemistry, vol. 49, no. 5, pp. 1403-1404, 1998.
[168] Y. B. Park and S. B. Kim, "Isolation and identification of antitumor promoters from the seeds of Cassia tora," Journal of Microbiology and Biotechnology, vol. 21, no. 10, pp. 10431048, 2011.

[169] J. M. Cherng, W. Chiang, J. H. Wang et al., “Anthraquinones of edible wild vegetable Cassia tora stimulate proliferation of human $\mathrm{CD}^{+} \mathrm{T}$ lymphocytes and secretion of interferongamma or interleukin 10," Food Chemistry, vol. 107, no. 4, pp. 1576-1580, 2008.

[170] S. K. Hyun, H. Lee, S. S. Kang, H. Y. Chung, and J. S. Choi, "Inhibitory activities of Cassia tora and its anthraquinone constituents on angiotensin - converting enzyme," Phytotherapy Research, vol. 23, no. 2, pp. 178-184, 2009.

[171] M. Jimenez-Coello, K. Y. Acosta-Viana, E. Guzman-Marin, C. Perez Gonzalez, and M. Salud Perez Gutierrez, "Anti-trypanosomal activity of (8-hydroxymethylen)-trieicosanyl acetate against infective forms of Trypanosoma cruzi," Pharmaceutical Biology, vol. 48, no. 6, pp. 666-671, 2010.

[172] E. Guzmán, C. Pérez, M. A. Zavala, K. Y. Acosta-Viana, and S. Pérez, "Antiprotozoal activity of (8-hydroxymethylen)trieicosanyl acetate isolated from Senna villosa," Phytomedicine, vol. 15, no. 10, pp. 892-895, 2008.

[173] B. Salehi, M. Shivaprasad Shetty, N. V. Anil Kumar et al., "Veronica plants-drifting from farm to traditional healing, food application, and phytopharmacology," Molecules, vol. 24, no. 13, p. 2454, 2019.

[174] M. Sharifi-Rad, N. V. Anil Kumar, P. Zucca et al., "Lifestyle, oxidative stress, and antioxidants: back and forth in the pathophysiology of chronic diseases," Frontiers in Physiology, vol. 11, p. 21, 2020.

[175] R. R. Mititelu, R. Pădureanu, M. Băcănoiu et al., "Inflammatory and oxidative stress markers-Mirror tools in rheumatoid arthritis," Biomedicine, vol. 8, no. 5, p. 125, 2020.

[176] B. Salehi, J. Sharifi-Rad, F. Cappellini et al., "The therapeutic potential of anthocyanins: current approaches based on their molecular mechanism of action," Frontiers in Pharmacology, vol. 11, p. 20, 2020.

[177] D. Tsoukalas, P. Fragkiadaki, A. O. Docea et al., "Association of nutraceutical supplements with longer telomere length," International Journal of Molecular Medicine, vol. 44, no. 1, pp. 218-226, 2019.

[178] B. Salehi, Sharifi-Rad, Capanoglu et al., "Cucurbita plants: from farm to industry," Applied Sciences-Basel, vol. 9, no. 16, p. 3387, 2019.

[179] R. Padureanu, C. V. Albu, R. R. Mititelu et al., "Oxidative stress and inflammation interdependence in multiple sclerosis," Journal of Clinical Medicine, vol. 8, no. 11, p. $1815,2019$.

[180] D. Calina, A. M. Buga, M. Mitroi et al., "The treatment of cognitive, behavioural and motor impairments from brain injury and neurodegenerative diseases through cannabinoid system modulation-evidence from in vivo studies," Journal of Clinical Medicine, vol. 9, no. 8, p. 2395, 2020.

[181] B. Salehi, C. Quispe, I. Chamkhi et al., "Pharmacological properties of chalcones: a review of preclinical including molecular mechanisms and clinical evidence," Frontiers in Pharmacology, vol. 11, pp. 592654-592654, 2021.

[182] J. Sharifi-Rad, S. Kamiloglu, B. Yeskaliyeva et al., "Pharmacological activities of psoralidin: a comprehensive review of the molecular mechanisms of action," Frontiers in Pharmacology, vol. 11, p. 11, 2020. 
[183] B. Salehi, A. Prakash Mishra, M. Nigam et al., "Ficus plants: state of the art from a phytochemical, pharmacological, and toxicological perspective," Phytotherapy Research, vol. 35, no. 3, pp. 1187-1217, 2021.

[184] S. Thabit, H. Handoussa, M. Roxo, N. S. el Sayed, B. Cestari de Azevedo, and M. Wink, "Evaluation of antioxidant and neuroprotective activities of Cassia fistula (L.) using theCaenorhabditis elegansmodel," PeerJ, vol. 6, article e5159, 2018.

[185] J. F. Campos, D. T. H. de Castro, M. J. Damião et al., "The chemical profile of Senna velutina leaves and their antioxidant and cytotoxic effects," Oxidative Medicine and Cellular Longevity, vol. 2016, 12 pages, 2016.

[186] S. I. Ahmed, M. Q. Hayat, M. Tahir et al., "Pharmacologically active flavonoids from the anticancer, antioxidant and antimicrobial extracts of Cassia angustifolia Vahl," BMC Complementary and Alternative Medicine, vol. 16, no. 1, pp. 1-9, 2016.

[187] L. Guarize, J. C. da Costa, L. B. Dutra, R. F. Mendes, I. V. A. Lima, and E. Scio, "Anti-inflammatory, laxative and intestinal motility effects of Senna macranthera leaves," Natural Product Research, vol. 26, no. 4, pp. 331-343, 2012.

[188] G. A. Silva, J. A. Monteiro, E. B. Ferreira et al., "Total phenolic content, antioxidant and anticancer activities of four species of Senna mill. from Northeast Brazil," International Journal of Pharmacy and Pharmaceutical Sciences, vol. 6, pp. 199202, 2014.

[189] B. Ita and G. Ndukwe, "Antioxidant activity of Senna alata root extracts," Journal of Natural Products and Resources, vol. 3, no. 1, pp. 94-96, 2017.

[190] A. Phaiphan and B. Baharin, "Ultrasound-assisted extraction produce better antibacterial and antioxidant activities of Senna siamea (Lam.) leaf extracts than solvent extraction," Malaysian Journal of Microbiology, vol. 15, pp. 34-43, 2019.

[191] A. Q. Laghari, S. Memon, A. Nelofar, and A. H. Laghari, "Extraction, identification and Antioxidative properties of the flavonoid-rich fractions from leaves and flowers of Cassia angustifolia," American Journal of Analytical Chemistry, vol. 2, no. 8, pp. 871-878, 2011.

[192] B. Sagnia, D. Fedeli, R. Casetti, C. Montesano, G. Falcioni, and V. Colizzi, "Antioxidant and anti-inflammatory activities of extracts from Cassia alata, Eleusine indica, Eremomastax speciosa, Carica papaya and Polyscias fulva medicinal plants collected in Cameroon," PLoS One, vol. 9, no. 8, article e103999, 2014.

[193] M. Navarro, I. Moreira, E. Arnaez et al., "Proanthocyanidin characterization, antioxidant and cytotoxic activities of three plants commonly used in traditional medicine in Costa Rica: Petiveria alliaceae L., Phyllanthus niruri L. and Senna reticulata Willd," Plants, vol. 6, no. 4, p. 50, 2017.

[194] Y. W. Mak, L. O. Chuah, R. Ahmad, and R. Bhat, "Antioxidant and antibacterial activities of hibiscus (Hibiscus rosasinensis L.) and Cassia (Senna bicapsularis L.) flower extracts," Journal of King Saud University-Science, vol. 25, no. 4, pp. 275-282, 2013.

[195] U. Channa, A. M. Shah, S. Bhatti, A. A. Memon, A. B. Ghanghro, and M. N. Memon, "Phytochemical analysis and antibacterial properties of Cassia Senna alata," Rawal Medical Journal, vol. 45, no. 1, pp. 223-226, 2020.

[196] I. I. Madubunyi and O. J. Ode, "In vitro and in vivo antioxidant potential of the methanolic extract of Cassia singueana Delile (Fabaceae) lock leaves," Comparative Clinical Pathology, vol. 21, no. 6, pp. 1565-1569, 2012.
[197] O. Ottu, S. Atawodi, and E. Onyike, “Antioxidant, hepatoprotective and hypolipidemic effects of methanolic root extract of Cassia singueana in rats following acute and chronic carbon tetrachloride intoxication," Asian Pacific Journal of Tropical Medicine, vol. 6, no. 8, pp. 609-615, 2013.

[198] M. N. Abubacker, R. Ramanathan, and T. S. Kumar, "In vitro antifungal activity of Cassia alata Linn. Flower extract," Natural Product Radiance, vol. 7, no. 1, pp. 6-9, 2008.

[199] S. Mohideen, E. Sasikala, and P. Aruhaj, "Pharmacognosy of Cassia alata Linn-leaves," Ancient Science of Life, vol. 24, no. 4, pp. 192-198, 2005.

[200] R. Borges-Argáez, C. I. Canche-Chay, L. M. Peña-Rodríguez, S. Said-Fernández, and G. M. Molina-Salinas, "Antimicrobial activity of Diospyros anisandra," Fitoterapia, vol. 78, no. 5, pp. 370-372, 2007.

[201] A. T. de Castro, A. P. Castro, M. S. Silva et al., "In vitro evaluation of the schistosomicidal effect of the extracts, fractions and major 3-hydroxy-2,6-dialkyl-substituted piperidine alkaloids from the flowers of Senna spectabilis (Fabaceae)," Bioorganic \& Medicinal Chemistry Letters, vol. 26, no. 17, pp. 4197-4204, 2016.

[202] T. Hennebelle, B. Weniger, H. Joseph, S. Sahpaz, and F. Bailleul, "Senna alata," Fitoterapia, vol. 80, no. 7, pp. 385-393, 2009.

[203] A. Ogunjobi and M. Abiala, "Antimicrobial activity of Senna alata and Phyllanthus amarus," Global journal of pharmacology, vol. 7, no. 2, pp. 198-202, 2013.

[204] A. A. Makinde, J. O. Igoli, L. Ta'Ama, S. J. Shaibu, and A. Garba, "Antimicrobial activity of Cassia alata," African Journal of Biotechnology, vol. 6, no. 13, 2007.

[205] G. Ehiowemwenguan, J. Inetianbor, and J. Yakubu, “Antimicrobial qualities of Senna alata," IOSR Journal of Pharmacy and Biological Sciences, vol. 9, no. 2, pp. 47-52, 2014.

[206] W. F. Sule, I. O. Okonko, S. Omo-Ogun et al., "Phytochemical properties and in-vitro antifungal activity of Senna alata Linn. Crude stem bark extract," Journal of Medicinal Plant Research, vol. 5, no. 2, pp. 176-183, 2011.

[207] S. Y. Timothy, C. H. Wazis, R. G. Adati, and I. D. Maspalma, "Antifungal activity of aqueous and ethanolic leaf extracts of Cassia alata Linn," Journal of Applied Pharmaceutical Science, vol. 2, no. 7, p. 182, 2012.

[208] M. Wuthi-udomlert, P. Kupittayanant, and W. Gritsanapan, "In vitro evaluation of antifungal activity of anthraquinone derivatives of Senna alata," Journal of Health Research, vol. 24, no. 3, pp. 117-122, 2010.

[209] S. Phongpaichit, N. Pujenjob, V. Rukachaisirikul, and M. Ongsakul, "Antifungal activity from leaf extracts of Cassia alata L., Cassia fistula L. and Cassia tora L," Songklanakarin Journal of Science and Technology, vol. 26, no. 5, pp. 741748, 2004.

[210] J. Sharifi-Rad, C. Quispe, A. Rahavian et al., "Bioactive compounds as potential agents for sexually transmitted diseases management: a review to explore molecular mechanisms of action," Frontiers in Pharmacology, vol. 12, no. 1886, 2021.

[211] S. Albayrak, A. Aksoy, O. Sagdic, and S. Albayrak, "Antioxidant and antimicrobial activities of different extracts of some medicinal herbs consumed as tea and spices in Turkey," Journal of Food Biochemistry, vol. 36, no. 5, pp. 547-554, 2012.

[212] S. Jain, R. A. Sharma, R. Jain, and C. Mittal, "Antimicrobial screening of Cassia occidentalis lin vivo andin vitro," Phytotherapy Research, vol. 12, no. 3, pp. 200-204, 1998. 
[213] O. O. Ogbole, J. A. Adeniji, and E. O. Ajaiyeoba, “Anthraquinones and triterpenoids from Senna siamea (Fabaceae) Lam inhibit poliovirus activity," African Journal of Microbiology Research, vol. 8, no. 31, pp. 2955-2963, 2014.

[214] O. O. Ogbole, J. A. Adeniji, E. O. Ajaiyeoba, and D. F. Adu, "Anti-polio virus activity of medicinal plants selected from the Nigerian ethno-medicine," Academic Journals, vol. 12, no. 24, pp. 3878-3883, 2013.

[215] M. Shaheen, M. Borsanyiova, S. Mostafa, S. Bopegamage, and N. El-Esnawy, "Antiviral activity of Cassia alata extracts against cardiac coxsackievirus B3 infections in vitro and in vivo," Tropical Journal of Pharmaceutical Research, vol. 8, no. 2, pp. 117-125, 2009.

[216] W. Woradulayapinij, N. Soonthornchareonnon, and C. Wiwat, "In vitro HIV type 1 reverse transcriptase inhibitory activities of Thai medicinal plants and Canna indica L. rhizomes," Journal of Ethnopharmacology, vol. 101, no. 1-3, pp. 84-89, 2005.

[217] WHO, Schistosomiasis, Wolrd Health Organization, 2020.

[218] G. M. de Albuquerque Melo, M. C. R. Silva, T. P. Guimarães et al., "Leishmanicidal activity of the crude extract, fractions and major piperidine alkaloids from the flowers of Senna spectabilis," Phytomedicine, vol. 21, no. 3, pp. 277-281, 2014.

[219] E. E. Caamal-Fuentes, M. Graniel-Sabido, G. J. Mena-Rejón, and R. E. Moo-Puc, "Anti-giardia activity and acute toxicity of a methanol extract of Senna racemosa bark," Journal of Ethnopharmacology, vol. 193, pp. 604-606, 2016.

[220] R. E. Moo-Puc, G. J. Mena-Rejon, L. Quijano, and R. CedilloRivera, "Antiprotozoal activity of Senna racemosa," Journal of Ethnopharmacology, vol. 112, no. 2, pp. 415-416, 2007.

[221] T. Eguale, D. Tadesse, and M. Giday, "In Vitro anthelmintic activity of crude extracts of five medicinal plants against egg-hatching and larval development of Haemonchus contortus," Journal of Ethnopharmacology, vol. 137, no. 1, pp. 108113, 2011.

[222] I. M. Villaseñor, A. P. Canlas, M. P. Pascua, M. N. Sabando, and L. A. Soliven, "Bioactivity studies on Cassia alata Linn. Leaf extracts," Phytotherapy Research, vol. 16, no. S1, pp. 93-96, 2002.

[223] M. T. Chomnawang, S. Surassmo, V. S. Nukoolkarn, and W. Gritsanapan, "Antimicrobial and weed inhibitory activities of Senna spectabilis extracts against plant pathogens," International Journal of Agricultural Technology, vol. 14, no. 7 Special Issue, pp. 1445-1454, 2018.

[224] M. T. Chomnawang et al., "Antimicrobial effects of Thai medicinal plants against acne-inducing bacteria," Journal of Ethnopharmacology, vol. 101, no. 1-3, pp. 330-333, 2005.

[225] G. P. Mcnicol, "The effect of a standardised senna preparation on the human bowel," Journal of Pharmacy and Pharmacology, vol. 10, no. 1, pp. 499-506, 2011.

[226] V. I. Thamlikitkul, N. Bunyapraphatsara, T. Dechatiwongse et al., "Randomized controlled trial of Cassia alata Linn. For constipation," Journal of the Medical Association of Thailand, vol. 73, no. 4, pp. 217-222, 1990.

[227] O. Kinnunen, W. Winblad, P. Koistinen, and I. Salokannel, "Safety and efficacy of a bulk laxative containing Senna versus lactulose in the treatment of chronic constipation in geriatric patients," Pharmacology, vol. 47, no. 1, pp. 253-255, 1993.

[228] S. Damodaran and S. Venkataraman, "A study on the therapeutic efficacy of Cassia alata, Linn. Leaf extract against Pity- riasis versicolor," Journal of Ethnopharmacology, vol. 42, no. 1, pp. 19-23, 1994.

[229] P. Ramesh, K. S. Kumar, M. R. Rajagopal, P. Balachandran, and P. K. Warrier, "Managing morphine-induced constipation: a controlled comparison of an Ayurvedic formulation and Senna," Journal of Pain and Symptom Management, vol. 16, no. 4, pp. 240-244, 1998.

[230] B. A. van Gorkom, A. Karrenbeld, A. J. Limburg, and J. H. Kleibeuker, "The effect of sennosides on colonic mucosal histology and bowel preparation," Zeitschrift für Gastroenterologie, vol. 36, no. 1, pp. 13-18, 1998.

[231] J. Phutsisen, C. Kietpeerakool, N. Jampathong et al., "Effects of Cassia alata Linn on bowel function recovery following surgery for gynecological cancer: a randomized controlled trial," Complementary Therapies in Medicine, vol. 47, article 102222, 2019.

[232] K. A. Santos-Jasso, J. L. Arredondo-García, J. Maza-Vallejos, and P. Lezama-del Valle, "Effectiveness of senna vs. polyethylene glycol as laxative therapy in children with constipation related to anorectal malformation," Journal of Pediatric Surgery, vol. 52, no. 1, pp. 84-88, 2017.

[233] C. Feudtner, J. Freedman, T. Kang, J. W. Womer, D. Dai, and J. Faerber, "Comparative effectiveness of Senna to prevent problematic constipation in pediatric oncology patients receiving opioids: a multicenter study of clinically detailed administrative data," Journal of Pain and Symptom Management, vol. 48, no. 2, pp. 272-280, 2014.

[234] B. Ergül, L. Filik, E. Koçak, Z. Doğan, and M. Sarıkaya, "Efficacy and safety of gum chewing in adjunct to high-dose Senna for bowel cleansing before colonoscopy: a singleblind randomized controlled trial," Saudi Journal of Gastroenterology, vol. 20, no. 6, pp. 356-359, 2014.

[235] M. Patel, M. O. Schimpf, D. M. O'Sullivan, and C. A. LaSala, "The use of Senna with docusate for postoperative constipation after pelvic reconstructive surgery: a randomized, double-blind, placebo-controlled trial," American Journal of Obstetrics and Gynecology, vol. 202, no. 5, pp. 479.e1479.e5, 2010.

[236] J. Raposo and P. Velho, "Prolonged ingestion of senna: weight loss, cyclic edema, dyspepsia and hepatoneuromyopathy," Medicină Internă, vol. 17, no. 2, pp. 81-84, 2010.

[237] S. Kositchaiwat, W. Suwanthanmma, R. Suvikapakornkul, V. Tiewthanom, P. Rerkpatanakit, and C. Tinkornrusmee, "Comparative study of two bowel preparaton regimens for colonoscopy: Senna tabletsvssodium phosphate solution," World Journal of Gastroenterology, vol. 12, no. 34, pp. 5536-5539, 2006.

[238] S.-H. Cho, T. H. Kim, N. H. Lee, H. S. Son, I. J. Cho, and T. Y. $\mathrm{Ha}$, "Effects of Cassia tora fiber supplement on serum lipids in Korean diabetic patients," Journal of Medicinal Food, vol. 8, no. 3, pp. 311-318, 2005.

[239] F. Radaelli, G. Meucci, V. Terruzzi et al., "Efficacy and acceptability of high dose Senna compared with standard polyethylene glycol solution for colon cleansing prior to colonoscopy: preliminary results of a randomized, investigator-blind trial," Gastrointestinal Endoscopy, vol. 61, no. 5, p. AB119, 2005.

[240] B. A. van Gorkom, A. Karrenbeld, T. van der Sluis, J. Koudstaal, E. G. E. de Vries, and J. H. Kleibeuker, "Influence of a highly purified senna extract on colonic epithelium," Digestion, vol. 61, no. 2, pp. 113-120, 2000. 
[241] L. L. Zhong, C. W. Cheng, Y. Chan et al., "Chinese herbal medicine (Ma Zi Ren wan) for functional constipation: study protocol for a prospective, double-blinded, double-dummy, randomized controlled trial," Trials, vol. 14, no. 1, p. 366, 2013.

[242] L. L. Zhong, C. W. Cheng, W. Kun et al., "Efficacy of MaZiRenWan, a Chinese herbal medicine, in patients with functional constipation in a randomized controlled trial," Clinical Gastroenterology and Hepatology, vol. 17, no. 7, pp. 1303-1310.e18, 2019.

[243] U. Beuers, U. Spengler, and G. R. Pape, "Hepatitis after chronic abuse of senna," Lancet, vol. 337, no. 8737, pp. 372373, 1991.

[244] B. Vanderperren, M. Rizzo, L. Angenot, V. Haufroid, M. Jadoul, and P. Hantson, "Acute liver failure with renal impairment related to the abuse of Senna anthraquinone glycosides," Annals of Pharmacotherapy, vol. 39, no. 7-8, pp. 1353-1357, 2005.

[245] S. Soyuncu, Y. Cete, and A. E. Nokay, "Portal vein thrombosis related to Cassia angustifolia," Clinical Toxicology, vol. 46, no. 8, pp. 774-777, 2008.

[246] J. Sharifi-Rad, C. F. Rodrigues, Z. Stojanović-Radić et al., "Probiotics: versatile bioactive components in promoting human health," Medicina, vol. 56, no. 9, p. 433, 2020.

[247] M. T. Islam, C. Quispe, M. Martorell et al., "Dietary supplements, vitamins and minerals as potential interventions against viruses: perspectives for COVID-19," International Journal for Vitamin and Nutrition Research, pp. 1-18, 2021.

[248] P. Mitrut, A. O. Docea, A. M. Kamal et al., "Colorectal cancer and inflammatory bowel disease," Colorectal Cancer - from Pathogenesis to Treatment, L. Rodrigo, Ed., pp. 185-199, 2016.

[249] O. M. Zlatian, M. V. Comănescu, A. F. Roşu et al., "Histochemical and immunohistochemical evidence of tumor heterogeneity in colorectal cancer," Romanian Journal of Morphology and Embryology, vol. 56, no. 1, pp. 175-181, 2015.

[250] N. Mascolo, R. Capasso, and F. Capasso, "Senna. A safe and effective drug," Phytotherapy Research, vol. 12, no. S1, pp. S143-S145, 1998.

[251] C. Cirillo and R. Capasso, "Constipation and botanical medicines: an overview," Phytotherapy Research, vol. 29, no. 10, pp. 1488-1493, 2015.

[252] X. Wang and J. Yin, "Complementary and alternative therapies for chronic constipation," Evidence-based Complementary and Alternative Medicine, vol. 2015, Article ID 396396, 2015.

[253] F. Capasso and T. S. Gaginella, Laxative. A Practical Guide, Springer-Verlag Italia, Milan, 1997.

[254] J. Labenz, G. Hopmann, F. Leverkus, and G. Börsch, "Bowel cleansing prior to colonoscopy. A prospective, randomized, blind comparative study," Medizinische Klinik, vol. 85, no. 10, pp. 581-585, 1990.

[255] S. B. Park and Y. S. Kim, "Simultaneous separation of three isomeric sennosides from senna leaf (Cassia acutifolia) using counter-current chromatography," Journal of Separation Science, vol. 38, no. 20, pp. 3502-3507, 2015.

[256] https://www.cbsnews.com/news/norway-covid-19-vaccineelderly-deaths-no-link/.

[257] A. Vilanova-Sanchez, A. C. Gasior, N. Toocheck et al., "Are Senna based laxatives safe when used as long term treatment for constipation in children?," Journal of Pediatric Surgery, vol. 53, no. 4, pp. 722-727, 2018.

[258] J. O. Greenhalf and H. S. Leonard, "Laxatives in the treatment of constipation in pregnant and breast-feeding mothers," Practitioner, vol. 210, no. 256, pp. 259-263, 1973.

[259] C. M. Prather, "Pregnancy-related constipation," Current Gastroenterology Reports, vol. 6, no. 5, pp. 402-404, 2004.

[260] J. M. Gattuso and M. A. Kamm, "Adverse effects of drugs used in the management of constipation and diarrhoea," Drug Safety, vol. 10, no. 1, pp. 47-65, 1994.

[261] N. Ács, F. Bánhidy, E. H. Puhó, and A. E. Czeizel, “No association between severe constipation with related drug treatment in pregnant women and congenital abnormalities in their offspring: a population-based case-control study," Congenital Anomalies, vol. 50, no. 1, pp. 15-20, 2010.

[262] S. O. Müller, I. Eckert, W. K. Lutz, and H. Stopper, "Genotoxicity of the laxative drug components emodin, aloe-emodin and danthron in mammalian cells: topoisomerase II mediated?," Mutation Research, vol. 371, no. 3-4, pp. 165-173, 1996.

[263] W. F. Baldwin, "Clinical study of Senna administration to nursing mothers: assessment of effects on infant bowel habits," Canadian Medical Association Journal, vol. 89, no. 11 , pp. 566-568, 1963.

[264] P. Faber and A. Strenge-Hesse, "Relevance of rhein excretion into breast milk," Pharmacology, vol. 36, no. 1, pp. 212-220, 1988.

[265] F. Capasso, T. S. Gaginella, G. Grandolini, and A. A. Izzo, Phytotherapy: A Quick Reference to Herbal Medicine, Springer-Verlag, Heidelberg, Germany, 2003.

[266] G. H. Ritsema and G. Eilers, "Potassium supplements prevent serious hypokalaemia in colon cleansing," Clinical Radiology, vol. 49, no. 12, pp. 874-876, 1994.

[267] V. H. Waldhäusl, "Laxative-induced hypokalemic myopathy. A case history," Wiener Klinische Wochenschrift, vol. 92, no. 3, pp. 101-103, 1980.

[268] M. T. Wang, I. H. Li, W. J. Lee, T. Y. Huang, H. B. Leu, and A. L. F. Chan, "Exposure to sennoside-digoxin interaction and risk of digoxin toxicity: a population-based nested casecontrol study," European Journal of Heart Failure, vol. 13, no. 11, pp. 1238-1243, 2011.

[269] Y. Cao, Y. He, C. Wei et al., "Aquaporins alteration profiles revealed different actions of Senna, Sennosides, and Sennoside a in diarrhea-rats," International Journal of Molecular Sciences, vol. 19, no. 10, p. 3210, 2018.

[270] N. Mascolo, E. Mereto, F. Borrelli et al., "Does senna extract promote growth of aberrant crypt foci and malignant tumors in rat colon?," Digestive Diseases and Sciences, vol. 44, no. 11, pp. 2226-2230, 1999.

[271] A. Lyden-Sokolowski, A. Nilsson, and P. Sjöberg, "Two-year carcinogenicity study with sennosides in the rat: emphasis on gastro-intestinal alterations," Pharmacology, vol. 47, no. 1, pp. 209-215, 1993.

[272] E. Mereto, M. Ghia, and G. Brambilla, "Evaluation of the potential carcinogenic activity of Senna and cascara glycosides for the rat colon," Cancer Letters, vol. 101, no. 1, pp. 79-83, 1996. 